\title{
Intergenerational persistence in health in developing countries : the penalty of gender inequality?
}

Article

Accepted Version

Bhalotra, S. and Rawlings, S. (2011) Intergenerational persistence in health in developing countries : the penalty of gender inequality? Journal of Public Economics, 95 (3-4). pp. 286-299. ISSN 0047-2727 doi:

https://doi.org/10.1016/j.jpubeco.2010.10.016 Available at https://centaur.reading.ac.uk/28679/

It is advisable to refer to the publisher's version if you intend to cite from the work. See Guidance on citing.

To link to this article DOI: http://dx.doi.org/10.1016/j.jpubeco.2010.10.016

Publisher: Elsevier

All outputs in CentAUR are protected by Intellectual Property Rights law, including copyright law. Copyright and IPR is retained by the creators or other copyright holders. Terms and conditions for use of this material are defined in the End User Agreement.

www.reading.ac.uk/centaur 
Central Archive at the University of Reading

Reading's research outputs online 


\title{
Intergenerational Persistence in Health in Developing Countries: \\ The penalty of gender inequality?
}

\author{
Sonia Bhalotra and Sam Rawlings \\ University of Bristol (Economics and CMPO)
}

\begin{abstract}
This paper is motivated to investigate the often neglected payoff to investments in the health of girls and women in terms of next generation outcomes. This paper investigates the intergenerational persistence of health across time and region as well as across the distribution of maternal health. It uses comparable micro-data on as many as 2.24 million children born of about 0.6 million mothers in 38 developing countries in the 31 year period, 1970-2000. Mother's health is indicated by her height, BMI and anemia status. Child health is indicated by mortality risk and anthropometric failure. We find a positive relationship between maternal and child health across indicators and highlight non-linearities in these relationships. The results suggest that both contemporary and childhood health of the mother matter and that the benefits to the next generation are likely to be persistent. Averaging across the sample, persistence shows a considerable decline over time. Disaggregation shows that the decline is only significant in Latin America. Persistence has remained largely constant in Asia and has risen in Africa. The paper provides the first cross-country estimates of the intergenerational persistence in health and the first estimates of trends.
\end{abstract}

Keywords: intergenerational persistence, mobility, health, developing countries, cohort trends, inequality JEL codes: I10, J11, O57

Acknowledgements: We are grateful to Paul Clarke, Tom Hertz and an anonymous referee for helpful discussions and to Alex Barr for help with setting up the data. This paper is dedicated to Steve Nickell and his enthusiasm for papers that "draw a picture" of important socioeconomic phenomena. It is forthcoming in the Journal of Public Economics 


\section{Introduction}

There is growing evidence of the long term and often multiplicative benefits of investing in children (Case et al., 2005; Currie, 2009) and recognition that investments made during critical periods of development draw larger returns or, conversely, that failure to invest in early childhood can lead to irreversible damage (Cunha and Heckman, 2007; Almond and Currie, 2010). The origins of life in utero constitute one such critical period, when growth is rapid and neurological and physiological development is particularly sensitive to the environment. Maternal stress and nutritional deprivation tend to stimulate permanent changes in tissue structure and function that help the foetus survive but that are associated with abnormal structure, function, and disease in adult life. A later life penalty from foetal adaptation has been noted in terms of earlier onset of later life morbidities (Barker and Levy, 1994), reduced stature and increased risk of obesity (Deaton, 2007; Fung, 2009) and cognitive outcomes and earnings (Almond, 2006).

Mother's health is an important element of the foetal environment, exerting direct effects and also mediating the impact of shocks to the external environment. A vast cross-disciplinary literature documents the impact on intrauterine growth retardation of poor maternal health during pregnancy, measured as smoking, alcohol consumption, stress, infection or nutritional deprivation (Kramer 1987, Almond 2006, Camacho 2008, Cogswell et al. 2003). In fact it is not only the contemporaneous health of the mother or health during pregnancy that counts but rather the stock of her health (Barker, 1997), in the accumulation of which her own early life health environment plays a critical role. Of particular interest, a girl's exposure to adverse conditions can induce developmental changes that have intergenerational impacts (Barker and Osmond 1987; Barker 1992; Drake and Walker 2004; Gluckman and Hanson 2005). There is some evidence of this in the economics literature (Almond and Chay, 2006; Fung and Wei, 2009; Bhalotra, 2010a; Bhalotra and Venkataramani, 2010). Identified mechanisms include the following. Mothers who are themselves low birth weight tend to show reduced weight gain (Hackman et al., 1983) and increased risk of developing hypertension during pregnancy (Klebanoff et al., 1999), factors that predispose them to having low birth weight babies (Cawley et al., 1954; Currie and Moretti, 2007). Girls who are born small and do not exhibit catch up growth, failing to attain the height predicted by their genetic potential tend to have reduced uterine and ovarian size which also predicts lower birth weight of their offspring (Ibanez et al. 2000). Overall, evidence is emerging to suggest that the benefits of investments in foetal and early childhood health extend not only into adulthood but, through mothers, into the next generation.

The primacy of mother's health is pertinent in developing countries many of which are characterized by systematic under-investment in girls and women. The relative neglect of girls and women has been strikingly brought to light by Amartya Sen's work (e.g. Sen 1990, 1992). Further work has 
documented the variety of forms this takes (Harriss 1990; Bhalotra and Attfield 1998; deRose et al., 2000; Bharadwaj and Nelson 2010), showing also that girls and women bear the brunt of adverse shocks (Behrman and Deolalikar 1990, Dercon and Krishnan 2000, Bhalotra 2010b). This neglect is not confined to societies characterized by son preference but, rather, is widespread (Hill and Upchurch 1995, Preston, 1976; Baird et al. forthcoming). The contribution of this paper is to investigate the implications of health deprivation amongst girls and women for next generation outcomes for both boys and girls. In this respect it provides the first systematic empirical investigation of the argument in Osmani and Sen (2003) that society at large suffers- for generations- from the unequal treatment of girls and women.

While childhood mortality rates in developing countries have declined over the period, they are still higher than can be explained by costs of nutrition or treatment, and income growth alone appears unlikely to make a substantial contribution to further reductions (Deaton, 2006). Mother's education and public health provision have been identified as having potential in this direction (Deaton, 2006), but there is relatively limited emphasis - or evidence- in the literature on the role of mother's health.

Two features of the analysis in this paper make it well suited to the objective of assessing next generation impacts of under-investment in the health of girls and women. First, it uses comparable microdata on as many as 2.24 million children born of about 0.6 million mothers born in 38 developing countries in the 30 year period, 1970-2000. This allows us to draw general patterns, to make inter-regional comparisons and to investigate trends. We also investigate how the transmission coefficients change across the distribution of maternal health, so as to estimate directly the long run penalties of deprived health. Second, we use a number of indicators of mother's health and child health that together describe short and long term impacts. For the mother we investigate indicators of anemia and her body mass index around the time of birth alongside her (adult) height. Height relative to a country (or ethnic or sub-region) mean reflects the cumulative impact of her health environment from conception to adulthood (Cole, 2000; Deaton, 2007; Gunnell, 2002; Martorell and Habicht, 1986; Fogel, 2004; Schultz, 2009; Steckel, 2009; Strauss and Thomas, 2008), so capturing underinvestment in girls in early life. For the child, we use neonatal, infant and under-5 mortality risk, low birth weight, stunting and the age-gender adjusted z-score of height. To the extent that adult height summarises the history of life-course shocks sustained by the mother and low birth weight is portentous of adult health (e.g. Black and Devereux, 2010), the correlations described here are of relevance to understanding the emergence of "health dynasties".

There is no previous comparable cross-country evidence on levels of or trends in the intergenerational transmission of health and even single country studies are scarce (Solon 2002; Black and Devereux, 2010, pp. 63-65). It is particularly difficult to compare estimates of health persistence from 
across individual studies because the measures of health used vary so much (e.g. birth weight, height, BMI, mental health, self-reported health status). It is even more difficult to find consistent time series data with which trends can be compared across regions. ${ }^{1}$

The focus on developing countries is relevant not only because of the gender gap in investments but also because the absolute levels of health and resources tend to be low and the returns to health "mobility" are likely to be much higher than in richer environments. The three decades across which we analyse trends in the transmission coefficient constitute a period of momentous change and turbulence in the economic and health environment. For example, parts of Latin America and Asia experienced periods of unprecedented growth while large parts of Africa exhibited negative growth. The health environment was directly altered by new technologies and nationwide interventions including the Expanded Immunization Programme initiated in 1974 and rolled out over the next two decades. Many countries saw gains in life expectancy of greater than twenty years during 1960-2000 (Maddison, 2004). However, by the early 1990s, HIV-AIDS was reversing gains in Africa (Soares, 2006).

What do we find? Indicators of both the contemporary health of the mother and of her health stock are significant predictors of the survival and growth of her births in most countries in the sample. The average effects identified are large relative to the sample means of the dependent variables. In the linear models, a standard deviation decrease in mother's height or BMI raises the risk of poor child health by between 5 and 10 per cent, depending on the measure. These tendencies are widespread, being statistically significant in 20 to 29 of the 38 countries. Intergenerational persistence varies considerably across the three continents and within continent, by country, reflecting long standing differences in underlying levels and inequality in health. While the intergenerational persistence of health has weakened over time in Latin America, in Asia and Africa it has shown no tendency to fade in the last thirty years.

How do pairs of the alternative measures of health compare? Controlling for common unobservable trends and individual characteristics including the education of the mother and father and mother's age at birth, we find that children of shorter mothers are significantly more likely to be low birth weight, to experience neonatal, infant and under-5 mortality and, conditional upon survival (to the interview date) to be stunted. Low maternal BMI $(<18.5)$ is a risk factor for low birth weight and stunting amongst children, indeed, these risks appear to fall monotonically with BMI. Low BMI appears to have no impact on mortality, which is instead elevated amongst mothers with high BMI (>24.9). Low BMI is widely regarded as indicating (current) nutritional deprivation; what is less recognised is that high BMI

\footnotetext{
${ }^{1}$ In contrast, education is typically measured in years, income is often measured as lifecycle-adjusted family income and a number of longitudinal or cohort data sets for richer countries contain education and income data.
} 
(obesity) may arise from poor net nutrition in early life (Fung, 2009; Luo et al., 2006; Venkataramani, 2010a). We find that mothers with anemia are more likely to bear low birth weight children and more likely to lose them to early life mortality. The impact of anemia on stunting given survival depends upon its severity.

Most previous studies of mobility present linear estimates. But the mechanisms underlying health transmission suggest that it may be important to allow for nonlinearities. Also, all but one of our measures of child health indicates poor health. Estimating the persistence coefficient in different regions of the (mother's) health distribution, we find that increases in the risks of mortality and stunting associated with having a short mother are systematically larger than the decrease in risk derived from having a tall mother, and marginal effects are increasing in distance from mean height in both directions. For BMI we identify the expected non-linearity, with adverse effects on child health being associated with levels that are both too low and too high, using conventionally determined cut-offs. Overall, the estimates confirm that there is substantial intergenerational persistence at the low end of the (mother's) health distribution, suggesting that this may be where returns to investments in women's health are largest.

Given the finding that persistence is stronger at the low end, we may expect average persistence to decline with improvements in maternal health over time. Alternatively, positive trends in public health programmes that effectively target children at most risk will tend to weaken persistence. Using the pooled sample of 31 cohorts in 1970-2000 we find an erosion of 20-30\% per decade in the regression coefficient relating child mortality to mother's height. Even after adjusting this for the rise in the relative inequality of mother's height and child mortality, we find average declines of $10-30 \%$. This looks fairly impressive, especially in view of the record of limited income and education mobility. However, disaggregating by continent, we find that these trends are only statistically significant in Latin America. There is largely no trend in Asia except that the relationship between under-5 mortality and height has grown tighter. What is striking is that persistence, especially for neonatal mortality, has increased in Africa.

Given the bi-causal relationship between health and socio-economic status, these findings are relevant to understanding the intergenerational persistence of earnings. The once popular view was that cross-sectional income inequality was driven by stochastic elements like luck and ability (e.g. Roy, 1950). Influenced by estimates of intergenerational persistence in earnings in the US, economists have increasingly adopted from sociology the view that family background and the extent of intergenerational mobility are important determinants of inequality (Becker and Tomes, 1979; Atkinson, 1981; Bowles and Gintis, 2002). However the literature has not made much progress in identifying the precise mechanisms that drive intergenerational mobility (Currie, 2009). The focus has been upon education as the element of 
human capital that determines earnings (Grawe and Mulligan, 2002; Behrman et al., 2001) but the evidence increasingly points towards at least equal importance of health (Case et al., 2005; Eriksson et al., 2005; Currie, 2009). This paper contributes to that evidence.

\section{Methodology}

The significance of the mother's early life environment (proxied by her height) in predicting the health of her babies underlines that the intergenerational transmission of health involves not only genomic but also non-genomic mechanisms. The dramatic variation in the transmission coefficient across countries and, in Latin America, across time would also seem to indicate non-genomic mechanisms. ${ }^{2}$ While some variation is consistent with genetic mechanisms if, for example, the degree of assortative mating varies across region and time (Chadwick and Solon, 2002), we may expect that any such variation is small. A third indication of the importance of non-genomic elements arises from studies that show that mother's size has a stronger influence on offspring size than father's size. This suggests the importance of the in utero environment that the mother provides over and above genetic influences that flow from both parents (Walton and Hammond (1938), Morton (1955), Venkataramani 2010b, Bhalotra; in progress). For a given birth size, mother's health will further tend to influence post-birth health and survival given the greater significance of mother's health in relation to breastfeeding and early childhood care.

This said, our objective is to describe patterns of health mobility, distinguishing the transmission of weak and strong health. Like a lot of the mobility literature, we do not attempt to identify a structural parameter or to disentangle the non-genomic from the genomic element of the relationship between maternal and child health. This is inherently difficult to the extent that traits that appear to be genetically inherited may reflect a perpetuation of the consequences of environmentally driven foetal programming through several generations (Drake and Walker, 2004). For example, the evidence suggests that each of birth weight, adult height and obesity (at least amongst women) are heritable and that each is at the same time a barometer of the scars of environmental deprivation. Moreover, genomic and non-genomic mechanisms most likely interact (Ridley, 2003; Cunha and Heckman, 2007; van den Berg et al., 2008), invalidating the commonly used specifications for human capital production in which they appear additively. In their recent survey of intergenerational mobility, Black and Devereux (2010) argue that there have been relatively few attempts to estimate causal effects and that the estimates, as they exist, raise as many questions as they answer; also see Holmlund, Lindahl, and Plug (2008).

\section{Baseline Model}

\footnotetext{
${ }^{2}$ In other words, differences in health persistence between societies are likely to reflect differences in resources and health provision even if the level of health persistence is in part determined by genetic transmission.
} 
Pooling the individual data from across countries, we estimate the following equation

$$
C_{\text {imjt }}=a+\beta H_{\mathrm{m}}+X_{\text {im }}^{\prime} \lambda+\gamma_{\mathrm{jt}}+\varepsilon_{\text {imjt }}
$$

The dependent variable $C_{\text {imjt }}$ is a binary variable indicating poor health of child $i$ born to mother $m$ in country $j$ in year $t$ and $H_{\mathrm{m}}$ indicates the health of the mother. Since the dependent variable is an inverse measure of health, we expect $\beta<0$ for mother's height and BMI and $\beta>0$ for anemia. The country-year fixed effects, $\gamma_{\mathrm{jt}}$ control for all relevant time-varying unobservables. They will, importantly, absorb average height differences between countries (Ruff, 2002), country-specific nonlinear trends in child health created by medical progress or changes in institutions for delivery of preventive health care (Cutler et al., 2006), and the impact of shocks like AIDS, civil war or famine that strike in the child's birth year. The estimation is on within-country variation across individual families. ${ }^{3}$ As there are ethnic differences in height, we investigate including fixed effects for ethnicity. Estimates are obtained with and without controls, $X$, for individual characteristics including birth month, gender and birth order of the child, education of the mother and her partner, her age at birth, religion and urban status, some of which pick up the socioeconomic position of the household. We use the linear probability estimator, having confirmed that predictions lie predominantly within the $[0,1]$ interval. Standard errors are robust to arbitrary forms of heteroskedasticity and to non-independence within countries, including correlation across years. Below we discuss extensions that allow $\beta$ to vary with the (relative) level of mother's height, the birth year of the child and country. We also estimated a specification that allows more general slope heterogeneity at the mother level by including the demeaned covariates $X_{m}$ interacted with $H_{m}$; for the child-specific elements of $\mathrm{X}_{\mathrm{im}}$, we use the mother-level averages. We expect that the uninteracted coefficient on $H_{m}$ is an estimate of the average partial effect (or, in the case below, where we use height dummies, the average treatment effect); see Wooldridge 2005.

\section{Asymmetry and non-linearity}

Nonparametric estimates of the intergenerational correlation of health indicate that it is stronger at both tails and stronger for height below the mean than for height above the mean. We therefore estimate these more general equations:

$$
\begin{aligned}
& C_{\text {imjt }}=a+\beta H_{\mathrm{m}}+\varrho H_{\mathrm{m}}^{2}+\mathrm{X}_{\mathrm{im}}^{\prime} \lambda+\gamma_{\mathrm{jt}}+\varepsilon_{\mathrm{imjt}} \\
& C_{\text {imjt }}=a+\beta_{1} \text { tallhalf }_{m}+\beta_{2} \text { tall }_{m}+\beta_{3} \text { tall }_{m}+\beta_{4} \text { shorthalf }_{m}
\end{aligned}
$$

\footnotetext{
3 Mothers are of different cohorts and there is therefore variation in their early life conditions.
} 


$$
+\beta_{5} \text { short }_{m}+\beta_{6} \text { short }_{m}+X_{\mathrm{im}} \lambda+\gamma_{\mathrm{jt}}+\varepsilon_{\mathrm{imjt}}
$$

Equation (2) allows a single turning point to be estimated from the data. Equation (3) imposes the thresholds at which the slope of the relationship changes but allows for six different coefficients. In equations (1) and (2), maternal height is in metres. In equation (3) it is replaced with six dummy variables indicating the mother's place in the country-specific height distribution. These indicate whether her height is between 0.5 and 1, 1 and 2, or greater than 2 standard deviations above (tall) or below (short) mean height in her country. We similarly investigate asymmetry in the effects of BMI and anemia. We include indicator variables for low BMI $(<18.5)$ and high BMI $(>24.5)$, treating normal BMI, lying between these limits, as the omitted category. For anemia, we include indicators for 'none' and 'severe', casting 'mild' and 'moderate" as the omitted categories.

\section{Trends in intergenerational persistence}

For the analysis of trends we use only mother's height and childhood mortality since the other indicators are only available for recent births. We initially introduce an interaction of maternal height with a linear trend in equation (1). To allow for a more flexible trend, we estimate (1) for each of the six five-year cohorts of children born during 1970-2000 to obtain $\beta_{c}$. These estimates are standardized by the ratio of the within-cohort standard deviation of mother and child health to get:

$$
\theta_{c}=\beta_{c} *\left(\frac{\sigma_{m}^{c}}{\sigma_{i}^{c}}\right)
$$

$\theta_{c}$ is interpreted as the predicted standard deviation change in mortality risk for each standard deviation change in maternal height; it is bounded between 0 and 1 . This adjustment factors out the cross-sectional dispersion of the health indicator in the two generations. Even if $\beta$ is declining, $\theta$ may not decline if inequality in child health is falling faster than inequality in mother's health. In a third specification, we allow for a completely flexible relation over time. We estimate equation (1) for each year, plot the estimated $\beta_{\mathrm{t}}$ against year and fit a lowess curve to the scatter. We also standardise these estimates to obtain $\theta_{t}$

\section{Spatial differences in intergenerational persistence}

To investigate spatial differences in intergenerational persistence, equation (1) is estimated by continent and country to obtain $\beta_{\mathrm{j}}$, and these are standardized using the continent or country specific ratio of the standard deviations of maternal and child health to get $\theta_{j}$. As there are large differences in the level of child health across countries, we also present $\beta_{\mathrm{j}}$ normalised by the mean level of child health in the sample:

$$
\tau_{j}=\left(\frac{\beta_{j}}{C_{j}}\right)
$$


where $C_{\mathrm{j}}$ is the mean of the dependent variable.

\section{Measures of Health}

\section{Child health}

Improvements in life expectancy in developing countries arise primarily from improvements in child survival. As many as 30\% of all deaths in developing countries are amongst children, compared with less than $1 \%$ in richer countries (Cutler et al., 2006). It is estimated that malnutrition is the underlying cause of about half of all infant deaths (Murray and Lopez, 1997). Poor nutrition increases vulnerability to infectious disease to which children under the age of five are especially vulnerable because their immune systems are not fully developed (Scrimshaw et al., 1968). Nutritional deprivation leaves a permanent scar even amongst those who survive through to adulthood (Elo and Preston, 1992; van den Berg et al., 2006). Low birth weight and stunting are early indicators of this scar. This paper therefore indicates child health by childhood mortality, measured as death up until the age of 1 (neonatal), 12 (infant) or 60 (under 5) months, low birth weight, and stunting (low height). We also investigate one measure of child health across the distribution, the z-score of child height adjusted for country, age-in-months and gender. Low birth weight, neonatal and infant mortality are often used as proxies for foetal nutrition (e.g. Barker and Osmond, 1986; Drake and Walker, 2004). Stunting and under-5 mortality, which involve longer postnatal exposure periods, incorporate more of the impact of the extrinsic environment. Indeed, infant and under5 mortality rates are often used as indicators of the infectious disease environment (e.g. Deaton, 2007; Reidpath and Allotey, 2003). Stunting is an easily measured effect of the malnutrition-infection complex that predicts generalized functional impairment on a wide range of biological, behavioral and social dimensions in children and adults in developing countries (Martorell, 1995). Child height is commonly thought of as a good stock measure of net nutrition and height up to the age of three is strongly linked to adult stature (Martorell, 1999).

\section{Maternal health}

Malnutrition of women and girls is widespread in developing countries. There is the scourge of poverty and infection and, further, unequal distribution within households, with a tendency towards systematic under-investment in females (section 1). We use three measures of mother's nutrition- height (adjusted for country fixed effects), body mass index (BMI) and anemia status. The first is a stock measure and the latter two are flow measures. It is useful to obtain results on the same data for these alternative indicators. These measures are more objective than self-reported health status (e.g. Schultz, 2009). Previous studies, mostly set in richer countries, have tended to use birth weight to indicate maternal health (e.g. Drake and 
Walker, 2004; Currie and Moretti, 2007). Mother's birth weight is not available in our data but it is correlated with final height (Emanuel et al., 1992; Costa, 1998).

An important aspect of wellbeing and of the bearing and rearing of children in developing countries is that mothers are often fatigued. BMI and anemia capture this. They are both correlated with disease, malaria, and poor nutrition (WHO, 2008) and strong predictors of low birth weight and preterm delivery (Neggars and Goldenberg, 2003; Levy et al., 2005). BMI is the most widely accepted measure of adult nutrition. Anemia reflects both dietary deficiencies and poor iron utilization associated with infection. Maternal anemia lowers offspring iron stores, possibly well into the first year of life (Allen, 2000). Potential mechanisms for the impact of the mother's height on the health of her offspring were discussed in section 1. It is estimated that in developed countries, environmental factors explain about $20 \%$ of variation in height, but this figure is likely to be higher in developing countries due to higher levels of environmental stress (Silventoinen, 2003) which tend to limit attainment of genetic potential (Mironov, 1999). There are permanent differences in height across regions that are hard to reconcile with nutritional differences and may arise from natural selection based on millennia of different climates and resources (Ruff, 2002). For example, African women are the tallest in the developing world but they grow up in very poor conditions (Deaton, 2007). Nevertheless, cohort variation in height within sub-Saharan Africa is sensitive to indicators of the early life nutritional environment (Akachi and Canning, 2007). We have confirmed that this is also the case in the current sample, where birth year GDP, the regional infant mortality rate and the average education of mothers in the cohort influences the height of adult women (Bhalotra 2009).

\section{Data}

The microdata are compiled from 77 Demographic and Health Surveys (DHS) for 38 developing countries. Multiple country surveys are pooled across rounds. The estimation sample contains comparable information on as many as 2.24 million children born to 600,000 mothers during 1970-2000 derived from surveys dated 1991-2006. Details are in Tables A.1, A.2 and Figure A.12. The data offer the following advantages. (1) They are of unprecedented scope in this literature; previous epidemiological research often relies upon small samples and no previous work by economists has analysed cross-country microdata on this scale or attempted to describe trends. (2) Biological mothers and children are linked through fertility records, avoiding the problem common in cross-sectional surveys of the presence of non-biological children which, in Africa, is a major issue. (3) A number of indicators of health are available, allowing us to analyse indicators of the contemporary and permanent health of the mother and of the survival and (prenatal and postnatal) growth of the child. (4) Height (mother and child) and the BMI and anemia status 
of the mother are measured by surveyors using state of the art tools. This avoids the bias in commonly used subjective assessments of health. (5) Surveys were conducted across countries using very similar questionnaires and measurement tools. (6) The surveys provide complete retrospective fertility histories for women aged 15 to 49 years at the time of the survey in which the dates of all births and any deaths are recorded. Interview dates span 1986-2006, whilst births occur across 1952-2006. These histories are exploited to construct cohort data on mortality across three decades, as in (Bhalotra, 2010b), permitting analysis of trends. (7) Retrospective records that include all births eliminate sample selection problems in the mortality and birth weight measures since inclusion in the sample is not conditional on survival to the survey date. (8) An advantage of cross-country microdata is that they can be merged with countrylevel panel data (by country and birth year of the child) to look at how mobility varies with country-level income and institutions. We merge in GDP and immunization rates (a measure of public health). The appendix describes the countries in the sample, the sources and definitions of all variables analyzed, and explains how we deal with censoring, potential selectivity, missing data and outliers. It also presents descriptive statistics and graphs. ${ }^{4}$

\section{Results}

Nonparametric relationships between alternative pairs of indicators of maternal and child health are estimated using lowess predictions of the binary dependent variables (Figure 1). ${ }^{5}$ They consistently suggest a positive intergenerational correlation of health. The rest of this section discusses the parametric estimates presented in Tables 1-3. The estimated coefficients are significant and of the expected sign in every specification. To the extent that non-genomic mechanisms are at play (sections 1 and 2), these results suggest that the benefits of investing in the health of girls extend to their births.

\section{Mother's height}

Increases in mother's height lower the risk of poor child health for all measures of child health. They also raise the z-score of child health, a measure that is not weighted at the low end (Table A5). The average effects identified are large relative to the sample means of the dependent variables. For instance, a one standard deviation (s.d.) decrease in mother's height is associated with an elevation of low birth weight risk of $7.4 \%$ of the mean rate in the sample and with an elevation of neonatal mortality risk of $9.3 \%$ of the sample rate. A quadratic in height is significant for mortality and stunting risk, indicating attenuation of the effect of mother's height on child health as height increases. The probability of low birth weight, in

\footnotetext{
${ }^{4}$ The appendix is available online at http://www.efm.bris.ac.uk/ecsrb/bhalotra.htm. Henceforth Tables $A$.n indicate tables in this appendix.

${ }^{5}$ Country-specific non-parametric plots are in the appendix and a discussion of the non-parametric plots is in the working paper version, Bhalotra and Rawlings (2010a).
} 
contrast, appears to be well specified by the linear model. The specification that includes indicators for the mother's place in the height distribution of her country shows that the intergenerational correlation of health tends to be strongest at the tails of the height distribution and especially so at the low end of the distribution. For example, the increase in neonatal mortality risk from having a mother with height between 1 and 2 s.d. below the mean (short1) is more than twice the decrease in risk from having a mother between 1 and 2 s.d. above the mean (tall1). Moving from height more than two s.d. below the mean to height 1-2 s.d. below the mean reduces risks of low birth weight and neonatal mortality by $14 \%$ and $25 \%$ of their sample means. In contrast, moving up on the other side of the mean, from height 1-2 s.d. above mean to height more than 2 s.d. above mean yields gains of $5 \%$ and $0 \%$ of the mean respectively; see Table 1c. Asymmetry is apparent for all measures of ill-health but while it is significant for mortality and stunting, it cannot be rejected in the case of birth weight. No significant asymmetry is apparent when the z-score of child height is regressed upon the range of levels of mother's height.

The reported estimates are conditional upon characteristics $\mathrm{X}_{\mathrm{im}}$. Excluding these raises $\beta$ by $50 \%$ in the specification with height in meters. The estimated coefficients on height are insensitive to controlling for ethnicity or sub-region fixed effects and to incorporating slope heterogeneity at the mother level. While there is some evidence of heterogeneity across mothers in the intergenerational correlation of health within country, this would appear to be independent of her relative height. The baseline specification therefore identifies the average partial (or treatment) effect. These additional estimates are reported in Bhalotra and Rawlings (2010b).

\section{Mother's body mass index}

In a linear specification, increases in maternal BMI lower the risk of low birth weight and stunting, raise the z-score of child height and raise mortality risk. For example, a one s.d. decrease in BMI is estimated to raise the risk of low birth weight by $10.8 \%$ of the mean and to lower the risk of neonatal mortality by $13.1 \%$ of the mean (Table $2 \mathrm{~b}$ ). We also estimate a model in which we distinguish low $(<18.5)$ and high (> 24.9) BMI from the intervening normal range. The risks of low birth weight and stunting fall monotonically with BMI but with different (implicit) curvature in the two cases. Low BMI raises the risk of low birth weight by almost twice as much as high BMI lowers it. On the other hand, gains in BMI only significantly reduce stunting risk when BMI crosses into the high range. When the dependent variable is the z-score of child height rather than stunting, high BMI has a positive influence on height that is significantly larger than the negative influence of low BMI. The positive association of child mortality and maternal BMI is driven by high BMI. This is striking, especially if viewed in relation to the emerging evidence that nutritional deprivation in early childhood can lead to obesity amongst women in adulthood 
(section 1). However it must also be viewed alongside our evidence that increases in BMI, even into the obesity range, lower anthropometric failure.

\section{Mother's anemia status}

Anemia significantly raises the risk of low birth weight and mortality risk, and lowers the z-score of child height (Table 2). It only significantly lowers stunting risk when it is classed as severe. The risks of low birth weight and neonatal mortality are lower by $5.7 \%$ and $16.9 \%$ of their mean rates amongst mothers who do not have anemia relative to mothers who do. Distinguishing mild or moderate from severe anemia shows that its marginal effects increase with its severity.

\section{Trends in intergenerational persistence: Overall and by region}

Linear trends suggest no significant change over time in the influence of maternal height on neonatal mortality risk but there is a significant weakening of its influence on infant and under-5 mortality with a lowering of the intergenerational correlation by 0.018 and 0.026 per decade, respectively (appendix). A nonparametric fit to a scatter of the estimated intergenerational coefficient from cross-sections for each year against year is in Figure 2. For the earlier years in our sample, the average intergenerational correlation rises but, after about 1975, it declines monotonically. A linear trend fitted to the scatter of $\beta_{\mathrm{t}}$ shows significant declines in persistence over time at rates that are substantially larger than suggested by the linear specification. The rates of decline are $0.011,0.036$ and 0.043 per decade for neonatal, infant and under- 5 mortality respectively (Table 3), which imply an erosion of about 31\%, 35\% and 31\% per decade in the intergenerational coefficients. The correlation or the coefficient multiplied by the relative change in inequality of mother's height and child mortality declines by $10 \%, 33 \%$ and $30 \%$, the decline for neonatal mortality being insignificantly different from zero. Estimates of $\beta_{\mathrm{c}}$ for five-year cohorts present a broadly similar picture to the estimates $\beta_{\mathrm{t}}$; details are in Bhalotra and Rawlings (2010a).

We repeat this exercise for each region-year; see Table 3 and Fig. A.4, A.5. Latin America shows a consistent improvement in health mobility over time through the three decades with rates of decline twice as large as the average rates reported above. Africa and Asia exhibit a tendency for intergenerational persistence to rise at the start of the period. Decline sets in by the early 1980s in Asia but only later, at the start of the 1990s, in Africa. The regression coefficients for Africa show a positive trend that is significant in the case of neonatal mortality and, once adjusted for the evolution of the ratio of standard deviations of height and mortality, for under-5 mortality. In Asia the relationship is stable over time, except that the relationship between under-5 mortality and height has grown significantly tighter. The average height of mothers grew by $0.16 \mathrm{~mm}, 0.07 \mathrm{~mm}$, and $0.40 \mathrm{~mm}$ p.a. in Africa, Asia, and Latin America. So, younger cohorts of women in Latin America gained height over older cohorts many times faster than in the other 
regions. Since the impact of mother's height on child mortality risk is decreasing in her height, this makes sense of the greater weakening of this tie in Latin America. Africa has suffered HIV/AIDS more than the other regions. Consistent with the mobility trend, economic growth picked up in Asia in the early 1980s and in Africa in the early 1990s. Latin America grew through the period albeit with a slowdown in the 1980s. It also experienced a greater expansion over the period of nationwide health interventions than the other two regions.

How do these results compare with previous estimates of intergenerational mobility? As discussed, there are no previous estimates of trends for measures of health. The few available studies of trends in intergenerational persistence in earnings and education suggest limited mobility in Europe and North America with the exception of the Nordic countries (Black and Devereux, 2010). Using data for 42 countries, 29 of which are developing or transition countries. Hertz et al. (2007) show that, while the slope of the relationship between parent and child years of education showed significant attenuation, the correlation remained more or less constant across half a century. Mobility measured by the correlation is weaker than that measured by the regression coefficient because the variance of parent's education has risen relative to the variance of children's education over time in many countries. Similarly, intergenerational income coefficients are often adjusted downwards because the variance of income tends to increase with age and the income of parents is often recorded at a more advanced age than that of their adult offspring (e.g. Blanden et al., 2004). The health data in our sample exhibit a similar tendency. Inequality measured by the standard deviation of mother's health $\sigma_{\mathrm{m}}{ }^{\mathrm{c}}$ fell slightly over the period but inequality in child mortality $\sigma_{\mathrm{i}}^{\mathrm{c}}$ fell much more, in line with secular declines in mortality. This led to a rise in the within-cohort ratio $\sigma_{m}^{c} / \sigma_{i}^{c}$ and the corresponding within-year ratio that is applied to adjust $\beta_{\mathrm{t}}$ Adjusting for the trend in the relative variance of the mother and child health indicators therefore attenuates the trend in $\beta$. The trend in the correlation is further dampened by the data becoming less scattered around the regression line. This is illustrated by Figure A.11 which shows the slope and fit of the relationship for a random sample of data from India. The slope declines significantly between cohorts 25 years apart but the scatter fits more closely around the regression line for the younger cohort.

\section{Spatial differences in intergenerational persistence}

Continent-specific estimates are in Table A.7. For mortality, the marginal effect of height is largest in Asia and smallest in Latin America. Indicators of mother's health are worst in Asia and incomes are highest in 
the LA countries. ${ }^{6}$ The ordering of continents by the size of the marginal effect of mother's health is reversed when we consider birth weight and stunting. A possible explanation for why, in Latin America, the effects of poor maternal health are largely felt on the anthropometric indices of children and not mortality is that there is less survival selection than in Asia and Africa. Estimates of equation (1) that include interaction terms between maternal height and 38 country dummies show that $\beta_{j}$ is significantly different across countries for all measures of child health. The number of countries with a significant $\beta$ and, amongst these, the range of $\beta, \theta$, and $\tau$ are summarised in Table A. 8 and Figure A.5. Country-specific estimates obtained by estimating the model for each country are in Tables A.9 - A.13. The range of $\theta_{j}$ is less than the range of $\beta_{j}$ since $\sigma_{\mathrm{m}}{ }^{\mathrm{j}}$ is similar across countries, whilst $\sigma_{\mathrm{i}}^{\mathrm{j}}$ is increasing in the size of $\beta_{\mathrm{j}}$ (see Tables A.9 - A.13). Thus $\sigma_{m}^{c} / \sigma_{i}^{c}$ is decreasing with $\beta_{j}$, and this compresses the distribution of $\theta_{j}$ The range of $\tau_{j}$ is greater than the range of $\beta_{j}$ because the coefficient on maternal height increases with average poor child health. Figure A.6 shows plots of the $\beta_{j}$ against country-specific averages of income, education, immunization rates and the levels of maternal and child health. Improvements in the environment weaken the tie between maternal height and child mortality (also see Bhalotra and Rawlings, 2010b). However, low birth weight and stunting risk show no significant association with the levels of maternal or child health, GDP immunization rates or mother's education.

\section{Conclusions}

This paper documents widespread intergenerational transmission of health from mothers to children using data on as many as 2.24 million births in 38 developing countries across three decades. We find that short stature and anemia of the mother each raise the likelihood that her births are low birth weight, suffer early life mortality and exhibit stunted growth. Low maternal BMI is a risk factor in low birth weight and stunting while high BMI is a risk factor for childhood mortality. Mother's health, by alternative indicators, is thus shown to impact size at birth, survival and child growth conditional upon survival. The results suggest that both contemporary and childhood health of the mother matter for the health of the next generation. BMI and anemia indicate health around the time of birth while adult height is a marker for health in childhood (Case and Paxson, 2010). Thus, under-investment in the health of girls and women contributes to explaining child mortality and intergenerational cycles of growth failure amongst survivors.

It is estimated that in at least two thirds of cases, low birth weight in developing countries signifies intrauterine growth retardation (ACC/SCN 2000: box 1). It also produces post-natal growth retardation to

\footnotetext{
${ }^{6}$ These results contrast with Hertz et al. (2007) who found the strongest levels of persistence in education in Latin America. However, health trends may be different and the samples analysed are different. We have 28 African countries, 7 LA and 3 Asian, whilst they have 4, 7, and 10, respectively.
} 
the extent that low birth weight babies are more prone to infection which, in turn, limits nutrient assimilation. More recent evidence indicates that low birth weight has a further range of impacts in adult life, including hypertension, insulin resistance, type 2 diabetes, cardio-vascular disease, obstructive lung disease, renal damage and some forms of cancer, and that these appear to be independent of SES and behaviours like smoking and drinking (Barker, 1998). Indeed, they are more likely to express in individuals who are growing up in conditions of resource plenty relative to their mothers. This may explain why, alongside infectious diseases, a range of chronic non-communicable diseases have taken their hold in developing countries (Yajnik, 2001, Osmani and Sen 2003).

Girls receive lower investments in both health and education in developing countries. To the extent that our estimates pick up non-genomic traits or, more generally, if genomic traits are more likely to express when resource conditions are poor (Turkheimer et al. 2003, van den Berg et al. 2008), our findings suggest that this may be a costly neglect. There is evidence from developing countries of the importance of health in raising educational attainment (Glewwe and Miguel, 2008) and productivity (Schultz, 2005) or, conversely, of poor health in generating poverty traps (Dasgupta and Ray, 1986). Together with evidence of the impact of education and income on health in poor households (Cutler et al., 2006; Bhalotra, 2010b) and of assortative matching in marriage (Pencavel, 1998), this implies that intergenerational persistence in health may explain some of the intergenerational persistence in education, earnings and economic inequality.

In the three decades analysed, there have been substantial advances in the diffusion of medical technology but at the same time, the majority of mothers continue to have little education and the effective provision of broad based public services remains poor. Economic growth has been erratic and unevenly distributed. We find a significant improvement in "health mobility" on average but disaggregation by continent presents a less rosy picture. Latin America exhibits a consistent improvement in health mobility through 1970-2000 with rates of decline twice as large as the average rates. In Africa and Asia, intergenerational persistence increased at the start of the period. Decline set in by the early 1980s in Asia but only later, at the start of the 1990s, in Africa. Overall, persistence increased in Africa, especially for neonatal mortality. It was more or less constant in Asia, with some indication of a tightening of the relationship for under-5 mortality.

\section{References}

ACC/SCN, 2000. Low Birthweight - Nutrition policy discussion paper No. 18 ACC/SCN.

Akachi, Y., Canning, D., 2007. The height of women in sub-Saharan Africa: The role of health, nutrition and income in childhood. Annals of Human Biology 34 (4), 397-410. 
Allen, L., 2000. Anemia and iron deficiency: Effects on pregnancy outcome. American Journal of Clinical Nutrition 71 (5), 1280S-1284S.

Almond, D., 2006. Is the 1918 influenza pandemic over? Long term effects of in utero influenza exposure in the post 1940 U.S. population. Journal of Political Economy 114 (4), 672-712.

Almond, D., Chay, K., 2006. The long-run and intergenerational impact of poor infant health: Evidence from cohorts born during the civil rights era. Mimeograph, Columbia University.

Almond, D., Currie, J., 2010. Human capital development before age five. NBER Working Paper No. 15827.

Atkinson, A., 1981. Intergenerational income mobility in Britain. Journal of Post Keynesian Economics 3, 194-218.

Baird, S., J. Friedman and N. Schady, 2010. Aggregate income shocks and infant mortality in the developing world. Review of Economics and Statistics, forthcoming.

Barker, D., 1992. Fetal and Infant Origins of Adult Disease. British Medical Journal Publishing.

Barker, D., 1997. Maternal nutrition, fetal nutrition and diseases in later life. Nutrition 13, 807-813.

Barker, D., Levy, L., 1994. Mothers, babies, and disease in later life. British Medical Journal Publishing Group, London.

Barker, D., Osmond, C., 1986. Infant mortality, childhood nutrition, and ischaemic heart disease in England and Wales. Lancet 1077-81 (8489), 1077-1081.

Barker, D., Osmond, D., 1987. Death rates from stroke in England and Wales predicted from past maternal mortality. British Medical Journal 295, 83-86.

Barker, D. J., 1998. In utero programming of chronic disease. Clinical Sciences 95 (2), 115-128.

Becker, G., Tomes, N., 1979. An equilibrium theory of the distribution of income and intergenerational mobility. The Journal of Political Economy 87 (6), 1153-1189.

Behrman, J., Deolalikar, A., 1990, 'Health and Nutrition', in H. Chenery and T.N. Srinivasan, Handbook of Development Economics, Vol.1, Ch.14, pp.631-711.

Behrman, J., Gaviria, A., Széekely, M., Birdsall, N., Galiani, S., 2001. Intergenerational mobility in Latin America. Economía 2 (1), 1-44.

Bhalotra, S and C. Attifield. 1998. Intrahousehold resource allocation in rural Pakistan: A semiparametric analysis. Journal of Applied Econometrics, 13(5):463-480, Sept/Oct 1998.

Bhalotra, S., (2009). Wuthering heights: Birth shocks and stature amongst Indian men and women. Mimeograph, University of Bristol.

Bhalotra, S., 2010a The intergenerational spillover of early life conditions: the very long arm of childhood. Mimeograph. University of Bristol

Bhalotra, S., 2010b. Fatal fluctuations? Cyclicality in infant mortality in India. Journal of Development Economics, Volume 93, Issue 1, September 2010, Pages 7-19. 
Bhalotra (in progress). Intergenerational persistence in health in India- mothers, fathers and the state. Mimeograph, University of Bristol.

Bhalotra, S., Rawlings, S., 2010a. Intergenerational Persistence in Health in Developing Countries: Trends and Country Differences. IZA Discussion Paper, forthcoming

Bhalotra, S., Rawlings, S., 2010b. Gradients in the intergenerational transmission of health in developing countries. Mimeograph, http://www.efm.bris.ac.uk/ecsrb/bhalotra.htm

Bhalotra, S., and Venkataramani, A., 2010. Long-run and intergenerational impacts of disease and medical technology: Evidence from the sulfa drug innovation. Mimeograph. University of Bristol and University of Washington at St Louis.

Bharadwaj, P., and Nelson, L., 2010. Discrimination begins in the womb: evidence of sex-selective prenatal investments. Mimeograph. University of San Diego

Black, S., Devereux, P., 2010. Recent developments in intergenerational mobility. NBER Working Paper 15889.

Black, S., Devereux, P., Salvanes, K. G., 2007. From the cradle to the labor market? The effect of birth weight on adult outcomes. The Quarterly Journal of Economics 122 (1), 409-439.

Blanden, J., Goodman, A., Gregg, P., Machin, S., 2004. Changes in Intergenerational Income Mobility in Britain, in Generational Income Mobility in North American and Europe. Cambridge University Press, pp. 122-146.

Bowles, S., Gintis, H., 2002. Schooling in capitalist America revisited. Sociology if Education 75 (1), 1-18.

Bumpass, L., Rindfuss, R. R., Janosik, R., 1978. Age and marital status at first birth and the pace of subsequent fertility. Demography 15 (1), 75-86.

Camacho, A., 2008. Stress and Birth Weight: Evidence from Terrorist Attacks, American Economic Review, 98, $511-515$.

Case, A., Fertig, A., Paxson, C., 2005. The lasting impact of childhood health and circumstance. Journal Of Health Economics 24 (2), 365-389.

Case, A., Paxson, C., 2010. Causes and consequences of early life health. NBER Working Papers 15637.

Cawley, R., Mckeown, T., Record, R., 1954. Parental stature and birth weight. Annals of Human Genetics 6, 448456.

Chadwick, L., Solon, G., 2002. Intergenerational income mobility among daughters. American Economic Review 92 (1), 335-44.

Cogswell, M. E.., Parvanta, I., Ickes, L., Yip, R., Brittenham, G.M., 2003. Iron supplementation during pregnancy, anemia, and birth weight: a randomized controlled trial. American Journal of Clinical Nutrition, 78, (4),773-81

Cole, T., 2000. Secular trends in growth. Proceedings of the Nutrition Society 59, 317-324.

Costa, D., 1998. Unequal at birth: A long-term comparison of income and birth weight. The Journal of Economic History 58 (4), 987-1009. 
Cunha, F., Heckman, J., 2007. The technology of skill formation. American Economic Review 97 (2), 31-47.

Currie, J., 2009. Healthy, wealthy, and wise: Socioeconomic status, poor health in childhood, and human capital development. Journal of Economic Literature 47 (1), 87-122.

Currie, J., Moretti, E., 2007. Biology as destiny? short- and long-run determinants of intergenerational transmission of birth weight. Journal of Labor Economics 25 (2), 231-263.

Cutler, D., Deaton, A., Lleras-Muney, A., 2006. The determinants of mortality. Journal of Economic Perspectives 20 (3), 97-120.

Dasgupta, P., Ray, D., 1986. Inequality as a determinant of malnutrition and unemployment: Policy.Economic Journal 96 (384), 1011-1034.

Deaton, A., 2007. Height, health and development. Proceedings of the National Academies of Science 104 (33), $13232-13237$.

Dercon, S., Krishnan, P., 2000. In sickness and in health: risk sharing within households in rural Ethiopia, Journal of Political Economy 108 (4), pp. 688-727

DeRose, L., Das, M., Millman, S., 2000. Does female disadvantage mean lower access to food? Population and Development Review 26 (3), 517-547.

Drake, A., Walker, B., 2004. The intergenerational effects of fetal programming: non-genomic mechanisms for the inheritance of low birth weight and cardiovascular risk. Journal of Endocrinology 180 (1), 1-16.

Elo, I., Preston, S., 1992. Effects of early-life conditions on adult mortality: A review. Population Index 58 (2), 186212.

Emmanuel, I., Filakti, H., Alberman, E., Evans, S., 1992. Intergenerational studies of human birthweight from the 1958 birth cohort. I. Evidence for a multigenerational effect. Obstetrical and Gynecological Survey 47.

Eriksson, T., Bratsberg, B., Raaum, O., 2005. Earnings persistence across generations: Transmission through health? Mimeograph.

Fogel, R, 2004. Health, nutrition, and economic growth. Economic Development and Cultural Change 52 (3), $643-$ 658.

Fung, W., 2009. Early childhood malnutrition and adult obesity: Evidence from the 1959-61 China famine. Harvard University, Mimeograph.

Fung, W., Wei, H., 2009. Intergenerational effects of the 1959-61 China famine. Mimeograph Harvard University.

Glewwe, P., Miguel, E., 2008. The Impact of child health and nutrition in the Handbook of Development Economics. Elsevier, 3561-3606.

Gluckman, P., Hanson, M., 2005. The Fetal Matrix: Evolution, Development, and Disease. Cambridge University Press, Cambridge, UK.

Grawe, N., Mulligan, C., 2002. Economic interpretations of intergenerational correlations. Journal of Economic Perspectives 16 (3), 45-58. 
Gunnell, D., 2002, Commentary: Can adult anthropometry be used as a 'biomarker' for prenatal and childhood exposures? International Journal of Epidemiology, 31 (2), 390-394

Harriss, B., 1990 The intrafamily distribution of Hunger in Dreze, J.P. and Sen, A.K. (eds) The political economy of hunger, Oxford: Clarendon

Heckman, J., 2007. The economics, technology, and neuroscience of human capability formation. PNAS, 104 (33), $13250-13255$

Hackman, E., Emanuel, I., van Belle, G., Daling, J., 1983. Maternal birth weight and subsequent pregnancy outcome. Journal of the American Medical Association 250 (15), 2016-2019.

Hertz, T., Jayasundera, T., Piraino, P., Selcuk, S., Smith, N., Verashchagina, A., 2007. The inheritance of educational inequality: International comparisons and fifty-year trends. The B.E. Journal of Economic Analysis and Policy 7 (2).

Hill, K., Upchurch, D., 1995. Gender differences in child health: Evidence from the Demographic and Health Surveys. Population and Development Review 21 (1), 127-151.

Hoddinott, J., Kinsey, B., 2001. Child growth in the time of drought. Oxford Bulletin of Economics and Statistics 63 (4), 409-436.

Holmlund, H., Lindahl, M., Plug, E., 2008. The Causal Effect of Parent's Schooling on Children's Schooling: A Comparison of Estimation Methods, IZA Discussion Paper No. 3630

Ibanez, L., Potau, N., Enriquez, G., de Zegher, F., 2000 Reduced uterine and ovarian size in adolescent girls born small for gestational age. Pediatric Research 47, 575-577.

Klebanoff, M., Secher, N., Mednick, B., Schulsinger, C., 1999. Maternal size at birth and the development of hypertension during pregnancy. Archives of Internal Medicine 159, 1607-1612.

Kramer, M. S., 1987, Determinants of Low Birth Weight: Methodological Assessment and Meta-Analysis. Bulletin of the World Health Organization, 65(5), 663-737.

Levy, A., Fraser, D., Katz, M., Mazor, M., Sheiner, E., 2005. Maternal anemia during pregnancy is an independent risk factor for low birthweight and preterm delivery. European Journal of Obstetrics \& Gynecology and Reproductive Biology 122 (2), 182-186.

Luo, Z., Mu, R., Zhang, X., 2006. Famine and overweight in China. Review of Agricultural Economics 28 (3), 296304.

Maddison, A., 2004. World Development and Outlook 1820-2030: A Quantitative Perspective. Working Paper, Meeting of OECD Economics \& Environment Directorates

Martorell, R., Habicht, J., 1986. Growth in early childhood in developing countries, in Human Growth: A Comprehensive Treatise. Vol. 3. Plenum Press, New York, pp. 241-262.

Martorell, R., 1995. Results and implications of the INCAP follow-up study. Journal of Nutrition 125 (Supplement), $1127 \mathrm{~S}-1138 \mathrm{~S}$.

Martorell, R., 1999. The nature of child malnutrition and its long-term implications. Food and Nutrition Bulletin 20, $288-292$. 
Mironov, B., 1999. New approaches to old problems: The well-being of the population of Russia from 1821 to 1910 as measured by physical stature. Slavic Review 58 (1), 1-26.

Morton N.E., 1955. The inheritance of human birth weight. Annals of Human Genetics; 20(2), 125-34

Murray, C., Lopez, A., 1997. Global mortality, disability, and the contribution of risk factors: Global burden of disease study. Lancet 349, 1436-42.

Neggars, Y., Goldenberg, R., 2003. Some thoughts on body mass index, micronutrient intakes and pregnancy outcome. Journal of Nutrition 133, 1737S-1740S.

ORC Macro, 2006. MEASURE DHS: Model Questionnaire with Commentary for Countries with the Expanded HIV Questions. MEASURE DHS Basic Documentation Number 2.

Osmani, S., Sen, A., 2003. The hidden penalties of gender inequality: Fetal origins of ill-health. Economics \& Human Biology 1 (1), 105-121.

Pencavel, J., 1998. Assortative mating by schooling and the work behavior of wives and husbands. The American Economic Review, Papers and Proceedings of the Hundred and Tenth Annual Meeting of the American Economic Association 88 (2), 326-329.

Preston, S., 1976. Mortality Patterns in National Populations: With Special Reference to Recorded Causes of Death. New York: Academic Press.

Reidpath, D., Allotey, P., 2003. Infant mortality rate as an indicator of population health. Journal of Epidemiology and Community Health 57 (5), 344-346.

Ridley, M., 2003. Nature via Nurture: Genes, experience, and what makes us human. Harper Collins Publishers, New York, US.

Roy, A., 1950. The distribution of earnings and of individual output. The Economic Journal 60 (239), 489-505.

Ruff, C., 2002. Variation in human body size and shape. Annual Review of Anthropology 31, 211-232.

Sen., A., 1990. More than 100 Million Women are Missing, New York Review of Books

Sen., A., 1992. Missing Women British Medical Journal 304, 587-588.

Schultz, T., 2005. Productive benefits of health: Evidence from low-income countries. IZA Discussion Paper 1482.

Schultz, T., 2009. Population and health policies. IZA Discussion Paper No. 4340.

Scrimshaw, N., Taylor, C., Gordon, J., 1968. Interactions of nutrition and infection. World Health Organisation monograph series No. 57.

Silventoinen, K., 2003. Determinants of variation in adult body height. Journal of Biosocial Sciences 35, 263-285.

Smith, J., 2009. The impact of childhood health on adult labor market outcomes. Review of Economics and Statistics 91 (3), 478-489.

Soares, R., 2006. On the determinants of mortality reductions in the developing world. Working Paper 529, Department of Economics, PUC-Rio. 
Solon, G., 2002. Cross-country differences in intergenerational earnings mobility. The Journal of Economic Perspectives 16 (3), 59-66.

Steckel, R., 2009. Heights and human welfare: Recent developments and new directions. Explorations in Economic History 46 (1), 1-23.

Strauss, J., Thomas, D., 2008. Health over the Life Course, in Handbook of Development Economics. Elsevier, pp. $3375-3465$.

Turkheimer, E., Haley, A., Waldron, M., D’Onofrio, B., Gottesman, I., 2003. Socioeconomic status modifies heritability of IQ in young children. Psychological Science 14 (6), 623-628.

van den Berg, G., Doblhammer, G., Christensen, K., 2008. Being born under adverse economic conditions leads to a higher cardiovascular mortality rate later in life: Evidence based on individuals born at different stages of the business cycle. Bonn: IZA Discussion Paper 3635.

van den Berg, G., Lindeboom, M., Lopez, M., 2006. Economic conditions early in life and individual mortality. American Economic Review 96 (1), 290-302.

Venkataramani, A., 2010a The Medium-Run Impact of Early Life Exposure to Clean Water Interventions: Evidence from Mexico. Mimeograph. School of Medicine. University of Washington at St Louis.

Venkataramani, A., 2010b The intergenerational transmission of height: Evidence from rural Vietnam. (July 27, 2010). Available at SSRN: http://ssrn.com/abstract $=1300137$

Walton, A., Hammond, J., 1938. The maternal effects on growth and conformation in Shire horse-Shetland pony crosses. Proceedings of the Royal Society of London. Series B, Biological Sciences 125, 311-335.

WHO, 2008. Worldwide prevalence of anemia 1993-2005, WHO global database on anemia. World Health Organisation.

Wooldridge JM 2005. Unobserved heterogeneity and estimation of average partial effects, in Donald Andrews and James Stock (eds.). Identification and Inference for Econometric Models: A Festschrift in Honor of Thomas J Rothenberg, Cambridge: Cambridge University Press.

Yajnik, C., 2001. Fetal Origins of Adult Disease: Where Do We Stand? International Journal Diabetes in Developing Countries, 21: 42-50 
Table 1a: Intergenerational Persistence: Maternal stature effects on child health indicators

\begin{tabular}{llllll}
\hline \hline & Neonatal Mortality & Infant Mortality & Under-5 Mortality & Low BW & Stunted \\
\hline A: Linear Height & & & & \\
\hline$\beta$ & $-0.066^{* *}$ & $-0.103^{* *}$ & $-0.139 * *$ & $-0.218^{* *}$ & $-0.098^{* *}$ \\
& $(0.008)$ & $(0.010)$ & $(0.013)$ & $(0.031)$ & $(0.007)$ \\
$\theta$ & -0.021 & -0.024 & -0.027 & -0.037 & -0.043
\end{tabular}

\begin{tabular}{llllll}
\hline \hline B: Non-Linear Height: Quadratic & & & & \\
\hline Mother's Height & $-0.835^{* *}$ & $-1.007^{* *}$ & $-1.227^{* *}$ & -1.234 & $-1.239^{* *}$ \\
& $(0.205)$ & $(0.203)$ & $(0.236)$ & $(1.005)$ & $(0.244)$ \\
Mother's Height2 & $0.246^{* *}$ & $0.289^{* *}$ & $0.348^{* *}$ & 0.323 & $0.363^{* *}$ \\
& $(0.064)$ & $(0.064)$ & $(0.075)$ & $(0.315)$ & $(0.077)$ \\
\hline \hline
\end{tabular}

C: Non-Linear Height: Deviations from country mean

\begin{tabular}{|c|c|c|c|c|c|}
\hline \multirow[t]{2}{*}{ Tall (0.5-1 s.d.) } & $-0.002 * *$ & $-0.005^{* *}$ & $-0.006^{* *}$ & $-0.011 * *$ & $-0.002 * *$ \\
\hline & $(0.001)$ & $(0.001)$ & $(0.001)$ & $(0.003)$ & $(0.001)$ \\
\hline \multirow[t]{2}{*}{ Tall (1-2 s.d.) } & $-0.004 * *$ & $-0.006^{* *}$ & $-0.008^{* *}$ & $-0.019 * *$ & $-0.004 * *$ \\
\hline & $(0.001)$ & $(0.001)$ & $(0.001)$ & $(0.003)$ & $(0.001)$ \\
\hline \multirow[t]{2}{*}{ Tall (> 2 s.d.) } & -0.004 & $-0.009 * *$ & $-0.012^{* *}$ & $-0.029 * *$ & -0.004 \\
\hline & $(0.002)$ & $(0.003)$ & $(0.003)$ & $(0.010)$ & $(0.003)$ \\
\hline \multirow[t]{2}{*}{ Short (0.5-1 s.d.) } & $0.004^{* *}$ & $0.005^{* *}$ & $0.007 * *$ & $0.013^{* *}$ & $0.007 * *$ \\
\hline & $(0.001)$ & $(0.001)$ & $(0.001)$ & $(0.003)$ & $(0.001)$ \\
\hline \multirow[t]{2}{*}{ Short (1-2 s.d.) } & $0.009 * *$ & $0.013^{* *}$ & $0.017 * *$ & $0.022 * *$ & $0.013^{* *}$ \\
\hline & $(0.001)$ & $(0.001)$ & $(0.001)$ & $(0.005)$ & $(0.002)$ \\
\hline \multirow[t]{2}{*}{ Short (> 2 s.d.) } & $0.021 * *$ & $0.030 * *$ & $0.039 * *$ & $0.051^{* *}$ & $0.035^{* *}$ \\
\hline & $(0.004)$ & $(0.005)$ & $(0.006)$ & $(0.016)$ & $(0.007)$ \\
\hline Observations & 2295740 & 2233720 & 1894526 & 324097 & 285440 \\
\hline mean (dep. var.) & 0.049 & 0.097 & 0.145 & 0.202 & 0.025 \\
\hline s.d.(dep. var.) & 0.216 & 0.296 & 0.352 & 0.402 & 0.157 \\
\hline mean (height) & 1.559 & 1.559 & 1.559 & 1.569 & 1.566 \\
\hline s.d. (height) & 0.069 & 0.069 & 0.069 & 0.068 & 0.069 \\
\hline $\mathrm{p}>\chi^{2}:($ tallhalf$/$ shorthalf $)$ & 0.000 & 0.000 & 0.000 & 0.000 & 0.000 \\
\hline $\mathrm{p}>\chi^{2}:($ tall $1 /$ short 1$)$ & 0.000 & 0.000 & 0.000 & 0.000 & 0.000 \\
\hline $\mathrm{p}>\chi^{2}:($ tall2/short 2$)$ & 0.000 & 0.000 & 0.000 & 0.014 & 0.000 \\
\hline
\end{tabular}

Robust standard errors in brackets, allowing for clustering within country. ${ }^{*}$ significant at $5 \%,{ }^{* *}$ significant at $1 \%$. Mortality samples are adjusted to allow full exposure to the relevant risk. Low BW is 1 (low birth weight). Birth weight and height are available only for recent births. Controls include country-year fixed effects, child gender, birth order and birth month, mother's religion, age at birth, education, partner's education and country-year fixed effects. In Panels A and B, mother's height is in metres. $\theta$ is $\beta$ standardized by the ratio of the standard deviation of mother's height to the standard deviation of child health. Tall (0.5-1 s.d.), Tall (1-2 s.d.) and Tall (> 2s.d.) are indicators for being between 0.5 and 1 , between 1 and 2 , and greater than 2 standard deviations above mean height, respectively. The 'short' dummies are similarly defined. Means of Tall (0.5-1 s.d.), Tall (1-2 s.d.) and Tall (> 2 s.d.) are 0.15, 0.10, and 0.01, respectively. Means of Short (0.5-1 s.d.), Short (1-2 s.d.) and Short ( $>2$ s.d.) are 0.16, 0.10, and 0.01, respectively. The $\mathrm{p}>\chi^{2}$ statistic gives the significance level at which we are unable to reject the null that the coefficients for tallhalf/shorthalf, tall1/short1, or tall2/short 2 are significantly different in magnitude from one another. 
Table 1b: Changes in predicted child health associated with a 1 s.d. increase in mother's height

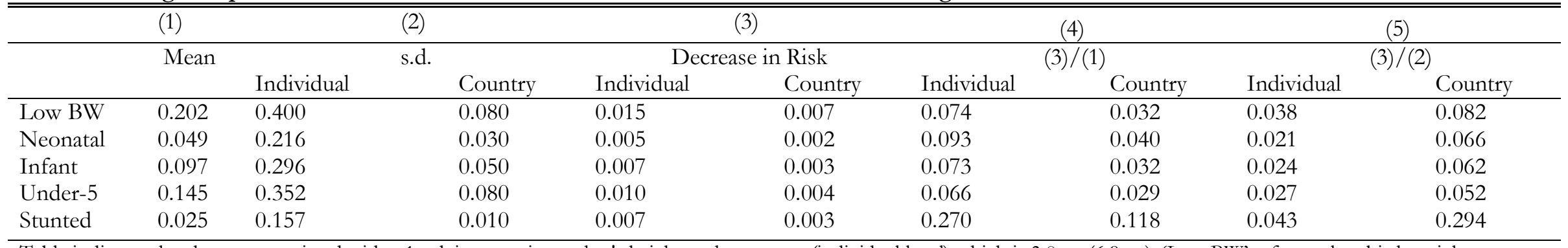

Table indicates the changes associated with a 1 s.d. increase in mother's height at the country (individual level) which is $3.0 \mathrm{~cm}(6.9 \mathrm{~cm})$. 'Low BW' refers to low birth weight.

'Individual' and 'Country' refer to which level the s.d. are calculated at. Means are the same at the country and individual level.

Table 1c: Changes in predicted child health associated with changes in mother's height across the height distribution

\begin{tabular}{|c|c|c|c|c|c|}
\hline & Low BW & Neonatal & Infant & Under-5 & Stunted \\
\hline \multicolumn{6}{|c|}{ Change in Risk of Poor Child Health } \\
\hline Tall (0.5-1 s.d.) & -0.011 & -0.002 & -0.005 & -0.006 & -0.002 \\
\hline Tall (1-2 s.d.) & -0.019 & -0.004 & -0.006 & -0.008 & -0.004 \\
\hline Tall (>2 s.d.) & -0.029 & -0.004 & -0.009 & -0.012 & -0.004 \\
\hline Short (0.5-1 s.d.) & 0.013 & 0.004 & 0.005 & 0.007 & 0.007 \\
\hline Short (1-2 s.d.) & 0.022 & 0.009 & 0.013 & 0.017 & 0.013 \\
\hline Short (>2 s.d.) & 0.051 & 0.021 & 0.030 & 0.039 & 0.035 \\
\hline \multicolumn{6}{|c|}{ Change in Risk/Mean } \\
\hline Tall (0.5-1 s.d.) & -0.054 & -0.041 & -0.052 & -0.041 & -0.080 \\
\hline Tall (1-2 s.d.) & -0.094 & -0.082 & -0.062 & -0.055 & -0.160 \\
\hline Tall (> 2 s.d.) & -0.144 & -0.082 & -0.093 & -0.083 & -0.160 \\
\hline Short (0.5-1 s.d.) & 0.064 & 0.082 & 0.052 & 0.048 & 0.280 \\
\hline Short (1-2 s.d.) & 0.109 & 0.184 & 0.134 & 0.117 & 0.520 \\
\hline Short (>2 s.d.) & 0.252 & 0.429 & 0.309 & 0.269 & 1.400 \\
\hline \multicolumn{6}{|c|}{ Change in Risk/s.d. } \\
\hline Tall (0.5-1 s.d.) & -0.138 & -0.067 & -0.100 & -0.075 & -0.200 \\
\hline Tall (1-2 s.d.) & -0.238 & -0.133 & -0.120 & -0.100 & -0.400 \\
\hline Tall (>2 s.d.) & -0.363 & -0.133 & -0.180 & -0.150 & -0.400 \\
\hline Short (0.5-1 s.d.) & 0.163 & 0.133 & 0.100 & 0.088 & 0.700 \\
\hline Short (1-2 s.d.) & 0.275 & 0.300 & 0.260 & 0.213 & 1.300 \\
\hline Short (>2 s.d.) & 0.638 & 0.700 & 0.600 & 0.488 & 3.500 \\
\hline
\end{tabular}

Table indicates the changes associated with switching each tall/short indicator in equation (3) from 0 to 1 . All changes are relative to the omitted category, which is height of mother within half a standard deviation of mean height in her country. Means and s.d. are calculated on the country-year panel. See Table 1a for sample rates, estimated coefficients, standard errors and significance levels. 


\begin{tabular}{|c|c|c|c|c|c|c|c|c|}
\hline & \multicolumn{4}{|c|}{ Mother's BMI } & \multicolumn{4}{|c|}{ Mother's Anemia Status } \\
\hline & Neonatal & Infant & Low BW & Stunted & Neonatal & Infant & Low BW & Stunted \\
\hline \multicolumn{9}{|l|}{ A: Linear Effects } \\
\hline \multirow[t]{2}{*}{$\mathrm{BMI}(\beta * 10)$} & $0.005^{* *}$ & $0.008^{* *}$ & $-0.054 * *$ & $-0.004 * *$ & & & & \\
\hline & $(0.001)$ & $(0.001)$ & $(0.007)$ & $(0.001)$ & & & & \\
\hline \multirow[t]{2}{*}{ Anemia $(\beta * 10)$} & & & & & $0.054 *$ & $0.129 * *$ & 0.106 & -0.031 \\
\hline & & & & & $(0.022)$ & $(0.031)$ & $(0.061)$ & $(0.028)$ \\
\hline \multirow[t]{2}{*}{ Low BMI $(\beta * 10)$} & 0.003 & 0.010 & $0.461 * *$ & 0.009 & & & & \\
\hline & $(0.011)$ & $(0.019)$ & $(0.055)$ & $(0.014)$ & & & & \\
\hline \multirow[t]{2}{*}{ High BMI $(\beta * 10)$} & $0.044 * *$ & $0.052^{* *}$ & $-0.234 * *$ & $-0.028^{*}$ & & & & \\
\hline & $(0.010)$ & $(0.013)$ & $(0.040)$ & $(0.012)$ & & & & \\
\hline \multirow[t]{2}{*}{ No Anemia $(\beta * 10)$} & & & & & $-0.049 *$ & $-0.130^{* *}$ & -0.094 & 0.032 \\
\hline & & & & & $(0.020)$ & $(0.030$ & $(0.061)$ & $(0.027)$ \\
\hline Severe Anemia $(\beta * 10)$ & & & & & 0.216 & -0.044 & 0.484 & 0.081 \\
\hline Observations & 226458 & 167843 & 210821 & 201717 & 19610 & 15895 & 17542 & 17096 \\
\hline mean (dep. var) & 0.025 & 0.050 & 0.205 & 0.024 & 0.031 & 0.062 & 0.19 & 0.025 \\
\hline s.d. (dep. var) & 0.158 & 0.217 & 0.404 & 0.153 & 0.173 & 0.241 & 0.392 & 0.155 \\
\hline mean (bmi) & 22.573 & 22.64 & 22.473 & 22.65 & & & & \\
\hline s.d. (bmi) & 3.786 & 3.844 & 3.721 & 3.784 & & & & \\
\hline mean (anemia) & & & & & 0.463 & 0.466 & 0.480 & 0.460 \\
\hline s.d. (anemia) & & & & & 0.499 & 0.499 & 0.500 & 0.498 \\
\hline $\mathrm{p}>\chi^{2}:$ (lowbmi/highbmi) & 0.004 & 0.075 & 0.000 & 0.019 & & & & \\
\hline $\mathrm{p}>\chi^{2}:($ no anemia $/$ severe anemia $)$ & & & & & 0.383 & 0.662 & 0.155 & 0.722 \\
\hline
\end{tabular}

Coefficients and standard errors are multiplied by 10 for ease of reading. Robust standard errors in brackets, allowing for clustering within country. $*$ significant at $5 \%, * *$ significant at $1 \%$. Mother's BMI is the ratio of weight in kilograms to the square of height in meters $\left(\mathrm{kg} / \mathrm{m}^{2}\right)$. Anemia is a dummy variable indicating whether the mother had either mild, moderate, or severe anemia at the time of the survey. Controls include country-year fixed effects, child gender, birth order and birth month, mother's religion, age at birth, education, and partner's education. There are no estimates for under- 5 mortality, since BMI and anemia are only collected for the 5 years preceding the survey, and for the mortality estimates we omit children who are not fully exposed to mortality risk. 'Low BW' refers to low birth weight. 
Table 2b: Changes in predicted child health associated with a 1 s.d. increase in mother's body mass index, BMI

\begin{tabular}{llllll}
\hline \hline \multicolumn{2}{l}{ (A): Mean and s.d. from individual-level data } & & & \\
& $(1)$ & $(2)$ & $(3)$ & $(4)$ & $(5)$ \\
\hline & Mean & s.d. & Change in Risk & $(3) /(1)$ & $(3) /(2)$ \\
Low BW & 0.205 & 0.404 & -0.022 & -0.108 & -0.055 \\
Neonatal & 0.025 & 0.158 & 0.003 & 0.131 & 0.021 \\
Infant & 0.05 & 0.217 & 0.002 & 0.041 & 0.009 \\
Stunted & 0.024 & 0.153 & -0.002 & -0.068 & -0.011 \\
\hline
\end{tabular}

\begin{tabular}{lcclll}
\hline \multicolumn{2}{l}{$(\mathrm{B}):$ Mean and s.d. from country-level data } & & & \\
& Mean & s.d. & Change in Risk & $(3) /(1)$ & $(3) /(2)$ \\
\hline Low BW & 0.197 & 0.139 & -0.010 & -0.052 & -0.073 \\
Neonatal & 0.028 & 0.014 & 0.002 & 0.054 & 0.108 \\
Infant & 0.056 & 0.026 & 0.001 & 0.017 & 0.036 \\
Stunted & 0.024 & 0.013 & -0.001 & -0.031 & -0.058
\end{tabular}

Using the coefficients in Table 2a, we compute changes associated with a 1 s.d. increase in maternal $\mathrm{BMI}$ at the country (individual level) which is 1.888 (4.092). Means and standard deviations at both the individual and the country-level are calculated from the sample of last-born children.

Table 2c: Changes in predicted child health associated with the mother not being anemic

\begin{tabular}{|c|c|c|c|c|c|}
\hline \multicolumn{6}{|c|}{ (A): Mean and s.d. from individual-level data } \\
\hline & $(1)$ & $(2)$ & (3) & $(4)$ & $(5)$ \\
\hline & Mean & s.d. & Change in Risk & $(3) /(1)$ & $(3) /(2)$ \\
\hline Low BW & 0.185 & 0.388 & -0.0106 & -0.057 & -0.027 \\
\hline Neonatal & 0.032 & 0.177 & -0.0054 & -0.169 & -0.031 \\
\hline Infant & 0.063 & 0.242 & -0.0129 & -0.205 & -0.053 \\
\hline Stunted & 0.025 & 0.157 & 0.0031 & 0.124 & 0.020 \\
\hline \multicolumn{6}{|c|}{ (B): Mean and s.d. from country-level data } \\
\hline & Mean & s.d. & Change in Risk & $(3) /(1)$ & $(3) /(2)$ \\
\hline Low BW & 0.197 & 0.139 & -0.011 & -0.054 & -0.076 \\
\hline Neonatal & 0.028 & 0.014 & -0.005 & -0.193 & -0.386 \\
\hline Infant & 0.056 & 0.026 & -0.013 & -0.230 & -0.496 \\
\hline Stunted & 0.024 & 0.013 & 0.003 & 0.129 & 0.238 \\
\hline
\end{tabular}

See notes to Table $2 \mathrm{~b}$. 
Table 3: Linear change per decade in $\beta_{\mathrm{t}}$ and $\theta_{\mathrm{t}}$

\begin{tabular}{llcl}
\hline \hline & Neonatal & Infant & Under-5 \\
& & $\beta_{\mathrm{t}}$, change per decade & \\
\hline Pooled Sample & $-0.011^{* *}$ & $-0.036^{* *}$ & $-0.043^{* *}$ \\
Africa & $0.010^{*}$ & 0.006 & 0.014 \\
Asia & -0.005 & 0.002 & 0.009 \\
Latin America & -0.012 & $-0.039^{* *}$ & $-0.070^{* *}$ \\
\hline & & $\theta_{\mathrm{t}}$, change per decade & \\
\hline Pooled Sample & -0.002 & $-0.008^{* *}$ & $-0.008^{* *}$ \\
Africa & $0.004^{* *}$ & 0.002 & $0.003^{*}$ \\
Asia & 0.001 & 0.003 & $0.005^{*}$ \\
Latin America & -0.002 & $-0.007^{* *}$ & $-0.011^{*}$ \\
\hline & & $\sigma_{\mathrm{m}}^{\mathrm{c}} / \sigma_{\mathrm{i}}^{\mathrm{c}}$, change per decade & \\
\hline Pooled Sample & $0.028^{* *}$ & $0.021^{* *}$ & $0.019^{* *}$ \\
Africa & $0.021^{* *}$ & $0.014^{* *}$ & $0.011^{* *}$ \\
Asia & $0.026^{* *}$ & $0.024^{* *}$ & $0.021^{* *}$ \\
Latin America & $0.053^{* *}$ & $0.052^{* *}$ & $0.01^{* *}$
\end{tabular}

\footnotetext{
* significant at 5\%, ** significant at $1 \%$. These are linear trends fitted to $\beta_{\mathrm{t}}$ and $\theta_{\mathrm{t}}$. Scatters and lowess fits are in Figures 2, A4 and A5. The regressions are run by year and include controls for mother and child characteristics.
} 
Figure 1: (a) Child health indicators against mother's height: Lowess predictions

Pooled sample
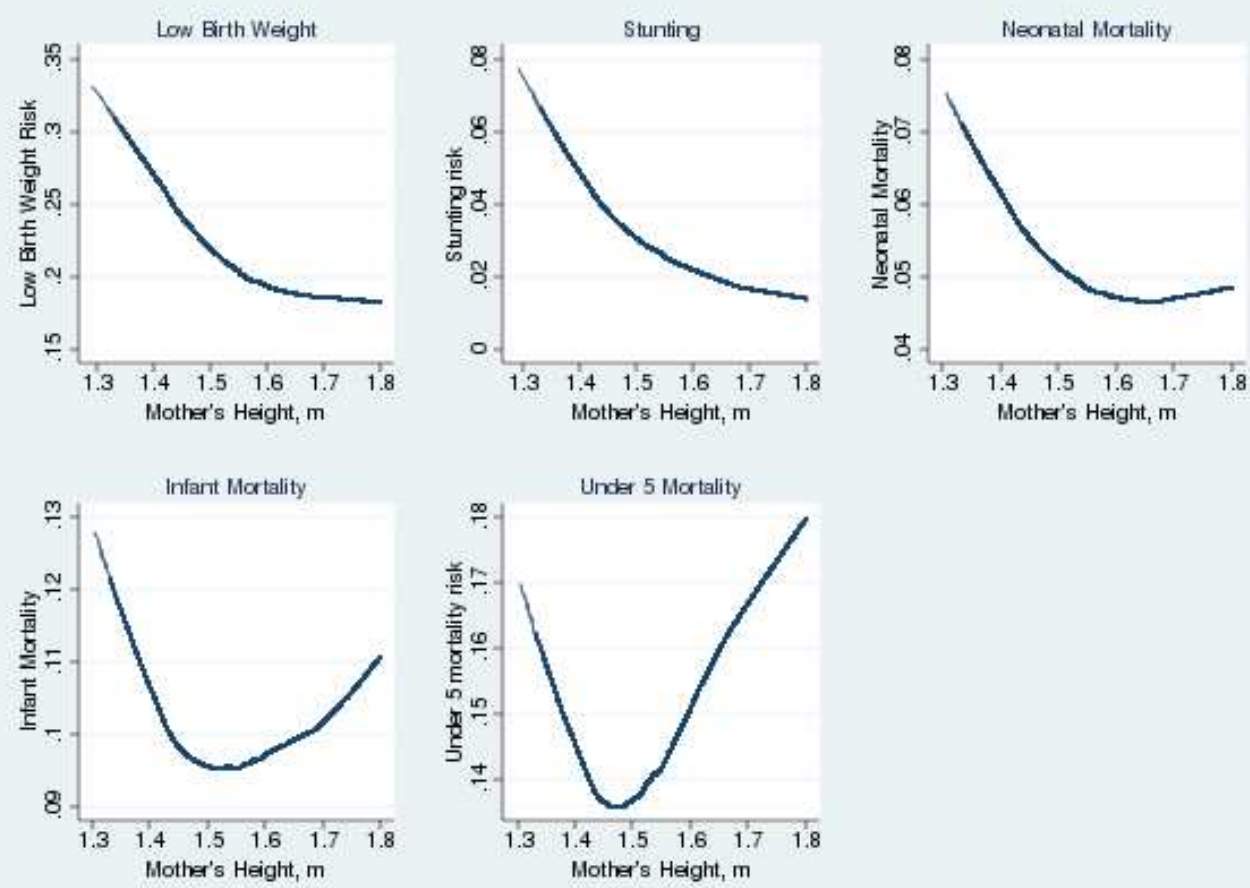

\section{Continent samples}
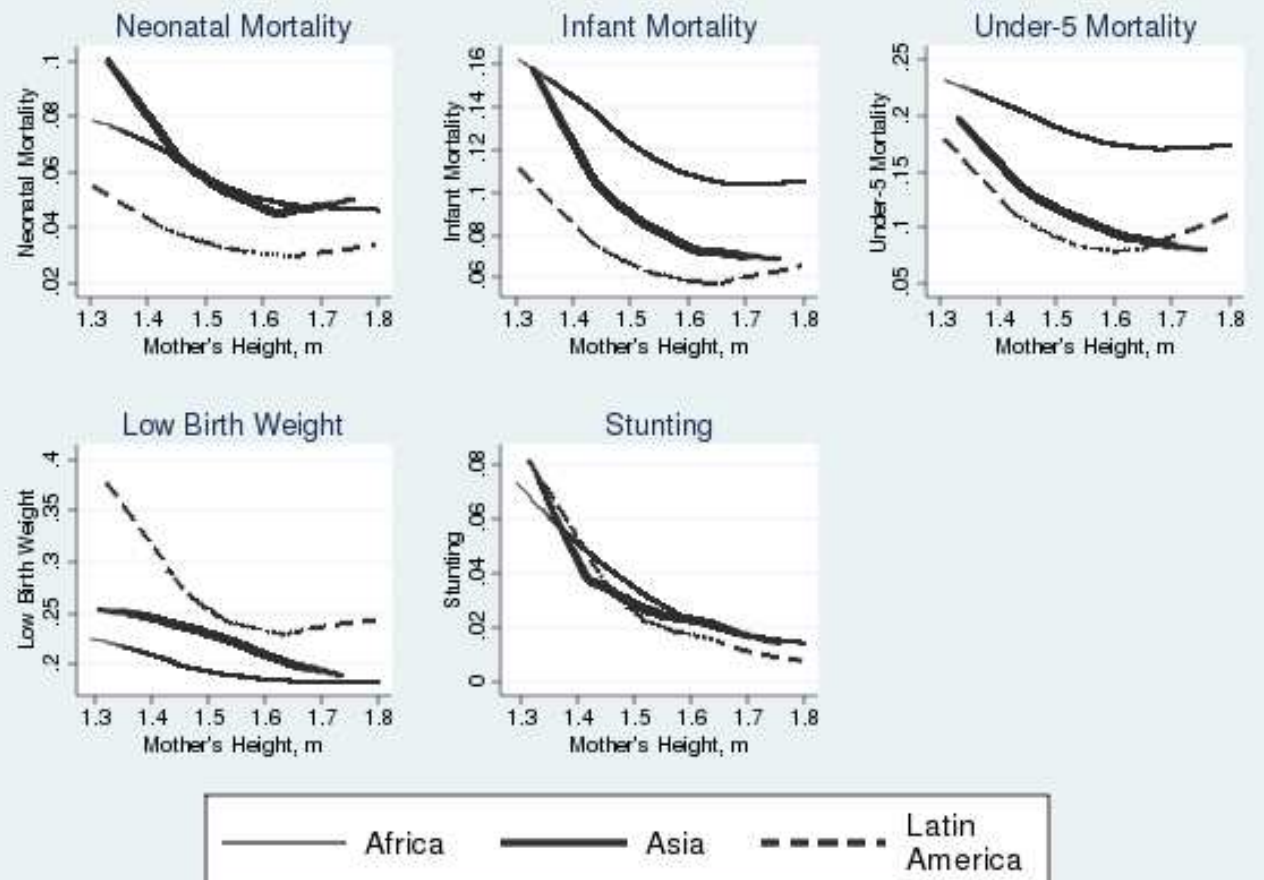

The lowess regressions are run on a random sample of $20 \%$ of observations (by country), since otherwise they are too computationally intensive. The 95th percentile of height is $1.675 \mathrm{~m}$, the 99 th percentile is $1.724 \mathrm{~m}$, and the uppermost height observation in the sample is $1.9 \mathrm{~m}$. 
(b) Child health indicators against mother's BMI: Lowess predictions Pooled sample
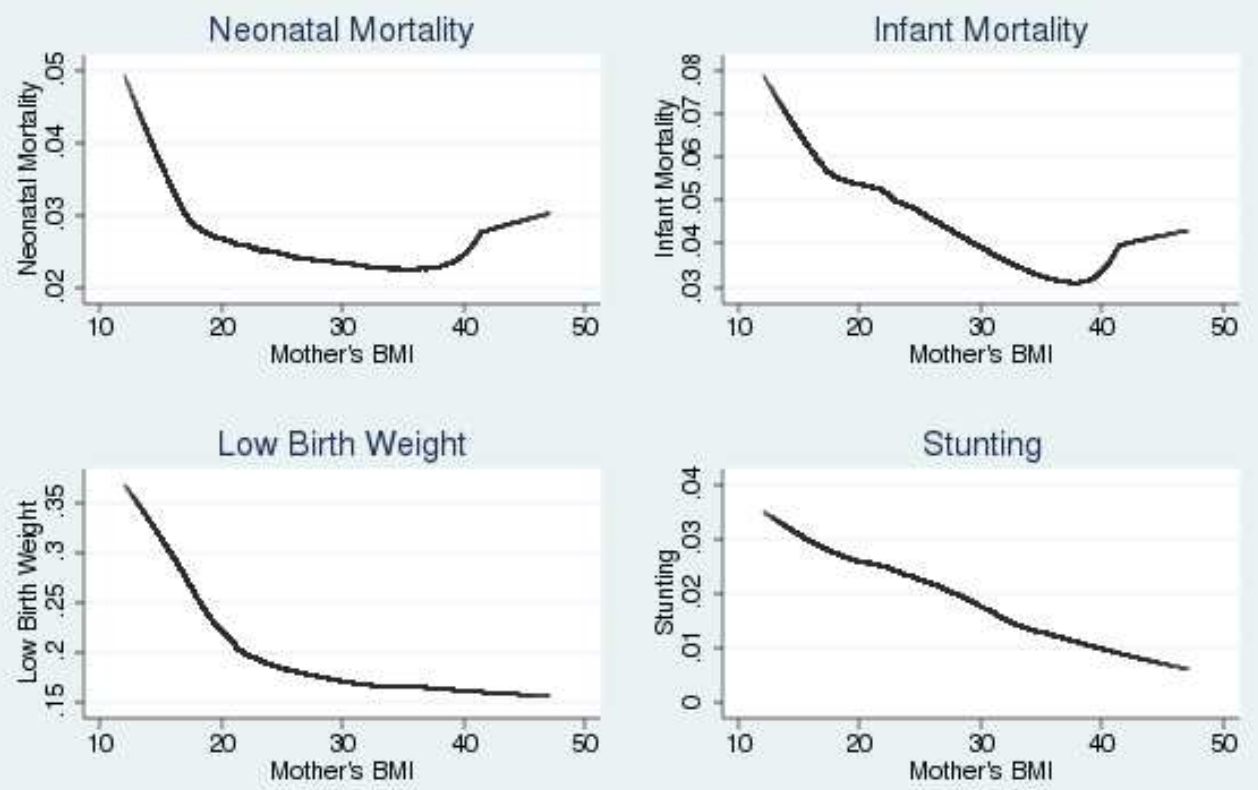

neopred

\section{Continent samples}
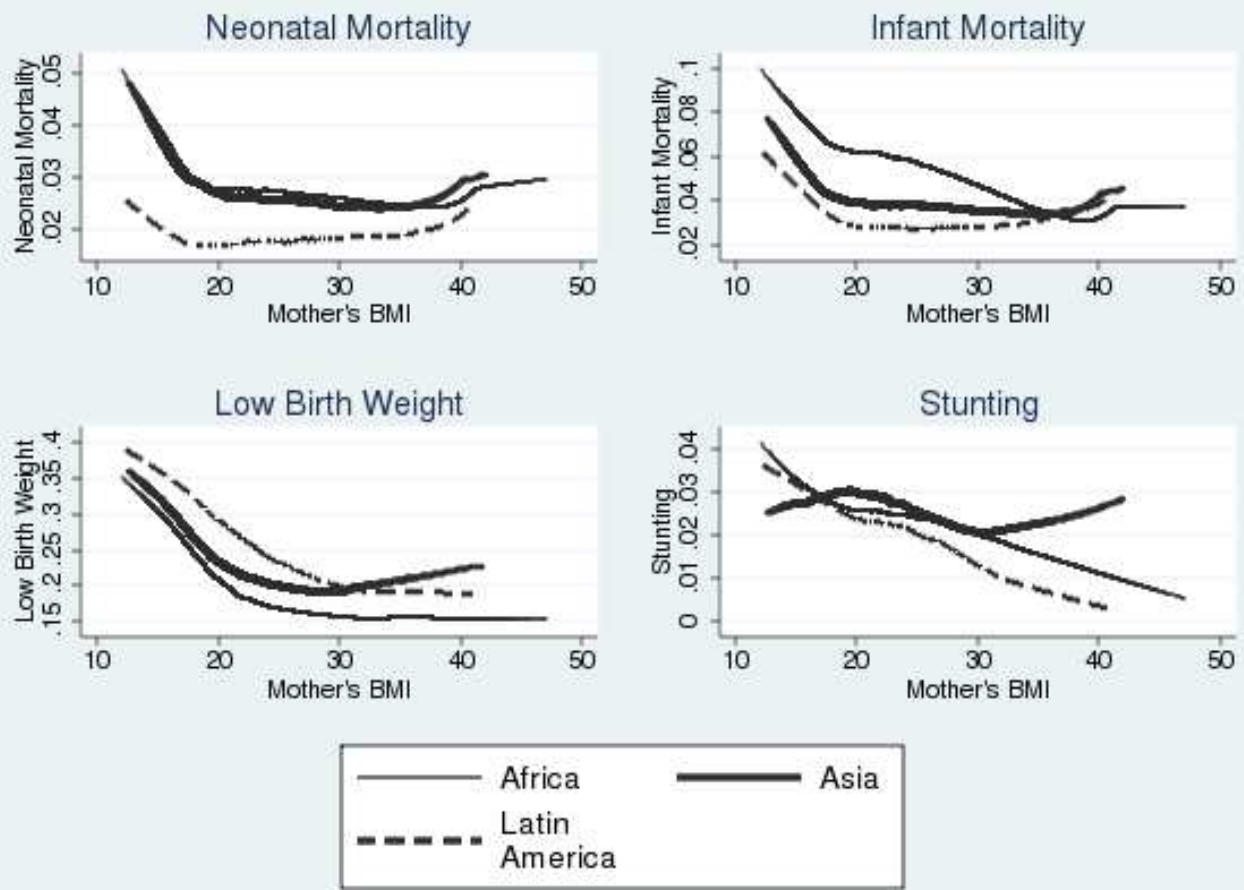
(c) Country-averaged prevalence of poor child health against maternal anemia prevalence
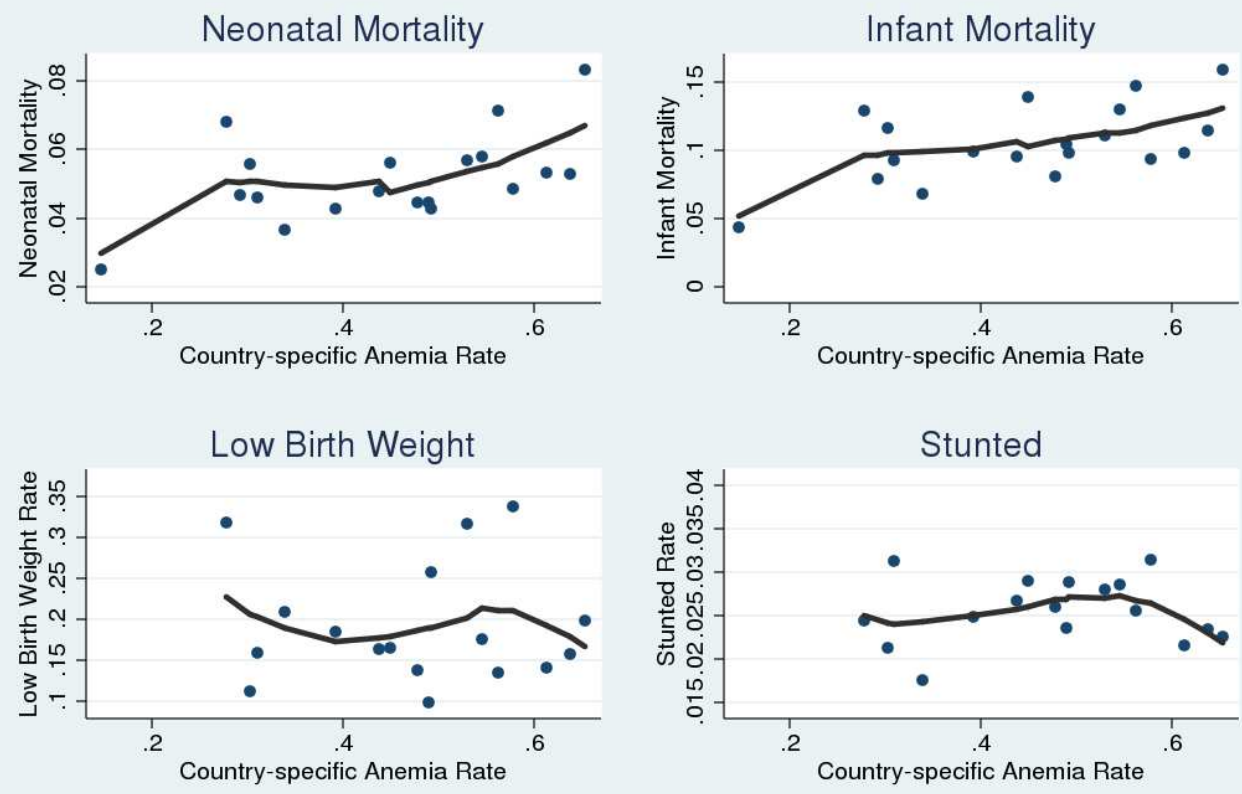

Lowess Fit

Figure 2: Trends in intergenerational persistence: $\beta_{t}$ (regression slope)
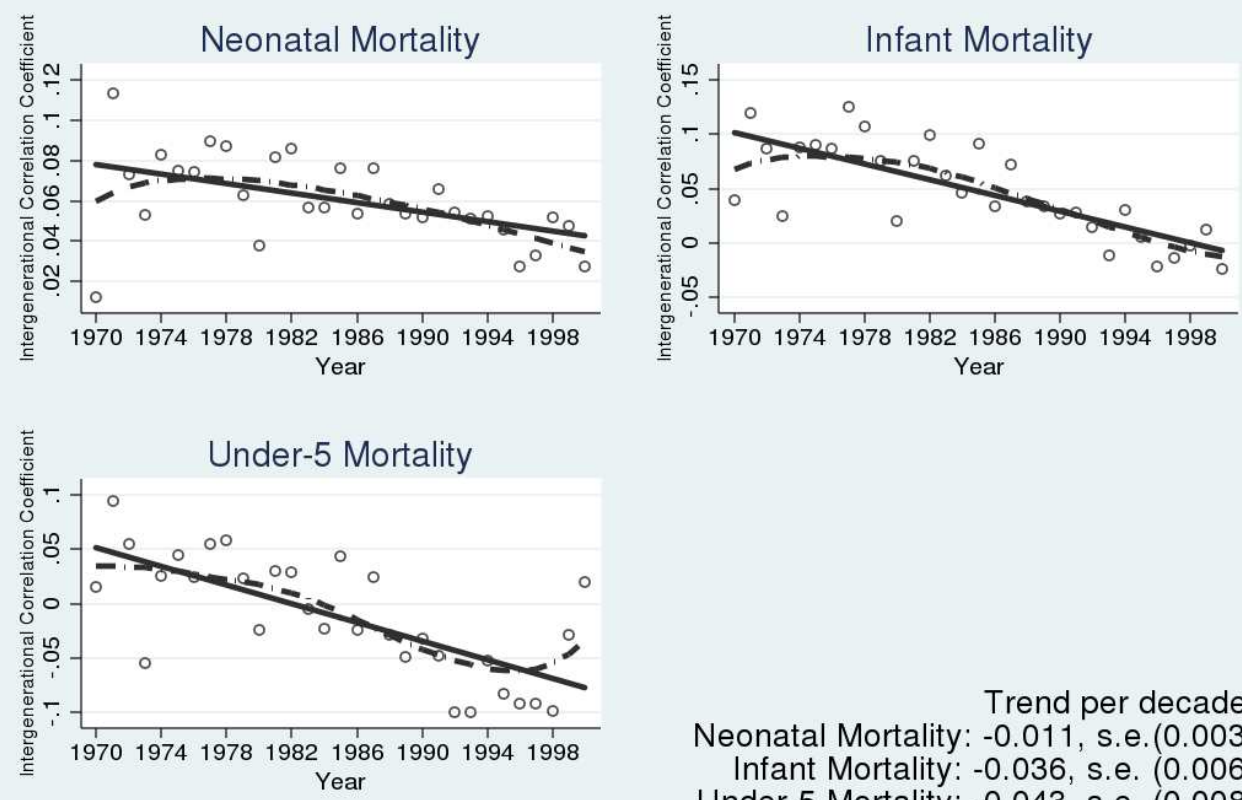

Trend per decade:

Neonatal Mortality: -0.011 , s.e.(0.003)

Infant Mortality: -0.036 , s.e. $(0.006)$

Under-5 Mortality: -0.043 , s.e. (0.008)

Linear Fit - =- Lowess Fit 
Trends in intergenerational persistence: $\theta_{t}$ (correlation coefficient)

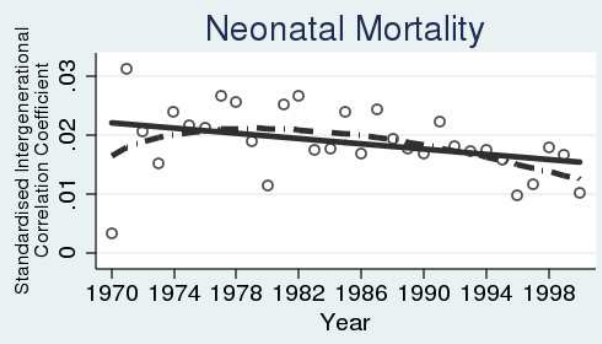

Linear Trend

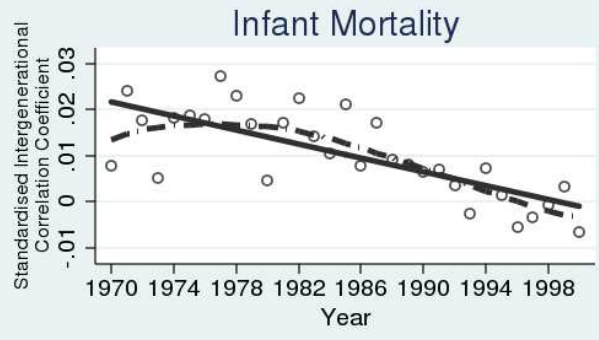

Linear Trend

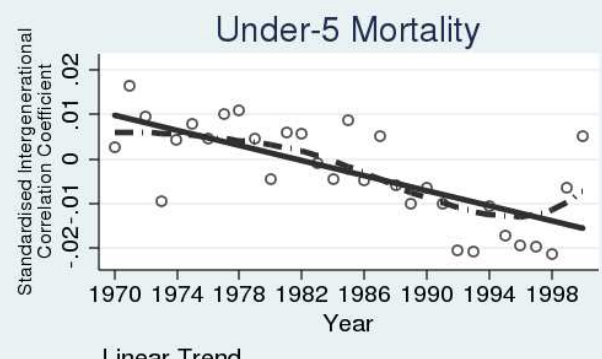

Trend per decade:

Neonatal Mortality: -0.002 , s.e. $(0.001)$

Infant Mortality: -0.008 , s.e. $(0.001)$

Under-5 Mortality: -0.008 , s.e. (0.002)

Linear Fit $=$-1- Lowess Fit 


\section{Data Appendix}

\section{Sources}

The DHS data are obtained from www.measuredhs.com. Data on log GDP per capita in constant 2000 prices (chain series; henceforth GDP) for 1970-2000 is obtained from the Penn World Tables (Summers et al. 2009). Immunization rates for measles and DPT (diphtheria and tetanus toxoid with pertussis) are available for 1985-2000 from the World Development Indicators for all countries in our sample other than Namibia. These data measure the percentage of children aged 12-23 months who have been vaccinated

\section{Mother's height}

Once fully attained, height is time-invariant, at least until shrinking sets in, and this is likely to be after age 49. As a result, mother's height at the time of the survey can be matched to outcomes for births as long as 30 years before the date of the survey, which facilitates analysis of trends. The fact that height is a measure of permanent health also avoids a problem that marks the literature on intergenerational earnings persistence. This is that estimates often use current rather than permanent income and are therefore sensitive to the life cycle pattern of income. (Zimmerman, 1992). Mother's (and children's) heights are measured to the nearest millimeter at the time of interview by trained surveyors. This avoids the potential biases associated with data on self-reported height (Thomas and Strauss, 1998); the use of self-reported height has, for example, been shown to bias downwards estimates of the heritability of height (MacGregor et al., 2006). We deal with censoring, selectivity, missing data and outliers as follows.

Women in developing countries often continue to grow until about the age of 21 (Deaton, 2007). To allow for full growth, we restrict the sample to women who are at least 21 at the time of the survey. Some surveys interview only ever-married women. ${ }^{7}$ To the extent that shorter women marry younger (Bhalotra, 2008), this creates a selectivity problem. This is limited by eliminating women older than 21 . We investigated instead, a cut-off at age 25 and at the (country-specific) 95th percentile of age at marriage. The results are robust to these variations. Height is missing for $21.5 \%$ of mothers. We impute these heights using prediction-matching ${ }^{8}$ on the assumption that the missing data are missing at random. To investigate this we estimated the model, pooling the actual and imputed data and including as a regressor an indicator for whether height was imputed. The coefficient on this regressor is small and insignificant for all measures of child health other than under- 5 mortality for which it is significant and very small (Table A.4). To remove outliers, we exclude women with height more than three standard deviations away from the country mean, losing about $0.42 \%$ of the available sample.

7 Table A1 in Bhalotra and Umana-Aponte (2010) identifies these surveys.

8 This is done using the -uvis- command in Stata (Royston, 2004). For reproducibility of results, we set the random number seed to an arbitrary number, 1001. For robustness, we use the bootstrap method, which does not rely on the assumption that $\beta$ is normally distributed. For some countries, mother's height is measured in some survey rounds and not in others. In such cases, we drop rounds in which height is not recorded, so the imputation is for surveys in which at least some heights are measured. We drop Nigeria from the analysis since it had a high occurrence of infeasible maternal heights, suggesting a problem with the measurement procedure. 


\section{Mother's BMI and anemia status}

Mother's BMI (ratio of weight in kilograms to the square of height in meters $\left(\mathrm{kg} / \mathrm{m}^{2}\right)$ ) is measured by surveyors rather than self-reported. It is collected for women with births in the three years preceding the survey, excluding women who are pregnant or less than three months postpartum. To remove outliers, we exclude women whose BMI is greater than 3 standard deviations away from the country mean. Data on anemia are collected by a finger prick blood test and are available for 20 of the 34 surveys taken after 1999, in 19 countries. Testing is voluntary and $43.0 \%$ of the potential sample volunteer. ${ }^{9}$ The data are recorded as a categorical variable indicating no, mild, moderate, or severe anemia. The BMI and anemia analyses are run restricting the sample to the most recent birth of each mother.

\section{Childhood mortality indicators}

Mortality information is available for all births to each mother from retrospective accounts, as a result of which it spans 31 birth cohorts, 1970-2000. The rest of this subsection describes how we deal with potential issues of selectivity and recall bias raised by the retrospective nature of the data and the more general issues of age heaping and censoring. An upper limit to the age of the mother at the time of the survey implies fewer births for the earlier years in the sample and that these births are disproportionately from young mothers (Bumpass et al., 1978; Bhalotra, 2009). We therefore limit the sample to children born after 1970 and control for maternal age at birth. We drop children born after the year 2000 because the data are relatively thin and come disproportionately from a few countries. Naturally, the sample only includes mothers who are alive at the time of interview and this sample is likely to be selectively healthy. We might expect that in a linear model in which individual child health is conditional upon mother's health, the mother-child correlation of health will be unbiased but in practice this will seldom hold because our measures of mother's health are partial and no one will not fully capture her risk of early mortality. Given that we find a stronger relationship of mother-child health indicators for mothers in weaker health, our estimates are likely to under-estimate the strength of this relationship. Mortality (and birth weight) are reported by the mother but interviewers conduct a number of probes to ensure the quality of birth history data (ORC Macro, 2006). Recall bias is a common concern with retrospective data but the DHS design is sensitive to this. Also, births and deaths are, by their nature, less likely to be remembered with error than, for example, income or expenditure. To account for the heaping of age at 'round' ages, we define mortality to include deaths in the first, twelfth and sixtieth month, although the convention is to measure neonatal, infant and under- 5 mortality as death before the age of 1,12 , and 60 months respectively. ${ }^{10}$ To ensure that children are fully exposed to the relevant mortality risk, the samples are

9 We recognise that the volunteers may not be a random sample of women but we control for age and education of mothers which are likely to determine selection into testing. There is no a priori reason that this self-selection is correlated with child health, although this cannot be ruled out.

10 The results for earnings transition matrices presented in O'Neill et al. (2007) suggest that measurement error in the dependent variable will lead us to under-estimate persistence. If there is measurement error in the indicators of both child and 
adjusted to exclude children younger than the cut-off age at the time of interview (e.g. children less than or equal to 12 months of age at interview are excluded from the sample used to analyse infant mortality).

\section{Indicators of growth failure in childhood}

Observations on birth weight and child anthropometric outcomes are only available for recent births and, at irregular intervals, span 1986-2000. Child height is measured by surveyors for surviving births in the three, four or five years preceding the survey, the range depending upon the survey (see Table A.2 for survey years for each country). Mothers are asked to provide subjective recall data on birth weight for births in the five years preceding the survey, whether or not they survived. ${ }^{11}$

We classify a child as stunted if their height is less than 2 standard deviations below the mean height in their country for their age and gender. This avoids the assumption that well nourished children in different populations have the same potential and the same trajectories of growth. The long-standing WHO convention has been to define stunting in developing countries with reference to the mean and s.d. of a sample of healthy American children but this has recently been called into question (Klasen and Moradi, 2000; De Onis et al., 2004. An unavoidable problem with using child height as the dependent variable is that the data are subject to survival selection. If taller children are systematically more likely to survive then this causes the stunting threshold to be higher than in the absence of mortality, leading to a 'healthier' group of stunted children. Outliers in child height are removed by setting boundaries at $30 \mathrm{~cm}$ and $120 \mathrm{~cm}$, which results in a loss of about 750 observations.

Birth weight data are scarce in developing countries because most births occur at home and there is no systematic registration of births. Measured birth weight (in grams) is only available for around 25\% of 'eligible' observations. Mothers' subjective assessment of birth weight, which classifies the child's birth weight as either above, at, or below average, is available for $60.54 \%$ of births in the 5 years prior to each survey. We use this to define low (i.e. below average) birth weight. Previous work has investigated the quality of these data- an encouraging result is that the mean birth weight for babies classified by mothers as small was less than 2500 grams in all except 7 of 62 countries (Blanc and Wardlaw, 2005).

mother's health then the impact on mobility estimates depends upon the correlation between the measurement errors. If it is low, as is likely in this setting where the indicators are different, then again we will tend to under-estimate persistence.

11 Lesotho, Honduras and Comoros have small sample sizes for child height and birth weight, and are excluded from these samples. Sample sizes for height (birth weight) were as follows: Comoros - 894 (998), Lesotho - 263 (670), Honduras - 15 (15) 
Table A1: Countries in Sample, by Continent

\begin{tabular}{|c|c|c|c|}
\hline Country & Country Code & Country & Country Code \\
\hline \multicolumn{4}{|l|}{ African Countries } \\
\hline Benin & $\mathrm{BE}$ & Madagascar & MD \\
\hline Burkina Faso & $\mathrm{BF}$ & Malawi & MW \\
\hline CAR & CR & Mali & ML \\
\hline Cameroon & $\mathrm{CM}$ & Morocco & MO \\
\hline Chad & $\mathrm{CH}$ & Mozambique & MZ \\
\hline Comoros & $\mathrm{CO}$ & Namibia & NB \\
\hline Cote d'Ivoire & $\mathrm{CI}$ & Niger & NG \\
\hline Egypt & EG & Rwanda & RW \\
\hline Ethiopia & ET & Senegal & $\mathrm{SE}$ \\
\hline Gabon & GB & Tanzania & $\mathrm{TZ}$ \\
\hline Ghana & $\mathrm{GH}$ & Togo & TO \\
\hline Guinea & GU & Uganda & UG \\
\hline Kenya & $\mathrm{KE}$ & Zambia & $\mathrm{ZB}$ \\
\hline Lesotho & LE & Zimbabwe & $\mathrm{ZW}$ \\
\hline \multicolumn{4}{|l|}{ Asian Countries } \\
\hline Cambodia & $\mathrm{CD}$ & Turkey & TK \\
\hline India & $\mathrm{IN}$ & & \\
\hline \multicolumn{4}{|c|}{ Latin American Countries } \\
\hline Brazil & $\mathrm{BR}$ & Honduras & $\mathrm{HO}$ \\
\hline Colombia & $\mathrm{CB}$ & Nicaragua & $\mathrm{NC}$ \\
\hline Dominican Republic & DR & Peru & $\mathrm{PE}$ \\
\hline Haiti & $\mathrm{HA}$ & & \\
\hline
\end{tabular}


Table A2: Country Characteristics

\begin{tabular}{|c|c|c|c|c|c|c|c|c|}
\hline \multirow[b]{2}{*}{ Country } & \multirow[b]{2}{*}{$\begin{array}{l}\% \text { GDP } \\
\text { growth, 1970- } \\
2000\end{array}$} & \multicolumn{7}{|c|}{ Means of Child Health } \\
\hline & & $\begin{array}{l}\text { Potential Birth } \\
\text { Year Sample }\end{array}$ & Interview Dates & $\begin{array}{l}\text { Neonatal } \\
\text { Mortality }\end{array}$ & $\begin{array}{l}\text { Infant } \\
\text { Mortality }\end{array}$ & $\begin{array}{l}\text { Under-5 } \\
\text { Mortality }\end{array}$ & $\begin{array}{l}\text { Low } \\
\text { Birth } \\
\text { Weight }\end{array}$ & Stunting \\
\hline Benin & 0.103 & 1960-2001 & 1996,2001 & 0.053 & 0.117 & 0.206 & 0.158 & 0.023 \\
\hline Brazil & $1.367^{*}$ & 1959-1996 & 1996 & 0.033 & 0.067 & 0.079 & 0.244 & 0.017 \\
\hline Burkina Faso & $0.955^{*}$ & 1955-2003 & $\begin{array}{l}\text { 1992-1993, 1998-1999, } \\
2003\end{array}$ & 0.053 & 0.132 & 0.23 & 0.176 & 0.027 \\
\hline CAR & $-0.927 *$ & 1958-1995 & 1994-1995 & 0.048 & 0.1 & 0.135 & 0.141 & 0.021 \\
\hline Cambodia & $-2.275^{*}$ & $1965-2000$ & 2000 & 0.051 & 0.097 & 0.153 & 0.164 & 0.024 \\
\hline Cameroon & 0.682 & 1960-2004 & 1998, 2004 & 0.059 & 0.107 & 0.17 & 0.163 & 0.03 \\
\hline Chad & -0.044 & 1960-2004 & 1996-1997, 2004 & 0.021 & 0.134 & 0.22 & 0.318 & 0.021 \\
\hline Colombia & $1.781 *$ & 1958-2005 & $1995,2000,2004-2005$ & 0.061 & 0.034 & 0.041 & 0.201 & 0.024 \\
\hline Comoros & -0.312 & 1961-1996 & 1996 & 0.034 & 0.11 & 0.15 & & \\
\hline Cote d'Ivoire & 0.123 & 1956-1999 & 1994, 1998-1999 & 0.059 & 0.106 & 0.165 & 0.163 & 0.024 \\
\hline $\begin{array}{l}\text { Dominican } \\
\text { Republic }\end{array}$ & $2.277^{*}$ & 1952-1996 & 1991, 1996 & 0.046 & 0.061 & 0.082 & 0.2 & 0.021 \\
\hline Egypt & $3.126^{*}$ & 1954-2005 & $\begin{array}{l}\text { 1992-1993, 1995-1996, } \\
\text { 2000, } 2005\end{array}$ & 0.068 & 0.095 & 0.127 & 0.159 & 0.028 \\
\hline Ethiopia & $1.018^{*}$ & 1955-1997 & 1992, 1997 & 0.034 & 0.13 & 0.201 & 0.318 & 0.021 \\
\hline Gabon & $-1.722^{*}$ & $1962-2000$ & 2000-2001 & 0.044 & 0.068 & 0.101 & 0.116 & 0.02 \\
\hline Ghana & 0.188 & $1957-2003$ & 1993-1994, 1998-1999 & 0.071 & 0.082 & 0.137 & 0.137 & 0.025 \\
\hline Guinea & -0.098 & 1961-2005 & 1999,2005 & 0.057 & 0.149 & 0.237 & 0.134 & 0.027 \\
\hline Haiti & -0.12 & $1957-2000$ & 1994-1995, 2000 & 0.025 & 0.114 & 0.178 & 0.317 & 0.028 \\
\hline Honduras & $0.471 *$ & 1969-2006 & 2005-2006 & 0.063 & 0.044 & 0.057 & & \\
\hline India & $2.831 *$ & $1961-2000$ & 1998-2000, 2005-2006 & 0.035 & 0.095 & 0.125 & 0.237 & 0.024 \\
\hline
\end{tabular}


Table A2: Country Characteristics

\begin{tabular}{|c|c|c|c|c|c|c|c|c|}
\hline Country & $\begin{array}{l}\% \text { GDP } \\
\text { growth, } \\
1970-2000\end{array}$ & $\begin{array}{l}\text { Potential Birth } \\
\text { Year Sample }\end{array}$ & Interview Dates & $\begin{array}{l}\text { Neonatal } \\
\text { Mortality }\end{array}$ & $\begin{array}{l}\text { Infant } \\
\text { Mortality }\end{array}$ & $\begin{array}{l}\text { Under-5 } \\
\text { Mortality }\end{array}$ & $\begin{array}{l}\text { Low } \\
\text { Birth } \\
\text { Weight }\end{array}$ & Stunting \\
\hline Kenya & $0.338^{*}$ & $1954-2003$ & 1993,2003 & 0.047 & 0.076 & 0.108 & 0.151 & 0.02 \\
\hline Lesotho & $2.889 *$ & $1967-2005$ & 2004-2005 & 0.043 & 0.08 & 0.094 & & \\
\hline Madagascar & $-1.860^{*}$ & $1962-2004$ & 1997, 2003-2004 & 0.056 & 0.099 & 0.158 & 0.258 & 0.029 \\
\hline Malawi & $1.210^{*}$ & 1954-2005 & $1992,2000,2004-2005$ & 0.083 & 0.141 & 0.231 & 0.165 & 0.027 \\
\hline Mali & $1.557 *$ & 1960-2001 & 1995-1996, 2001 & 0.047 & 0.163 & 0.281 & 0.198 & 0.02 \\
\hline Morocco & $1.659 *$ & 1953-2004 & $1992,2003-2004$ & 0.067 & 0.08 & 0.104 & 0.246 & 0.028 \\
\hline Mozambique & -0.27 & 1960-2004 & $1997,2003-2004$ & 0.039 & 0.16 & 0.227 & 0.185 & 0.038 \\
\hline Namibia & -0.139 & 1957-1992 & 1992 & 0.029 & 0.07 & 0.106 & 0.17 & 0.026 \\
\hline Nicaragua & $-2.984 *$ & 1961-2001 & 1997-1998, 2001 & 0.062 & 0.061 & 0.079 & 0.299 & 0.025 \\
\hline Niger & $-0.931 *$ & 1954-1998 & 1992, 1998 & 0.037 & 0.157 & 0.335 & 0.364 & 0.021 \\
\hline Peru & $-0.964 *$ & $1956-2000$ & 1991-1992, 2000 & 0.058 & 0.07 & 0.102 & 0.208 & 0.016 \\
\hline Rwanda & -0.688 & $1963-2005$ & 2000,2005 & 0.056 & 0.118 & 0.198 & 0.112 & 0.018 \\
\hline Senegal & -0.091 & $1954-2005$ & 1992-1993, 2005 & 0.049 & 0.096 & 0.17 & 0.337 & 0.032 \\
\hline Tanzania & 0.353 & $1953-2005$ & $\begin{array}{l}\text { 1991-1992, 1996, 2004- } \\
2005\end{array}$ & 0.045 & 0.107 & 0.165 & 0.098 & 0.02 \\
\hline Togo & $-1.965^{*}$ & 1958-1998 & 1998 & 0.05 & 0.096 & 0.166 & 0.183 & 0.02 \\
\hline Turkey & $2.068^{*}$ & $1957-1998$ & 1993, 1998 & 0.047 & 0.092 & 0.113 & 0.258 & 0.03 \\
\hline Uganda & -0.492 & 1959-2001 & $1995,2000-2001$ & 0.043 & 0.102 & 0.175 & 0.185 & 0.022 \\
\hline Zambia & $-1.861 *$ & 1954-2002 & $\begin{array}{l}\text { 1992,1996-1997, 2001- } \\
2002\end{array}$ & 0.041 & 0.104 & 0.17 & 0.121 & 0.021 \\
\hline Zimbabwe & -0.057 & 1957-1999 & 1994, 1999 & 0.028 & 0.06 & 0.085 & 0.164 & 0.024 \\
\hline
\end{tabular}

item * indicates growth was significant at 5\% level. \%`Low BW' refers to Low Birth Weight. 
Table A3: Correlations amongst indicators of child and maternal health (proportions)

\begin{tabular}{|c|c|c|c|c|c|c|c|c|c|c|c|c|}
\hline & \multicolumn{2}{|c|}{ Height } & \multicolumn{2}{|c|}{ Neonatal } & \multicolumn{2}{|c|}{ Infant } & \multicolumn{2}{|c|}{ Under-5 } & \multicolumn{2}{|c|}{ Low Birth Weight } & \multicolumn{2}{|c|}{ Stunted } \\
\hline & Tall & Short & 0 & 1 & 0 & 1 & 0 & 1 & 0 & 1 & 0 & 1 \\
\hline Neonatal & 0.04 & 0.05 & 1 & 1 & 0 & 0.51 & 0 & 0.36 & 0.03 & 0.06 & & \\
\hline Infant & 0.09 & 0.1 & 0.05 & 1 & 1 & 1 & 0 & 0.7 & 0.06 & 0.1 & & \\
\hline Under-5 & 0.12 & 0.14 & 0.09 & 1 & 0.04 & 1 & 1 & 1 & 0.08 & 0.12 & & \\
\hline Low BW & 0.18 & 0.21 & 0.2 & 0.34 & 0.2 & 0.28 & 0.2 & 0.26 & 1 & 1 & 0.2 & 0.27 \\
\hline Stunting & 0.19 & 0.28 & & & & & & & 0.02 & 0.03 & 1 & 1 \\
\hline
\end{tabular}

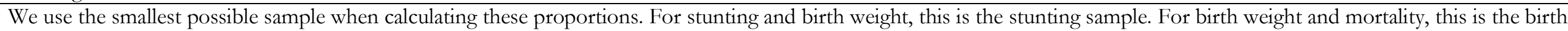

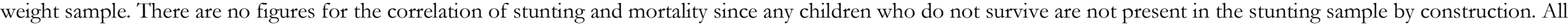

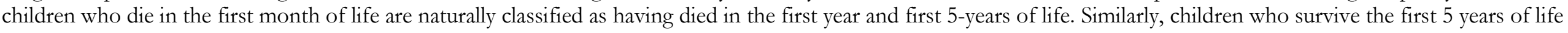

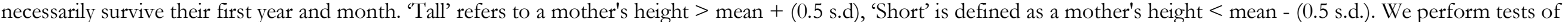
the significance of differences in means within each column, and find that all means are significantly different at the $1 \%$ level. 'Low BW' refers to low birth weight.

Table A4: Investigating Missing Data on Heights

\begin{tabular}{llllll}
\hline \hline & $\begin{array}{l}\text { Low Birth } \\
\text { Weight }\end{array}$ & Stunted & $\begin{array}{l}\text { Neonatal } \\
\text { Mortality }\end{array}$ & $\begin{array}{l}\text { Infant } \\
\text { Mortality }\end{array}$ & $\begin{array}{l}\text { Under-5 } \\
\text { Mortality }\end{array}$ \\
\hline Mother's Height & $-0.217^{* *}$ & $-0.098^{* *}$ & $-0.066^{* *}$ & $-0.103^{* *}$ & $-0.139^{* *}$ \\
& $(0.031)$ & $(0.007)$ & $(0.008)$ & $(0.010)$ & $(0.013)$ \\
Mother's Height is Missing & -0.006 & -0.001 & 0.002 & -0.000 & $-0.006^{*}$ \\
& $(0.005)$ & $(0.003)$ & $(0.001)$ & $(0.002)$ & $(0.003)$ \\
Observations & 324097 & 285440 & 2295740 & 2233720 & 1894526 \\
\hline
\end{tabular}

Robust standard errors in brackets. * significant at $5 \% * *$ significant at $1 \%$. Height is missing is an indicator variable for height having been imputed. 
Table A5: Alternative measure of child health: Z-scores of Height

\begin{tabular}{llll}
\hline \hline A: Linear & & & \\
\hline & Height & BMI & Anemia \\
\hline Height & $3.182^{* * *}$ & & \\
BMI & $(0.168)$ & & \\
& & $0.022^{* * *}$ & \\
Anemia & & $(0.001)$ & \\
& & & $-0.036^{*}$ \\
& & & $(0.017)$
\end{tabular}

\begin{tabular}{|c|c|c|c|}
\hline \multicolumn{4}{|l|}{ B: Non-Linear } \\
\hline \multirow[t]{2}{*}{ Tall (0.5-1 s.d.) } & $0.161^{* *}$ & & \\
\hline & $(0.011)$ & & \\
\hline \multirow[t]{2}{*}{ Tall (1-2 s.d.) } & $0.293 * *$ & & \\
\hline & $(0.022)$ & & \\
\hline \multirow[t]{2}{*}{ Tall (> 2 s.d.) } & $0.446^{* *}$ & & \\
\hline & $(0.044)$ & & \\
\hline \multirow[t]{2}{*}{ Short (0.5-1 s.d.) } & $-0.172^{* *}$ & & \\
\hline & $(0.011)$ & & \\
\hline \multirow[t]{2}{*}{ Short (1-2 s.d.) } & $-0.307 * *$ & & \\
\hline & $(0.015)$ & & \\
\hline \multirow[t]{2}{*}{ Short (> 2 s.d.) } & $-0.504 * *$ & & \\
\hline & $(0.031)$ & & \\
\hline \multirow[t]{2}{*}{ Low BMI } & & $-0.085^{* *}$ & \\
\hline & & $(0.013)$ & \\
\hline \multirow{2}{*}{ High BMI } & & $0.142^{* *}$ & \\
\hline & & $(0.010)$ & \\
\hline \multirow[t]{2}{*}{ No Anemia } & & & $0.034^{*}$ \\
\hline & & & $(0.016)$ \\
\hline \multirow[t]{2}{*}{ Severe Anemia } & & & $-0.102^{* *}$ \\
\hline & & & $(0.061)$ \\
\hline Observations & 283624 & 215193 & 20621 \\
\hline $\mathrm{p}>\chi^{2}:$ (tallhalf/shorthalf $)$ & 0.000 & & \\
\hline $\mathrm{p}>\chi^{2}:($ tall1 $/$ short 1$)$ & 0.000 & & \\
\hline $\mathrm{p}>\chi^{2}:($ tall2/short 2$)$ & 0.000 & & \\
\hline $\mathrm{p}>\chi^{2}:$ (lowbmi/highbmi) & & 0.000 & \\
\hline $\mathrm{p}>\chi^{2}:($ no anemia/severe anemia) & & & 0.074 \\
\hline
\end{tabular}

The dependent variable is the $z$-score of child height. The specifications correspond to those in Table 1 and 2. Robust standard errors in brackets, allowing for clustering within country. ${ }^{*}$ significant at $5 \%$ sym** significant at $1 \%$. Mother's height is in metres. Mother's BMI is the ratio of weight in kilograms to the square of the height in meters $\left(\mathrm{kg} / \mathrm{m}^{2}\right)$. Anemia is a dummy variable indicating whether the mother had mild, moderate, or severe anemia at the time of the survey. Estimator is OLS. We control for child gender, birth order and birth month, mother's religion, age at birth, education, and partner's education. Estimates include country-year fixed effects. Means and s.d. of variables are in Tables 1 and 2 . The $p>\chi^{2}$ statistic gives the significance level at which we are unable to reject the null that the coefficients for tallhalf/shorthalf, tall1/short1, or tall2/short2 are significantly different in magnitude from one another. Average Z-score for women who are greater than 2 standard deviations above the mean is 0.533 , average $z$ score for women who are less than 2 standard deviations below the mean is -0.566 . 
Table A6: Linear Trends in Intergenerational Persistence: Overall and by Continent

\begin{tabular}{|c|c|c|c|}
\hline & Neonatal Mortality & Infant Mortality & Under-5 Mortality \\
\hline \multicolumn{4}{|c|}{ Pooled Sample } \\
\hline \multirow[t]{2}{*}{ Trend } & 0.001 & $0.002 * *$ & $0.003 * *$ \\
\hline & $(0.000)$ & $(0.001)$ & $(0.001)$ \\
\hline Observations & 2295740 & 2233720 & 1894526 \\
\hline \multicolumn{4}{|c|}{ Africa } \\
\hline \multirow[t]{2}{*}{ Trend } & 0.000 & 0.001 & 0.001 \\
\hline & $(0.000)$ & $(0.001)$ & $(0.001)$ \\
\hline Observations & 1325293 & 1285169 & 1062923 \\
\hline \multicolumn{4}{|c|}{ Asia } \\
\hline \multirow[t]{2}{*}{ Trend } & 0.002 & 0.003 & 0.003 \\
\hline & $(0.001)$ & $(0.001)$ & $(0.003)$ \\
\hline Observations & 514309 & 504395 & 454733 \\
\hline \multicolumn{4}{|c|}{ Latin America } \\
\hline \multirow[t]{2}{*}{ Trend } & 0.002 & $0.005^{* *}$ & $0.003^{* *}$ \\
\hline & $(0.001)$ & $(0.001)$ & $(0.001)$ \\
\hline Observations & 456138 & 444156 & 376870 \\
\hline
\end{tabular}

Estimates are of the linear baseline model in panel A of Table 1, augmented with an interaction term between mother's height and a global trend. We now replace country-year fixed effects with country and year fixed effects and country-specific trends. 'Trend' reports the coefficient on the interaction term, an estimate of the rate of decline of the mother-child correlation of health. Robust standard errors in brackets, allowing for clustering within country. * significant at $5 \% * *$ significant at $1 \%$.Means and s.d. for the pooled sample are in Table 1. Continent-specific means and s.d. are in Table A.5. See notes to Table 1. 


\begin{tabular}{|c|c|c|c|}
\hline \multicolumn{4}{|c|}{ Neonatal Mortality } \\
\hline & Africa & Asia & Latin America \\
\hline \multirow{2}{*}{ Height $(\beta)$} & $-0.068^{* *}$ & $-0.093^{*}$ & $-0.030^{*}$ \\
\hline & $(0.007)$ & $(0.011)$ & $(0.011)$ \\
\hline$\theta$ & -0.019 & -0.023 & -0.011 \\
\hline$\tau$ & -1.308 & -1.691 & -0.882 \\
\hline Observations & 1325293 & 514309 & 456138 \\
\hline mean (neonatal) & 0.052 & 0.055 & 0.034 \\
\hline \multirow[t]{3}{*}{ s.d. (neonatal) } & 0.222 & 0.228 & 0.18 \\
\hline & \multicolumn{2}{|c|}{ Infant Mortality } & \\
\hline & Africa & Asia & Latin America \\
\hline \multirow[t]{2}{*}{ Height $(\beta)$} & $-0.108^{* *}$ & $-0.129 * *$ & $-0.057 *$ \\
\hline & $(0.010)$ & $(0.009)$ & $(0.018)$ \\
\hline$\theta$ & -0.022 & -0.026 & -0.015 \\
\hline$\tau$ & -0.964 & -1.483 & -0.877 \\
\hline Observations & 1285169 & 504395 & 444156 \\
\hline mean (infant) & 0.112 & 0.087 & 0.065 \\
\hline \multirow[t]{3}{*}{ s.d. (infant) } & 0.316 & 0.282 & 0.246 \\
\hline & \multicolumn{2}{|c|}{ Under-5 Mortality } & \\
\hline & Africa & Asia & Latin America \\
\hline \multirow{2}{*}{ Height $(\beta)$} & $-0.142 * *$ & $-0.170^{* *}$ & $-0.088^{*}$ \\
\hline & $(0.012)$ & $(0.013)$ & $(0.029)$ \\
\hline$\theta$ & -0.023 & -0.031 & -0.020 \\
\hline$\tau$ & -0.793 & -1.504 & -0.989 \\
\hline Observations & 1062923 & 454733 & 376870 \\
\hline mean (under-5) & 0.179 & 0.113 & 0.089 \\
\hline s.d. (under-5) & 0.383 & 0.317 & 0.284 \\
\hline mean (height) & 1.585 & 1.519 & 1.527 \\
\hline s.d. (height) & 0.063 & 0.057 & 0.064 \\
\hline
\end{tabular}




\begin{tabular}{llll}
\hline \hline & \multicolumn{2}{l}{ Low Birth Weight } & \\
& Africa & Asia & Latin America \\
\hline Height $(\beta)$ & $-0.182^{* *}$ & $-0.083^{* *}$ & $-0.424^{* *}$ \\
$\theta$ & $(0.029)$ & $(0.028)$ & $(0.075)$ \\
$\tau$ & -0.029 & -0.011 & -0.064 \\
& -0.973 & -0.367 & -1.717 \\
Observations & & & \\
mean(low birth weight) & 228381 & 35404 & 60312 \\
s.d. (low birth weight) & 0.187 & 0.226 & 0.247 \\
mean (height) & 0.39 & 0.418 & 0.431 \\
s.d. (height) & 1.587 & 1.52 & 1.534 \\
& 0.063 & 0.057 & 0.065 \\
\hline
\end{tabular}

\section{Stunted}

\begin{tabular}{llll} 
& Africa & Asia & Latin America \\
\hline Height $(\beta)$ & $-0.091^{* *}$ & $-0.079^{*}$ & $-0.122^{* *}$ \\
$\theta$ & $(0.007)$ & $(0.015)$ & $(0.023)$ \\
$\tau$ & -0.037 & -0.027 & -0.051 \\
& -3.640 & -2.821 & -5.083 \\
Observations & & & \\
mean (stunting) & 188705 & 29090 & 67645 \\
s.d. (stunting) & 0.025 & 0.028 & 0.024 \\
mean (height) & 0.157 & 0.164 & 0.153 \\
s.d. (height) & 1.586 & 1.523 & 1.53 \\
& 0.063 & 0.057 & 0.064
\end{tabular}

The linear baseline model in panel $\mathrm{A}$ of Table 1a is estimated by continent. $\beta$ are estimated coefficients, We normalise the marginal effect of height $(\tau)$ by dividing it by the continent-specific mean of dependant variable. We standardize it $(\theta)$ by multiplying it by the continent-specific ratio of the standard deviation of maternal height to the standard deviation of the dependant variable. Robust standard errors in brackets, allowing for clustering within country. ${ }^{*}$ significant at $5 \%$, ${ }^{* *}$ significant at $1 \%$. See notes to Table $1 \mathrm{a}$. 
Table A.8: Country Differences in Intergenerational Persistence: Range and Significance

\begin{tabular}{|c|c|c|c|c|c|}
\hline Health Measure & \multicolumn{2}{|c|}{ Country: Lowest } & \multicolumn{2}{|c|}{ Country: Highest } & Number of Significant Coefficients \\
\hline \multicolumn{6}{|c|}{ Marginal Effect, beta } \\
\hline Neonatal Mortality & Zambia & -0.029 & Comoros & -0.182 & $28 / 38$ \\
\hline Infant Mortality & Zimbabwe & -0.071 & Mozambique & -0.212 & $27 / 38$ \\
\hline Under-5 Mortality & Turkey & -0.065 & Niger & -0.283 & $29 / 38$ \\
\hline Low Birth Weight & Peru & -0.091 & Morroco & -0.694 & $20 / 35$ \\
\hline Stunting Incidence & Kenya & -0.062 & Ethiopia & -0.243 & $25 / 35$ \\
\hline \multicolumn{6}{|c|}{ Normalized Marginal Effect, tau } \\
\hline Neonatal Mortality & Zambia & -0.009 & Comoros & -0.044 & \\
\hline Infant Mortality & Guinea & -0.014 & Mozambique & -0.035 & \\
\hline Under-5 Mortality & Turkey & -0.012 & Nicaragua & -0.040 & \\
\hline Low Birth Weight & Chad & -0.655 & Colombia & -2.910 & \\
\hline Stunting Incidence & Kenya & -0.022 & Brazil & -0.104 & \\
\hline \multicolumn{6}{|c|}{ Standardized Marginal Effect, theta } \\
\hline Neonatal Mortality & Zambia & -0.69 & Honduras & -3.111 & \\
\hline Infant Mortality & Guinea & -0.541 & Honduras & -2.426 & \\
\hline Under-5 Mortality & Chad & -0.462 & Honduras & -2.528 & \\
\hline Low Birth Weight & Peru & -0.019 & Colombia & -0.086 & \\
\hline Stunting Incidence & Kenya & -2.385 & Brazil & -11.511 & \\
\hline
\end{tabular}


Table A9: Country-specific Estimates of Persistence: Low Birth Weight

\begin{tabular}{|c|c|c|c|c|c|c|c|c|c|c|c|c|}
\hline & $\mathrm{BE}$ & BR & $\overline{\mathrm{BF}}$ & CR & CD & CM & $\overline{\mathrm{CH}}$ & $\overline{\mathrm{CB}}$ & $\mathrm{CO}$ & $\overline{\mathrm{CI}}$ & 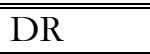 & 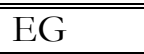 \\
\hline \multirow[t]{2}{*}{ Height $(\beta)$} & 0.028 & $-0.444 * *$ & $-0.200^{* *}$ & -0.136 & -0.006 & -0.170 & $-0.212^{*}$ & $-0.574 * *$ & $-0.327 * *$ & $-0.346^{* *}$ & $-0.235^{* *}$ & $-0.270 * *$ \\
\hline & $(0.075)$ & $(0.105)$ & $(0.053)$ & $(0.117)$ & $(0.073)$ & $(0.092)$ & $(0.089)$ & $(0.103)$ & $(0.091)$ & $(0.081)$ & $(0.039)$ & $(0.075)$ \\
\hline$\theta$ & 0.005 & -0.065 & -0.032 & -0.025 & -0.001 & -0.029 & -0.028 & -0.087 & -0.052 & -0.051 & -0.036 & -0.035 \\
\hline$\tau$ & 0.177 & -1.755 & -1.190 & -0.855 & -0.041 & -1.090 & -0.656 & -2.914 & -1.946 & -1.640 & -1.460 & -0.833 \\
\hline Observations & 6451 & 4263 & 14454 & 2058 & 7932 & 3884 & 7135 & 4509 & 4566 & 7105 & 29877 & 10345 \\
\hline mean (dep. var.) & 0.158 & 0.253 & 0.168 & 0.159 & 0.147 & 0.156 & 0.323 & 0.197 & 0.168 & 0.211 & 0.161 & 0.324 \\
\hline s.d. (dep. var.) & 0.365 & 0.435 & 0.374 & 0.366 & 0.355 & 0.363 & 0.468 & 0.398 & 0.374 & 0.408 & 0.368 & 0.468 \\
\hline mean (height) & 1.583 & 1.555 & 1.617 & 1.588 & 1.523 & 1.604 & 1.627 & 1.544 & 1.594 & 1.564 & 1.573 & 1.572 \\
\hline \multirow[t]{2}{*}{ s.d. (height) } & 0.06 & 0.064 & 0.059 & 0.068 & 0.054 & 0.061 & 0.061 & 0.06 & 0.06 & 0.06 & 0.056 & 0.06 \\
\hline & EET & $\overline{\mathrm{GGB}}$ & $\overline{\mathrm{GGH}}$ & $\overline{\mathrm{GGU}}$ & $\overline{\mathrm{HA}}$ & $\mathrm{HO}$ & IIN & KE & $\overline{\mathrm{LE}}$ & MD & MW & $\overline{\mathrm{ML}}$ \\
\hline \multirow{2}{*}{ Height $(\beta)$} & 0.029 & $-0.166^{*}$ & $-0.301 * *$ & $-0.251 * *$ & -0.091 & $-0.244 * *$ & -0.041 & $-0.287 * *$ & -0.110 & -0.174 & $-0.342^{* *}$ & $-0.300^{* *}$ \\
\hline & $(0.099)$ & $(0.072)$ & $(0.078)$ & $(0.081)$ & $(0.050)$ & $(0.056)$ & $(0.111)$ & $(0.052)$ & $(0.057)$ & $(0.090)$ & $(0.079)$ & $(0.109)$ \\
\hline$\theta$ & 0.006 & -0.028 & -0.054 & -0.033 & -0.012 & -0.042 & -0.005 & -0.045 & -0.016 & -0.023 & -0.052 & -0.050 \\
\hline$\tau$ & 0.257 & -1.153 & -2.213 & -0.789 & -0.368 & -1.638 & -0.164 & -1.783 & -0.489 & -0.702 & -1.819 & -1.667 \\
\hline Observations & 3181 & 6436 & 5306 & 9161 & 24479 & 10607 & 4672 & 15712 & 14640 & 7284 & 7017 & 3146 \\
\hline mean (dep. var.) & 0.113 & 0.144 & 0.136 & 0.318 & 0.247 & 0.149 & 0.25 & 0.161 & 0.225 & 0.248 & 0.188 & 0.18 \\
\hline \multirow[t]{2}{*}{ s.d. (height) } & 0.061 & 0.059 & 0.061 & 0.061 & 0.056 & 0.062 & 0.058 & 0.057 & 0.06 & 0.056 & 0.06 & 0.064 \\
\hline & $\mathrm{MO}$ & MZ & NB & $\mathrm{NC}$ & $\overline{\mathrm{NG}}$ & PE & RW & SE & TZ & TO & TK & \\
\hline \multirow[t]{2}{*}{ Height $(\beta)$} & $-0.694 * *$ & $-0.403^{* *}$ & $-0.332 * *$ & $-0.227 * *$ & 0.119 & $-0.091 *$ & -0.046 & -0.238 & -0.106 & 0.003 & -0.132 & \\
\hline & $(0.076)$ & $(0.083)$ & $(0.051)$ & $(0.059)$ & $(0.100)$ & $(0.043)$ & $(0.113)$ & $(0.144)$ & $(0.061)$ & $(0.044)$ & $(0.089)$ & \\
\hline$\theta$ & -0.086 & -0.050 & -0.045 & -0.044 & 0.015 & -0.019 & -0.007 & -0.030 & -0.017 & 0.001 & -0.021 & \\
\hline$\tau$ & -2.298 & -1.165 & -1.566 & -2.027 & 0.350 & -0.910 & -0.238 & -0.919 & -0.596 & 0.025 & -0.772 & \\
\hline Observations & 11640 & 9286 & 23634 & 8276 & 5916 & 13895 & 3543 & 2993 & 10210 & 15598 & 4886 & \\
\hline mean (dep. var.) & 0.302 & 0.346 & 0.212 & 0.112 & 0.34 & 0.1 & 0.193 & 0.259 & 0.178 & 0.122 & 0.171 & \\
\hline s.d. (dep. var.) & 0.459 & 0.476 & 0.408 & 0.316 & 0.474 & 0.3 & 0.395 & 0.438 & 0.383 & 0.327 & 0.376 & \\
\hline mean (height) & 1.533 & 1.606 & 1.501 & 1.58 & 1.625 & 1.562 & 1.589 & 1.561 & 1.585 & 1.58 & 1.599 & \\
\hline s.d. (height) & 0.057 & 0.059 & 0.055 & 0.061 & 0.06 & 0.062 & 0.06 & 0.055 & 0.063 & 0.06 & 0.061 & \\
\hline
\end{tabular}

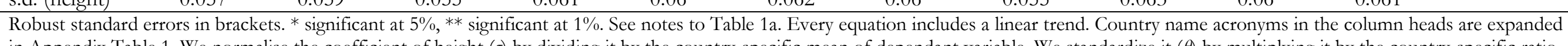

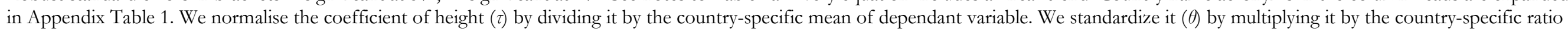
of the standard deviation of maternal height to the standard deviation of the dependant variable. 
Table A.10: Country-specific Estimates of Persistence: Stunting

\begin{tabular}{|c|c|c|c|c|c|c|c|c|c|c|c|c|}
\hline & $\mathrm{BE}$ & $\mathrm{BR}$ & $\mathrm{BF}$ & CR & CD & $\overline{\mathrm{CM}}$ & $\overline{\mathrm{CH}}$ & $\mathrm{CB}$ & $\mathrm{CO}$ & CI & DR & EG \\
\hline \multirow[t]{2}{*}{ Height $(\beta)$} & $-0.100^{* *}$ & $-0.224 * *$ & $-0.105^{* *}$ & -0.152 & -0.043 & $-0.118^{*}$ & $-0.097 * *$ & $-0.217 * *$ & $-0.107^{*}$ & $-0.114^{* *}$ & $-0.086^{* *}$ & -0.049 \\
\hline & $(0.035)$ & $(0.041)$ & $(0.026)$ & $(0.078)$ & $(0.051)$ & $(0.057)$ & $(0.033)$ & $(0.030)$ & $(0.042)$ & $(0.034)$ & $(0.018)$ & $(0.031)$ \\
\hline$\theta$ & -0.038 & -0.103 & -0.037 & -0.060 & -0.014 & -0.044 & -0.042 & -0.084 & -0.042 & -0.043 & -0.028 & -0.020 \\
\hline Observations & 5573 & 3598 & 11619 & 1861 & 3493 & 2250 & 5684 & 9573 & 3970 & 5841 & 27093 & 8380 \\
\hline mean (dep. var.) & 0.025 & 0.020 & 0.028 & 0.030 & 0.024 & 0.029 & 0.021 & 0.024 & 0.024 & 0.026 & 0.029 & 0.024 \\
\hline s.d. (dep. var.) & 0.156 & 0.139 & 0.166 & 0.170 & 0.153 & 0.167 & 0.142 & 0.153 & 0.154 & 0.158 & 0.167 & 0.153 \\
\hline mean (height) & 1.583 & 1.555 & 1.617 & 1.588 & 1.526 & 1.603 & 1.627 & 1.545 & 1.594 & 1.564 & 1.573 & 1.572 \\
\hline \multirow[t]{2}{*}{ s.d. (height) } & 0.060 & 0.064 & 0.059 & 0.067 & 0.051 & 0.062 & 0.061 & 0.059 & 0.060 & 0.060 & 0.055 & 0.061 \\
\hline & ET & $\overline{\mathrm{GGB}}$ & $\overline{\mathrm{GHH}}$ & 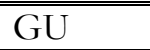 & $\overline{\mathrm{HA}}$ & $\mathrm{HO}$ & 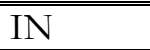 & "KE & LE & MD & MW & $\overline{\mathrm{ML}}$ \\
\hline \multirow[t]{2}{*}{ Height $(\beta)$} & $-0.243^{* *}$ & $-0.109 * *$ & -0.031 & $-0.131 * *$ & $-0.071 * *$ & $-0.110 * *$ & $-0.130 * *$ & $-0.062 *$ & -0.035 & -0.047 & $-0.130 * *$ & -0.037 \\
\hline & $(0.060)$ & $(0.038)$ & $(0.036)$ & $(0.033)$ & $(0.022)$ & $(0.026)$ & $(0.047)$ & $(0.029)$ & $(0.024)$ & $(0.040)$ & $(0.036)$ & $(0.051)$ \\
\hline$\theta$ & -0.095 & -0.039 & -0.012 & -0.049 & -0.024 & -0.046 & -0.047 & -0.022 & -0.014 & -0.015 & -0.047 & -0.016 \\
\hline$\tau$ & -10.125 & -4.037 & -1.240 & -4.679 & -2.536 & -4.783 & -4.815 & -2.385 & -1.591 & -1.516 & -4.643 & -1.682 \\
\hline Observations & 2714 & 5555 & 4040 & 7692 & 20463 & 9051 & 4041 & 12624 & 12011 & 6581 & 5776 & 2292 \\
\hline mean (dep. var.) & 0.024 & 0.027 & 0.025 & 0.028 & 0.028 & 0.023 & 0.027 & 0.026 & 0.022 & 0.031 & 0.028 & 0.022 \\
\hline mean (height) & 1.583 & 1.589 & 1.589 & 1.582 & 1.514 & 1.597 & 1.535 & 1.560 & 1.617 & 1.573 & 1.559 & 1.609 \\
\hline \multirow[t]{2}{*}{ s.d. (height) } & 0.060 & 0.059 & 0.061 & 0.061 & 0.056 & 0.062 & 0.058 & 0.056 & 0.059 & 0.056 & 0.060 & 0.065 \\
\hline & $\mathrm{MO}$ & $\overline{\mathrm{MZ}}$ & NB & $\mathrm{NC}$ & $\mathrm{NG}$ & PE & RW & 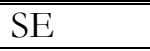 & TZ & TO & TK & \\
\hline \multirow[t]{2}{*}{ Height $(\beta)$} & -0.061 & $-0.150^{* *}$ & $-0.097 * *$ & $-0.117 * *$ & $-0.110^{*}$ & $-0.094 * *$ & 0.012 & $-0.137 * *$ & $-0.140 * *$ & $-0.101^{* *}$ & 0.004 & \\
\hline & $(0.034)$ & $(0.029)$ & $(0.016)$ & $(0.031)$ & $(0.044)$ & $(0.023)$ & $(0.045)$ & $(0.050)$ & $(0.030)$ & $(0.025)$ & $(0.045)$ & \\
\hline$\theta$ & -0.020 & -0.063 & -0.036 & -0.049 & -0.038 & -0.038 & 0.005 & -0.044 & -0.056 & -0.040 & 0.002 & \\
\hline$\tau$ & -2.033 & -7.500 & -4.619 & -5.318 & -3.548 & -3.917 & 0.522 & -4.567 & -5.385 & -4.391 & 0.174 & \\
\hline Observations & 10156 & 7219 & 30785 & 6372 & 4295 & 11654 & 3260 & 5134 & 8211 & 12559 & 4020 & \\
\hline mean (dep. var.) & 0.03 & 0.02 & 0.021 & 0.022 & 0.031 & 0.024 & 0.023 & 0.03 & 0.026 & 0.023 & 0.023 & \\
\hline s.d. (dep. var.) & 0.17 & 0.14 & 0.144 & 0.146 & 0.174 & 0.153 & 0.149 & 0.17 & 0.158 & 0.15 & 0.151 & \\
\hline mean (height) & 1.533 & 1.607 & 1.501 & 1.581 & 1.624 & 1.562 & 1.589 & 1.556 & 1.585 & 1.581 & 1.599 & \\
\hline s.d. (height) & 0.057 & 0.059 & 0.054 & 0.061 & 0.06 & 0.062 & 0.059 & 0.055 & 0.063 & 0.06 & 0.06 & \\
\hline
\end{tabular}

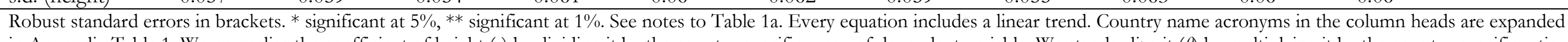

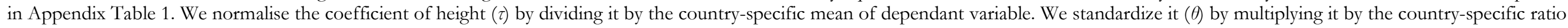
of the standard deviation of maternal height to the standard deviation of the dependant variable. 
Table A.11: Country-specific Estimates of Persistence: Neonatal Mortality

\begin{tabular}{|c|c|c|c|c|c|c|c|c|c|c|c|c|}
\hline & $\mathrm{BE}$ & BR & $\mathrm{BF}$ & CR & $\mathrm{CD}$ & CM & $\mathrm{CH}$ & $\mathrm{CB}$ & $\mathrm{CO}$ & CI & DR & EG \\
\hline Height $(\beta)$ & $\begin{array}{l}-0.085^{* *} \\
(0.020)\end{array}$ & $\begin{array}{l}-0.042^{*} \\
(0.019)\end{array}$ & $\begin{array}{l}-0.091 \text { ** } \\
(0.014)\end{array}$ & $\begin{array}{l}-0.048 \\
(0.028)\end{array}$ & $\begin{array}{l}-0.053^{*} \\
(0.021)\end{array}$ & $\begin{array}{l}-0.049 * * \\
(0.018)\end{array}$ & $\begin{array}{l}-0.032 \\
(0.019)\end{array}$ & $\begin{array}{l}0.005 \\
(0.008)\end{array}$ & $\begin{array}{l}-0.182^{* *} \\
(0.047)\end{array}$ & $\begin{array}{l}-0.131^{* *} \\
(0.024)\end{array}$ & $\begin{array}{l}-0.017 \\
(0.017)\end{array}$ & $\begin{array}{l}-0.051^{* *} \\
(0.009)\end{array}$ \\
\hline$\theta$ & -0.023 & -0.014 & -0.023 & -0.015 & -0.013 & -0.014 & -0.009 & 0.002 & -0.044 & -0.033 & -0.006 & -0.013 \\
\hline$\tau$ & -1.574 & -1.200 & -1.625 & -0.960 & -0.981 & -1.065 & -0.561 & 0.238 & -2.984 & -2.259 & -0.515 & -1.063 \\
\hline Observations & 35216 & 23716 & 73621 & 14310 & 39881 & 36063 & 39581 & 98780 & 7341 & 27770 & 31350 & 183100 \\
\hline mean (dep. var.) & 0.054 & 0.035 & 0.056 & 0.050 & 0.054 & 0.046 & 0.057 & 0.021 & 0.061 & 0.058 & 0.033 & 0.048 \\
\hline s.d. (dep. var.) & 0.225 & 0.184 & 0.230 & 0.218 & 0.226 & 0.210 & 0.231 & 0.145 & 0.239 & 0.234 & 0.177 & 0.213 \\
\hline mean (height) & 1.584 & 1.552 & 1.615 & 1.583 & 1.525 & 1.602 & 1.626 & 1.543 & 1.549 & 1.591 & 1.561 & 1.575 \\
\hline \multirow[t]{2}{*}{ s.d. (height) } & 0.061 & 0.063 & 0.059 & 0.066 & 0.054 & 0.062 & 0.062 & 0.060 & 0.058 & 0.059 & 0.061 & 0.056 \\
\hline & 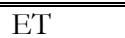 & "GB & 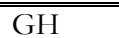 & 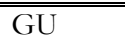 & 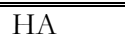 & $\overline{\mathrm{HO}}$ & 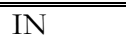 & $\overline{\mathrm{KKE}}$ & 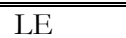 & $\overline{\mathrm{MDD}}$ & 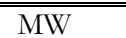 & 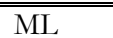 \\
\hline Height $(\beta)$ & $\begin{array}{l}-0.122^{* *} \\
(0.015)\end{array}$ & $\begin{array}{l}0.007 \\
(0.024)\end{array}$ & $\begin{array}{l}-0.049 * * \\
(0.018)\end{array}$ & $\begin{array}{l}-0.078^{* *} \\
(0.021)\end{array}$ & $\begin{array}{l}0.000 \\
(0.020)\end{array}$ & $\begin{array}{l}-0.084 * * \\
(0.015)\end{array}$ & $\begin{array}{l}-0.101 * * \\
(0.006)\end{array}$ & $\begin{array}{l}-0.048^{* *} \\
(0.013)\end{array}$ & $\begin{array}{l}-0.044 \\
(0.035)\end{array}$ & $\begin{array}{l}-0.051 * * \\
(0.018)\end{array}$ & $\begin{array}{l}-0.063^{* *} \\
(0.015)\end{array}$ & $\begin{array}{l}-0.078^{* *} \\
(0.017)\end{array}$ \\
\hline$\theta$ & -0.030 & 0.002 & -0.014 & -0.018 & 0.000 & -0.032 & -0.025 & -0.016 & -0.012 & -0.015 & -0.016 & -0.017 \\
\hline$\tau$ & -1.906 & 0.219 & -1.089 & -1.083 & 0.000 & -3.111 & -1.804 & -1.371 & -0.880 & -1.275 & -1.125 & -0.940 \\
\hline Observations & 71459 & 14679 & 37114 & 41874 & 36565 & 38312 & 441338 & 60662 & 11434 & 36567 & 77813 & 78973 \\
\hline mean (dep. var.) & 0.064 & 0.032 & 0.045 & 0.072 & 0.054 & 0.027 & 0.056 & 0.035 & 0.050 & 0.040 & 0.056 & 0.083 \\
\hline s.d. (dep. var.) & 0.245 & 0.177 & 0.208 & 0.258 & 0.227 & 0.161 & 0.230 & 0.185 & 0.218 & 0.197 & 0.229 & 0.275 \\
\hline mean (height) & 1.573 & 1.585 & 1.589 & 1.587 & 1.579 & 1.514 & 1.516 & 1.595 & 1.574 & 1.539 & 1.561 & 1.616 \\
\hline \multirow[t]{2}{*}{ s.d. (height) } & 0.061 & 0.061 & 0.060 & 0.061 & 0.061 & 0.061 & 0.056 & 0.062 & 0.061 & 0.058 & 0.057 & 0.060 \\
\hline & $\mathrm{MO}$ & MZ & NB & NC & NG & PE & RW & SE & $\bar{T} \mathrm{TZ}$ & TO & TK & UG \\
\hline Height $(\beta)$ & $\begin{array}{l}-0.064^{* *} \\
(0.017)\end{array}$ & $\begin{array}{l}-0.108^{* *} \\
(0.018)\end{array}$ & $\begin{array}{l}0.014 \\
(0.029)\end{array}$ & $\begin{array}{l}-0.060^{* *} \\
(0.012)\end{array}$ & $\begin{array}{l}-0.083^{* *} \\
(0.019)\end{array}$ & $\begin{array}{l}-0.038^{* *} \\
(0.009)\end{array}$ & $\begin{array}{l}-0.132^{* *} \\
(0.017)\end{array}$ & $\begin{array}{l}-0.008 \\
(0.016)\end{array}$ & $\begin{array}{l}-0.070^{* *} \\
(0.013)\end{array}$ & $\begin{array}{l}-0.067^{* *} \\
(0.023)\end{array}$ & $\begin{array}{l}-0.024 \\
(0.020)\end{array}$ & $\begin{array}{c}-0.046^{* *} \\
(0.016)\end{array}$ \\
\hline$\theta$ & -0.017 & -0.026 & 0.005 & -0.020 & -0.021 & -0.010 & -0.036 & -0.002 & -0.021 & -0.019 & -0.007 & -0.015 \\
\hline$\tau$ & -1.362 & -1.714 & 0.326 & -2.069 & -1.431 & -0.950 & -2.400 & -0.160 & -1.556 & -1.396 & -0.533 & -1.122 \\
\hline Observations & 47932 & 53648 & 11211 & 65311 & 46700 & 162104 & 48743 & 47204 & 68652 & 24303 & 33090 & 41175 \\
\hline mean (dep. var.) & 0.047 & 0.063 & 0.043 & 0.029 & 0.058 & 0.040 & 0.055 & 0.050 & 0.045 & 0.048 & 0.045 & 0.041 \\
\hline s.d. (dep. var.) & 0.212 & 0.242 & 0.202 & 0.168 & 0.234 & 0.196 & 0.228 & 0.217 & 0.207 & 0.215 & 0.207 & 0.198 \\
\hline mean (height) & 1.575 & 1.561 & 1.610 & 1.533 & 1.605 & 1.498 & 1.581 & 1.623 & 1.560 & 1.589 & 1.553 & 1.585 \\
\hline \multirow[t]{2}{*}{ s.d. (height) } & 0.057 & 0.059 & 0.065 & 0.057 & 0.059 & 0.054 & 0.062 & 0.062 & 0.062 & 0.061 & 0.059 & 0.063 \\
\hline & $\overline{\mathrm{ZZB}}$ & 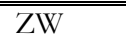 & & & & & & & & & & \\
\hline Height $(\beta)$ & $\begin{array}{c}-0.029 * \\
(0.014)\end{array}$ & $\begin{array}{c}-0.039 * \\
(0.017)\end{array}$ & & & & & & & & & & \\
\hline$\theta$ & -0.009 & -0.014 & & & & & & & & & & \\
\hline$\tau$ & -0.690 & -1.345 & & & & & & & & & & \\
\hline Observations & 61007 & 27141 & & & & & & & & & & \\
\hline mean (dep. var.) & 0.042 & 0.029 & & & & & & & & & & \\
\hline s.d. (dep. var.) & 0.201 & 0.167 & & & & & & & & & & \\
\hline mean (height) & 1.580 & 1.599 & & & & & & & & & & \\
\hline s.d. (height) & 0.061 & 0.061 & & & & & & & & & & \\
\hline
\end{tabular}

Robust standard errors in brackets. * significant at 5\%, ** significant at $1 \%$. See notes to Table 1 a. Every equation includes a linear trend. Country name acronyms in the column heads are expanded in Appendix Table 1 . We normalise the coefficient of height $(\tau)$ by dividing it by the country-specific mean of dependant variable. We standardize it $(\theta)$ by multiplying it by the country-specific ratio of the standard deviation of maternal height to the standard deviation of the dependant variable. 
Table A.12: Country-specific Estimates of Persistence: Infant Mortality

\begin{tabular}{|c|c|c|c|c|c|c|c|c|c|c|c|c|}
\hline & $\mathrm{BE}$ & BR & $\mathrm{BF}$ & CR & CD & CM & $\mathrm{CH}$ & CB & $\mathrm{CO}$ & CI & $\begin{array}{l}\text { DR } \\
\end{array}$ & EG \\
\hline Height $(\beta)$ & $\begin{array}{l}-0.162^{* *} \\
(0.029)\end{array}$ & $\begin{array}{l}-0.043 \\
(0.027)\end{array}$ & $\begin{array}{l}-0.117 * * \\
(0.021)\end{array}$ & $\begin{array}{l}-0.108^{* *} \\
(0.040)\end{array}$ & $\begin{array}{l}-0.117 * * \\
(0.029)\end{array}$ & $\begin{array}{l}-0.089^{* *} \\
(0.025)\end{array}$ & $\begin{array}{l}-0.084^{* *} \\
(0.028)\end{array}$ & $\begin{array}{l}-0.001 \\
(0.010)\end{array}$ & $\begin{array}{l}-0.138^{*} \\
(0.063)\end{array}$ & $\begin{array}{l}-0.170^{* *} \\
(0.032)\end{array}$ & $\begin{array}{l}-0.032 \\
(0.024)\end{array}$ & $\begin{array}{l}-0.102^{* *} \\
(0.013)\end{array}$ \\
\hline$\theta$ & -0.031 & -0.010 & -0.021 & -0.023 & -0.021 & -0.019 & -0.016 & 0.000 & -0.026 & -0.033 & -0.008 & -0.019 \\
\hline$\tau$ & -1.361 & -0.573 & -0.907 & -1.009 & -1.125 & -0.947 & -0.651 & -0.029 & -1.255 & -1.650 & -0.508 & -1.041 \\
\hline Observations & 34104 & 22997 & 71846 & 13646 & 38351 & 35524 & 38487 & 97312 & 6999 & 26574 & 30198 & 178259 \\
\hline mean (dep. var.) & 0.119 & 0.075 & 0.129 & 0.107 & 0.104 & 0.094 & 0.129 & 0.035 & 0.11 & 0.103 & 0.063 & 0.098 \\
\hline s.d. (dep. var.) & 0.324 & 0.263 & 0.335 & 0.309 & 0.305 & 0.292 & 0.335 & 0.185 & 0.313 & 0.304 & 0.243 & 0.297 \\
\hline mean (height) & 1.584 & 1.551 & 1.615 & 1.582 & 1.525 & 1.602 & 1.626 & 1.543 & 1.55 & 1.591 & 1.561 & 1.575 \\
\hline \multirow[t]{2}{*}{ s.d. (height) } & 0.061 & 0.063 & 0.059 & 0.066 & 0.054 & 0.062 & 0.062 & 0.06 & 0.059 & 0.059 & 0.061 & 0.056 \\
\hline & ET & GB & GH & $\mathrm{GU}$ & HA & $\mathrm{HO}$ & IN & $\mathrm{KE}$ & LE & $\mathrm{MD}$ & MW & ML \\
\hline Height $(\beta)$ & $\begin{array}{l}-0.173 * * \\
(0.021)\end{array}$ & $\begin{array}{l}-0.025 \\
(0.034)\end{array}$ & $\begin{array}{l}-0.085^{* *} \\
(0.025)\end{array}$ & $\begin{array}{l}-0.080^{* *} \\
(0.028)\end{array}$ & $\begin{array}{l}-0.045 \\
(0.028)\end{array}$ & $\begin{array}{l}-0.114 * * \\
(0.019)\end{array}$ & $\begin{array}{l}-0.134^{* *} \\
(0.008)\end{array}$ & $\begin{array}{l}0.000 \\
(0.018)\end{array}$ & $\begin{array}{l}-0.050 \\
(0.042)\end{array}$ & $\begin{array}{l}-0.110^{* *} \\
(0.026)\end{array}$ & $\begin{array}{l}-0.108^{* *} \\
(0.022)\end{array}$ & $\begin{array}{l}-0.108^{* *} \\
(0.023)\end{array}$ \\
\hline$\theta$ & -0.032 & -0.006 & -0.018 & -0.014 & -0.009 & -0.033 & -0.027 & 0.000 & -0.011 & -0.022 & -0.018 & -0.018 \\
\hline$\tau$ & -1.362 & -0.385 & -0.988 & -0.541 & -0.413 & -2.426 & -1.576 & 0.000 & -0.602 & -1.170 & -0.777 & -0.663 \\
\hline Observations & 69886 & 14106 & 35963 & 41059 & 34999 & 38312 & 434073 & 58882 & 11434 & 35697 & 75165 & 75563 \\
\hline mean (dep. var.) & 0.127 & 0.065 & 0.086 & 0.148 & 0.109 & 0.047 & 0.085 & 0.076 & 0.083 & 0.094 & 0.139 & 0.163 \\
\hline s.d. (dep. var.) & 0.333 & 0.246 & 0.281 & 0.355 & 0.312 & 0.211 & 0.279 & 0.264 & 0.276 & 0.291 & 0.346 & 0.369 \\
\hline mean (height) & 1.573 & 1.585 & 1.589 & 1.587 & 1.579 & 1.514 & 1.516 & 1.595 & 1.574 & 1.539 & 1.561 & 1.616 \\
\hline \multirow[t]{2}{*}{ s.d. (height) } & 0.061 & 0.061 & 0.06 & 0.061 & 0.061 & 0.061 & 0.056 & 0.062 & 0.061 & 0.058 & 0.057 & 0.06 \\
\hline & $\overline{\mathrm{MO}}$ & "MZ & NB & $\mathrm{NC}$ & NG & 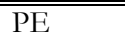 & RW & 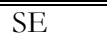 & 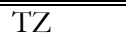 & 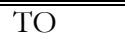 & 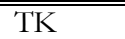 & 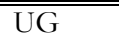 \\
\hline Height $(\beta)$ & $\begin{array}{l}-0.109^{* *} \\
(0.022)\end{array}$ & $\begin{array}{l}-0.212 * * \\
(0.026)\end{array}$ & $\begin{array}{l}-0.029 \\
(0.039)\end{array}$ & $\begin{array}{l}-0.118^{* *} \\
(0.017)\end{array}$ & $\begin{array}{l}-0.182^{* *} \\
(0.029)\end{array}$ & $\begin{array}{l}-0.071^{* *} \\
(0.013)\end{array}$ & $\begin{array}{l}-0.160^{* *} \\
(0.025)\end{array}$ & $\begin{array}{l}-0.023 \\
(0.023)\end{array}$ & $\begin{array}{l}-0.099 * * \\
(0.020)\end{array}$ & $\begin{array}{l}-0.076^{*} \\
(0.032)\end{array}$ & $\begin{array}{l}-0.050 \\
(0.027)\end{array}$ & $\begin{array}{l}-0.018 \\
(0.024)\end{array}$ \\
\hline$\theta$ & -0.023 & -0.035 & -0.007 & -0.028 & -0.030 & -0.014 & -0.031 & -0.005 & -0.020 & -0.016 & -0.010 & -0.004 \\
\hline$\tau$ & -1.346 & -1.442 & -0.387 & -1.903 & -1.238 & -0.922 & -1.391 & -0.235 & -0.934 & -0.768 & -0.556 & -0.184 \\
\hline Observations & 47109 & 52561 & 10606 & 64006 & 44532 & 156332 & 47192 & 46342 & 66383 & 23111 & 31971 & 39091 \\
\hline mean (dep. var.) & 0.081 & 0.147 & 0.075 & 0.062 & 0.147 & 0.077 & 0.115 & 0.098 & 0.106 & 0.099 & 0.09 & 0.098 \\
\hline s.d. (dep. var.) & 0.273 & 0.354 & 0.263 & 0.241 & 0.354 & 0.267 & 0.32 & 0.298 & 0.308 & 0.299 & 0.286 & 0.298 \\
\hline mean (height) & 1.575 & 1.561 & 1.61 & 1.533 & 1.605 & 1.498 & 1.581 & 1.623 & 1.56 & 1.589 & 1.553 & 1.586 \\
\hline \multirow[t]{2}{*}{ s.d. (height) } & 0.057 & 0.059 & 0.065 & 0.057 & 0.059 & 0.054 & 0.062 & 0.062 & 0.062 & 0.061 & 0.059 & 0.063 \\
\hline & ZB & $\mathrm{ZW}$ & & & & & & & & & & \\
\hline Height $(\beta)$ & $\begin{array}{l}-0.119 * * \\
(0.021)\end{array}$ & $\begin{array}{l}-0.072 * * \\
(0.024)\end{array}$ & & & & & & & & & & \\
\hline$\theta$ & -0.024 & -0.019 & & & & & & & & & & \\
\hline$\tau$ & -1.123 & -1.200 & & & & & & & & & & \\
\hline Observations & 58965 & 26083 & & & & & & & & & & \\
\hline mean (dep. var.) & 0.106 & 0.06 & & & & & & & & & & \\
\hline s.d. (dep. var.) & 0.308 & 0.237 & & & & & & & & & & \\
\hline mean (height) & 1.58 & 1.599 & & & & & & & & & & \\
\hline s.d. (height) & 0.061 & 0.061 & & & & & & & & & & \\
\hline
\end{tabular}


Table A.13: Country-specific Estimates of Persistence: Under-5 Mortality

\begin{tabular}{|c|c|c|c|c|c|c|c|c|c|c|c|c|}
\hline & $\overline{\mathrm{BE}}$ & BR & $\mathrm{BF}$ & CR & CD & CM & $\mathrm{CH}$ & CB & $\mathrm{CO}$ & CI & DR & EG \\
\hline Height $(\beta)$ & $-0.183^{* *}$ & -0.045 & $\begin{array}{l}-0.137 * * \\
0\end{array}$ & $-0.135^{*}$ & $-0.137 * *$ & $-0.124 * *$ & $-0.098^{* *}$ & -0.008 & $-0.157^{*}$ & $-0.215^{* *}$ & -0.016 & $-0.127 * *$ \\
\hline$\theta$ & -0.027 & $\begin{array}{l}(0.030) \\
-0.010\end{array}$ & $\begin{array}{l}(0.029) \\
-0.019\end{array}$ & $\begin{array}{l}(0.030) \\
-0.023\end{array}$ & $\begin{array}{l}(0.050) \\
-0.021\end{array}$ & $\begin{array}{l}(0.053) \\
-0.022\end{array}$ & $\begin{array}{l}(0.03 /) \\
-0.015\end{array}$ & $\begin{array}{l}(0.012) \\
-0.002\end{array}$ & -0.026 & $\begin{array}{l}(0.043) \\
-0.035\end{array}$ & $\begin{array}{l}(0.031) \\
-0.003\end{array}$ & $\begin{array}{l}(0.015) \\
-0.022\end{array}$ \\
\hline$\tau$ & -0.880 & -0.506 & -0.620 & -0.799 & -0.979 & -0.838 & -0.462 & -0.182 & -1.047 & -1.344 & -0.186 & -0.977 \\
\hline Observations & 26657 & 19375 & 58808 & 10540 & 31648 & 30582 & 32322 & 87703 & 5533 & 20801 & 24238 & 153139 \\
\hline mean (dep. var.) & 0.208 & 0.089 & 0.221 & 0.169 & 0.140 & 0.148 & 0.212 & 0.044 & 0.150 & 0.160 & 0.086 & 0.130 \\
\hline s.d. (dep. var.) & 0.406 & 0.285 & 0.415 & 0.374 & 0.347 & 0.355 & 0.409 & 0.204 & 0.357 & 0.366 & 0.281 & 0.336 \\
\hline mean (height) & 1.584 & 1.551 & 1.615 & 1.581 & 1.525 & 1.602 & 1.626 & 1.543 & 1.550 & 1.591 & 1.560 & 1.575 \\
\hline \multirow[t]{2}{*}{ s.d. (height) } & 0.061 & 0.062 & 0.059 & 0.065 & 0.054 & 0.062 & 0.062 & 0.060 & 0.060 & 0.059 & 0.061 & 0.057 \\
\hline & $\begin{array}{l}\text { ET } \\
\end{array}$ & 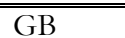 & 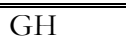 & 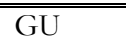 & 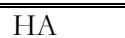 & $\overline{\mathrm{HO}}$ & 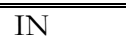 & $\overline{\mathrm{KKE}}$ & 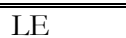 & $\overline{\mathrm{MMD}}$ & בMW & ML \\
\hline Height $(\beta)$ & $\begin{array}{l}-0.218^{* *} \\
(0.027)\end{array}$ & $\begin{array}{l}0.022 \\
(0.045)\end{array}$ & $\begin{array}{l}-0.109 * * \\
(0.034)\end{array}$ & $\begin{array}{l}-0.116^{* *} \\
(0.035)\end{array}$ & $\begin{array}{l}-0.085^{*} \\
(0.039)\end{array}$ & $\begin{array}{l}-0.153^{* *} \\
(0.021)\end{array}$ & $\begin{array}{l}-0.179 * * \\
(0.009)\end{array}$ & $\begin{array}{l}0.002 \\
(0.024)\end{array}$ & $\begin{array}{l}-0.043 \\
(0.048)\end{array}$ & $\begin{array}{l}-0.159^{* *} \\
(0.035)\end{array}$ & $\begin{array}{l}-0.127 * * \\
(0.029)\end{array}$ & $\begin{array}{l}-0.159^{* *} \\
(0.031)\end{array}$ \\
\hline$\theta$ & -0.033 & 0.005 & -0.019 & -0.017 & -0.013 & -0.039 & -0.032 & 0.000 & -0.009 & -0.026 & -0.017 & -0.021 \\
\hline$\tau$ & -1.085 & 0.224 & -0.757 & -0.492 & -0.489 & -2.508 & -1.613 & 0.019 & -0.439 & -1.067 & -0.567 & -0.566 \\
\hline Observations & 61012 & 11436 & 29115 & 36274 & 27451 & 38260 & 396147 & 47888 & 10688 & 29639 & 61909 & 59899 \\
\hline mean (dep. var.) & 0.201 & 0.098 & 0.144 & 0.236 & 0.174 & 0.061 & 0.111 & 0.108 & 0.098 & 0.149 & 0.224 & 0.281 \\
\hline s.d. (dep. var.) & 0.401 & 0.298 & 0.351 & 0.424 & 0.379 & 0.240 & 0.314 & 0.311 & 0.297 & 0.356 & 0.417 & 0.449 \\
\hline mean (height) & 1.573 & 1.585 & 1.589 & 1.587 & 1.578 & 1.514 & 1.516 & 1.594 & 1.574 & 1.540 & 1.562 & 1.616 \\
\hline \multirow[t]{2}{*}{ s.d. (height) } & 0.061 & 0.061 & 0.060 & 0.061 & 0.060 & 0.061 & 0.056 & 0.061 & 0.061 & 0.058 & 0.057 & 0.060 \\
\hline & $\mathrm{MO}$ & MZ & NB & $\mathrm{NC}$ & NG & $\overline{P \mathrm{PE}}$ & RW & SE & $\overline{T \text { TZ }}$ & TO & TTK & 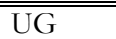 \\
\hline Height $(\beta)$ & $\begin{array}{l}-0.131^{* *} \\
(0.027)\end{array}$ & $\begin{array}{l}-0.223^{* *} \\
(0.033)\end{array}$ & $\begin{array}{l}0.006 \\
(0.054)\end{array}$ & $\begin{array}{l}-0.188^{* *} \\
(0.021)\end{array}$ & $\begin{array}{l}-0.283^{* *} \\
(0.042)\end{array}$ & $\begin{array}{l}-0.121^{* *} \\
(0.017)\end{array}$ & $\begin{array}{l}-0.178^{* *} \\
(0.033)\end{array}$ & $\begin{array}{l}-0.081 * * \\
(0.030)\end{array}$ & $\begin{array}{l}-0.183^{* *} \\
(0.026)\end{array}$ & $\begin{array}{l}-0.060 \\
(0.044)\end{array}$ & $\begin{array}{l}-0.065^{*} \\
(0.032)\end{array}$ & $\begin{array}{l}-0.061 \\
(0.035)\end{array}$ \\
\hline$\theta$ & -0.024 & -0.032 & 0.001 & -0.040 & -0.036 & -0.021 & -0.028 & -0.013 & -0.031 & -0.010 & -0.012 & -0.010 \\
\hline$\tau$ & -1.248 & -1.037 & 0.053 & -2.321 & -0.913 & -1.071 & -0.908 & -0.466 & -1.130 & -0.349 & -0.586 & -0.361 \\
\hline Observations & 40527 & 43777 & 8030 & 53395 & 34541 & 126448 & 40291 & 41112 & 54556 & 18108 & 26938 & 29548 \\
\hline mean (dep. var.) & 0.105 & 0.215 & 0.113 & 0.081 & 0.310 & 0.113 & 0.196 & 0.174 & 0.162 & 0.172 & 0.111 & 0.169 \\
\hline s.d. (dep. var.) & 0.307 & 0.410 & 0.317 & 0.273 & 0.463 & 0.317 & 0.397 & 0.379 & 0.369 & 0.377 & 0.314 & 0.375 \\
\hline mean (height) & 1.576 & 1.561 & 1.610 & 1.533 & 1.605 & 1.497 & 1.582 & 1.623 & 1.560 & 1.589 & 1.552 & 1.586 \\
\hline \multirow[t]{2}{*}{ s.d. (height) } & 0.057 & 0.059 & 0.065 & 0.058 & 0.059 & 0.054 & 0.062 & 0.062 & 0.062 & 0.062 & 0.060 & 0.063 \\
\hline & ZBB & $\overline{\mathrm{ZWW}}$ & & & & & & & & & & \\
\hline Height $(\beta)$ & $\begin{array}{l}-0.174^{* *} \\
(0.030)\end{array}$ & $\begin{array}{l}-0.091 * * \\
(0.032)\end{array}$ & & & & & & & & & & \\
\hline$\theta$ & -0.028 & -0.020 & & & & & & & & & & \\
\hline$\tau$ & -1.000 & -1.083 & & & & & & & & & & \\
\hline Observations & 45366 & 20825 & & & & & & & & & & \\
\hline mean (dep. var.) & 0.174 & 0.084 & & & & & & & & & & \\
\hline s.d. (dep. var.) & 0.379 & 0.277 & & & & & & & & & & \\
\hline mean (height) & 1.580 & 1.599 & & & & & & & & & & \\
\hline s.d. (height) & 0.061 & 0.061 & & & & & & & & & & \\
\hline
\end{tabular}


Figure A.1: Alternative Indicators of Child Health against Mother's Health: Country-specific Lowess Predictions a) Height: Mortality Indicators
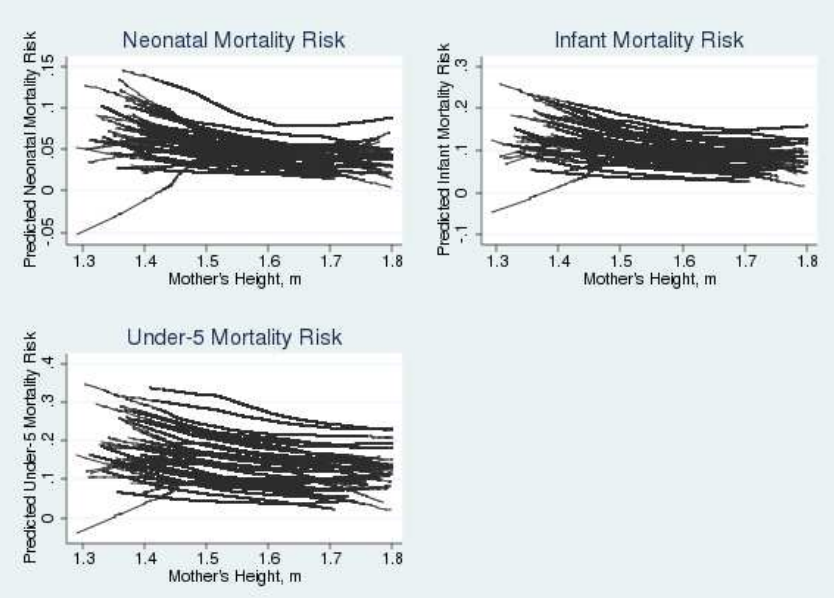

b) Height: Low Birth Weight and Stunting

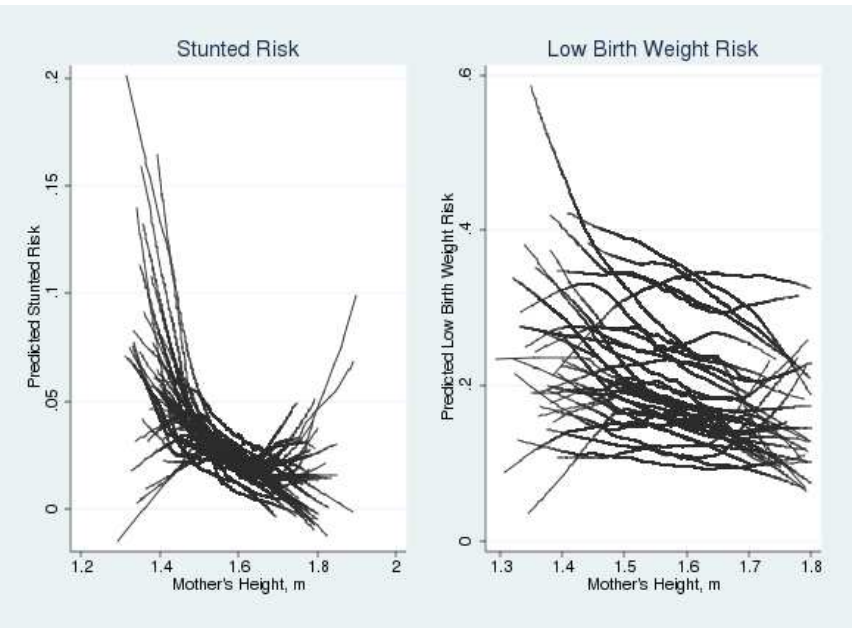

c) BMI: Mortality Indicators
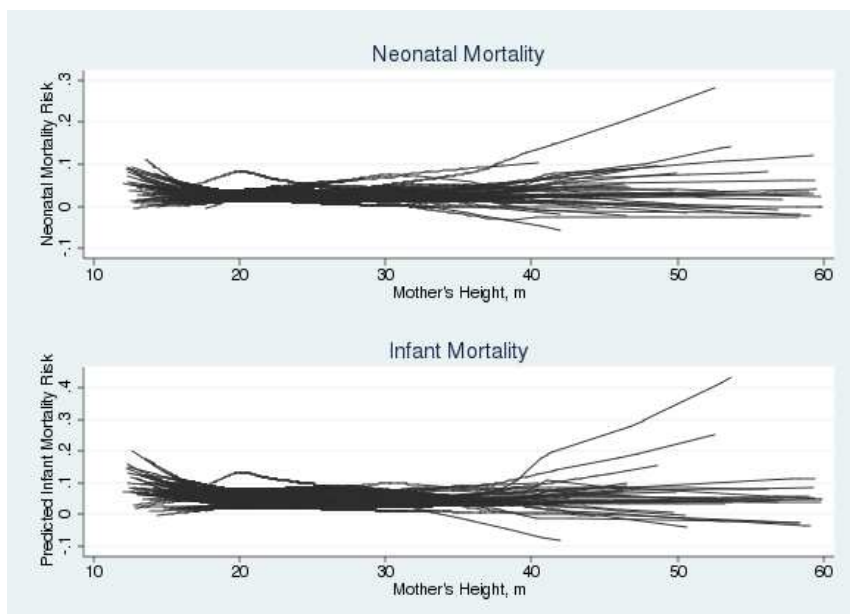
d) BMI: Low Birth Weight and Stunted

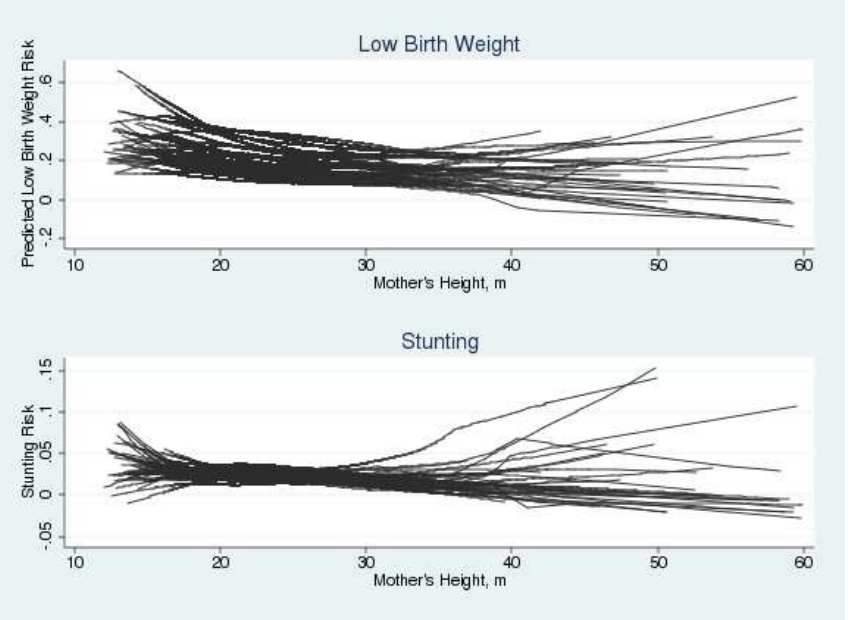

Figure A3: Trends in Intergenerational Persistence across Cohorts: $\beta \mathrm{c}$
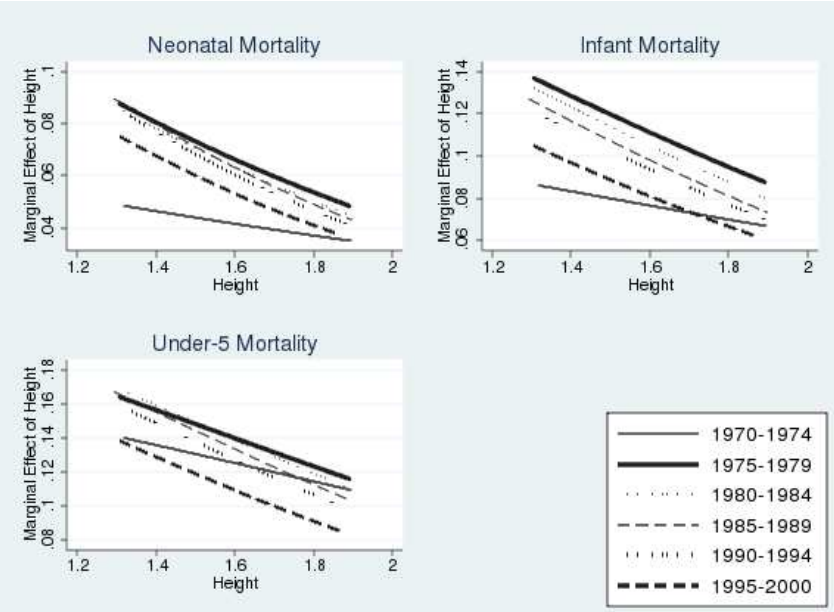

Figure plots the probit marginal effect of height over the height distribution, for each cohort

Figure A.4: Trends in Intergenerational Persistence across Years, $\beta \mathrm{t}$, by continent

a) Neonatal Mortality

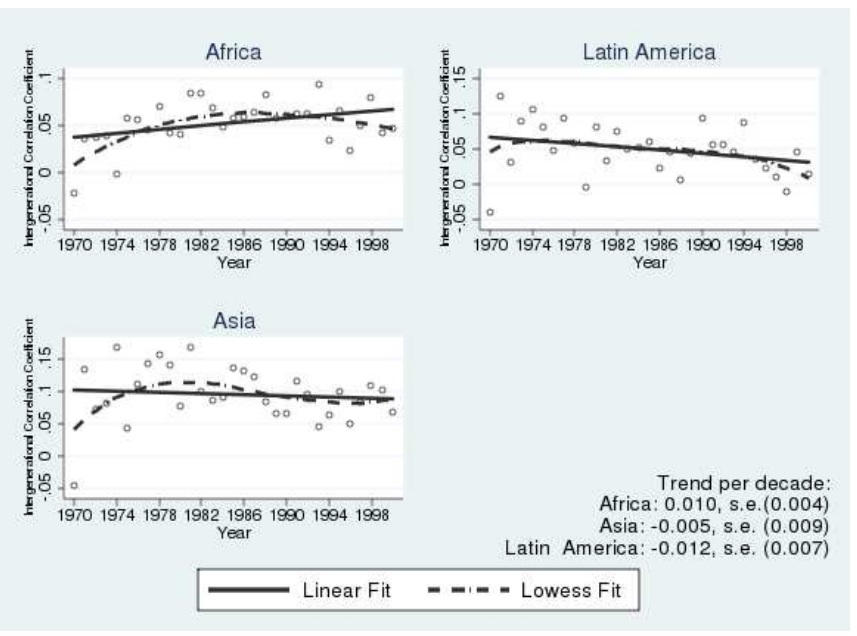




\section{b) Infant Mortality}

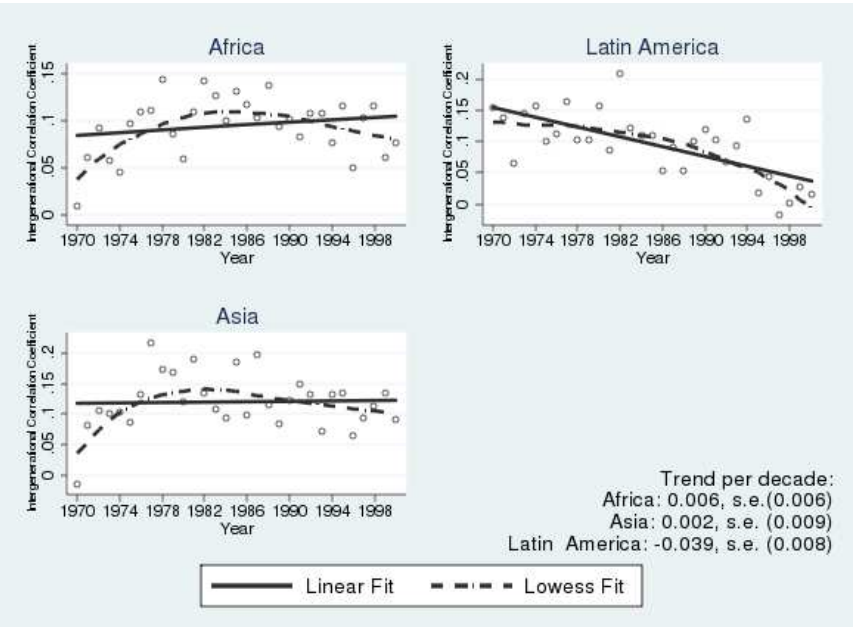

c) Under-5 Mortality

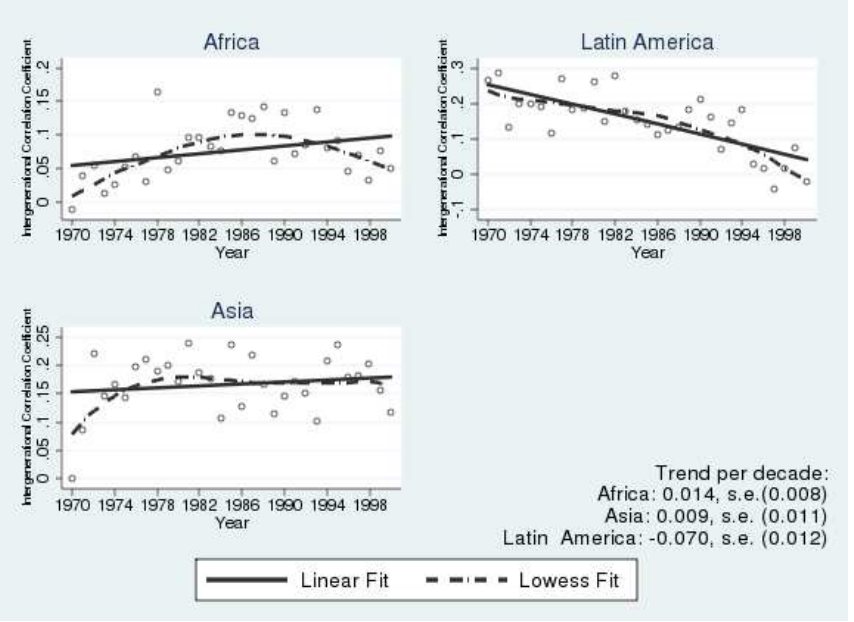

Plot of year-specific $\beta$ from a regression of child health against mother's height, with child and household controls.

Figure A.5: Trends in Standardised Intergenerational Persistence across Years, $\theta$, by continent

\section{a) Neonatal Mortality}

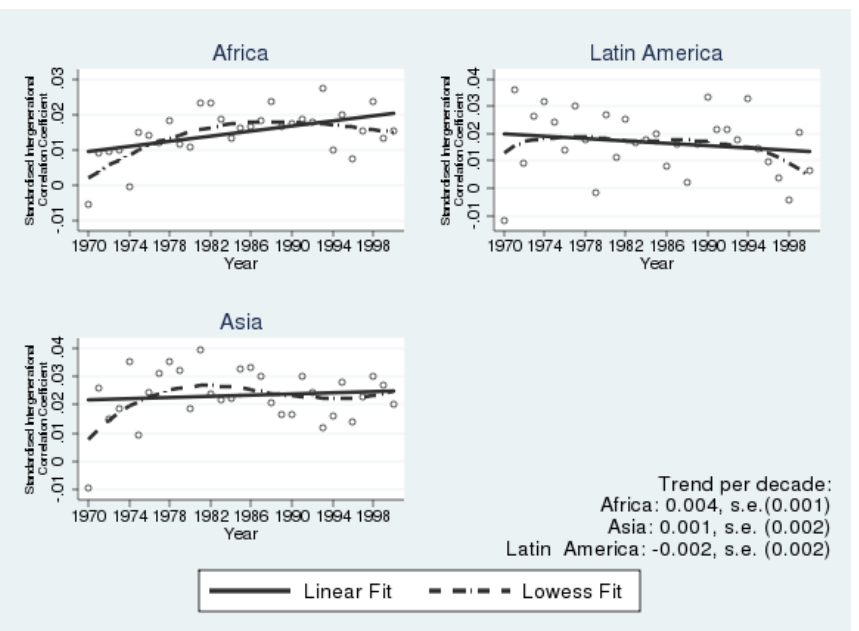




\section{b) Infant Mortality}
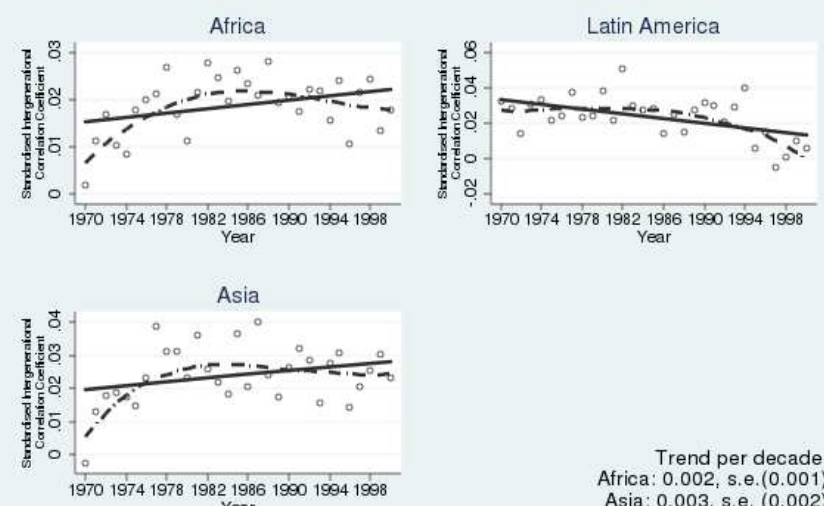

19701974197819821986199019941998

Trend per decade

Africa: 0.002 , s.e. $(0.001)$ Asia: 0.003 , s.e. $(0.002)$ Latin America: -0.007 , s.e. $(0.002)$

Linear Fit - - - - Lowess Fit

c) Under-5 Mortality

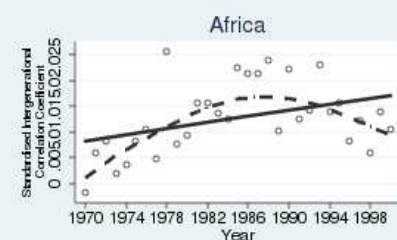

Year

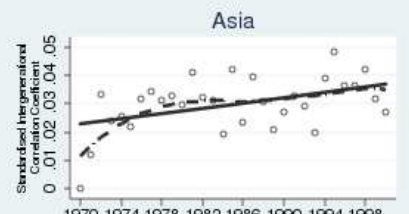

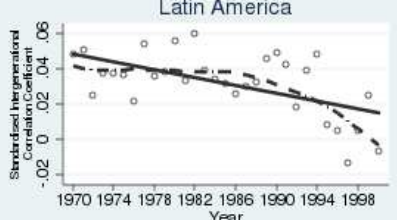

Year

Trend per decade
Africa: 0.003 , s.e. $(0.001)$

Asia: 0.005 , s.e. $(0.002)$ Latin America: -0.011 , s.e. $(0.003)$ Linear Fit - - - - Lowess Fit

Figure A.6: Density Plots of $\beta$,,$\theta$, and $\tau$ j: Countries with significant $\beta$ J
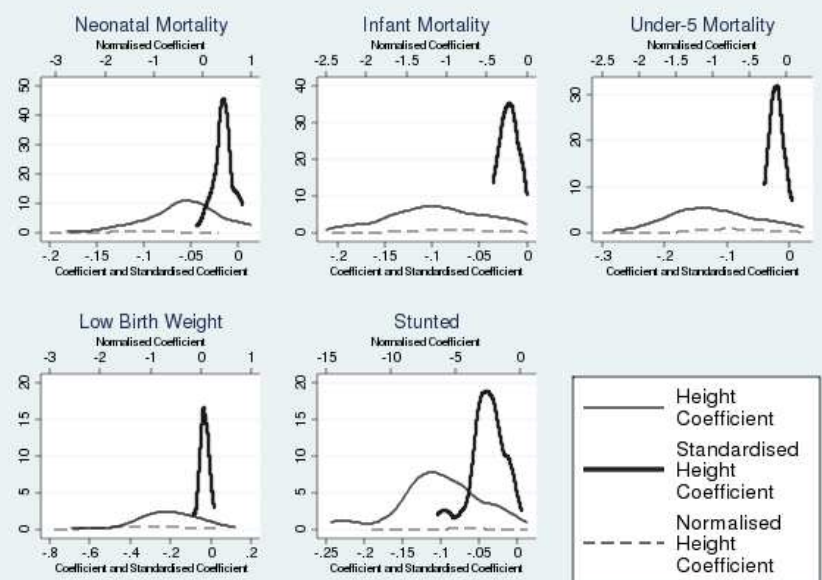
Figure A.7: Country Variation in Intergenerational Persistence

a) Against Mother Height

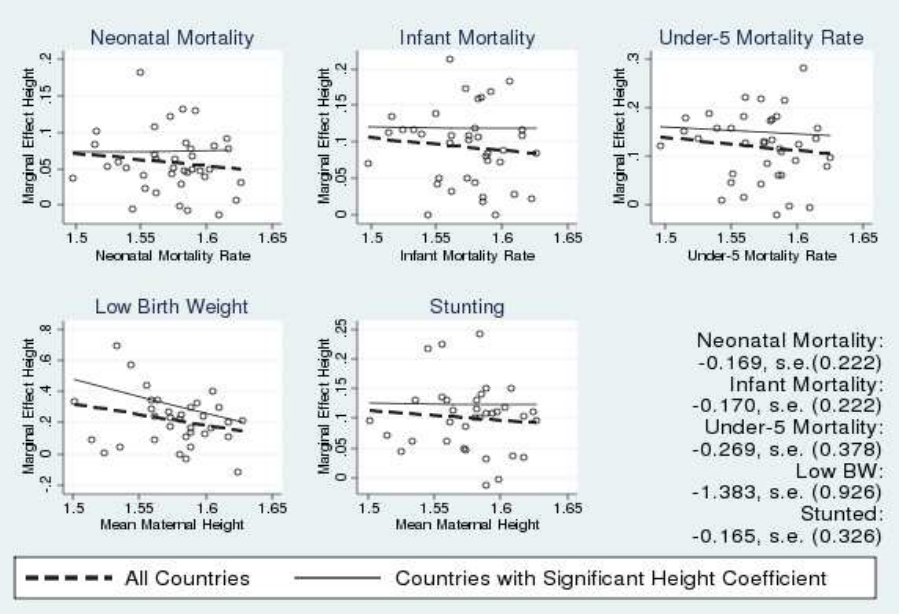

b) Against Level of Child Health

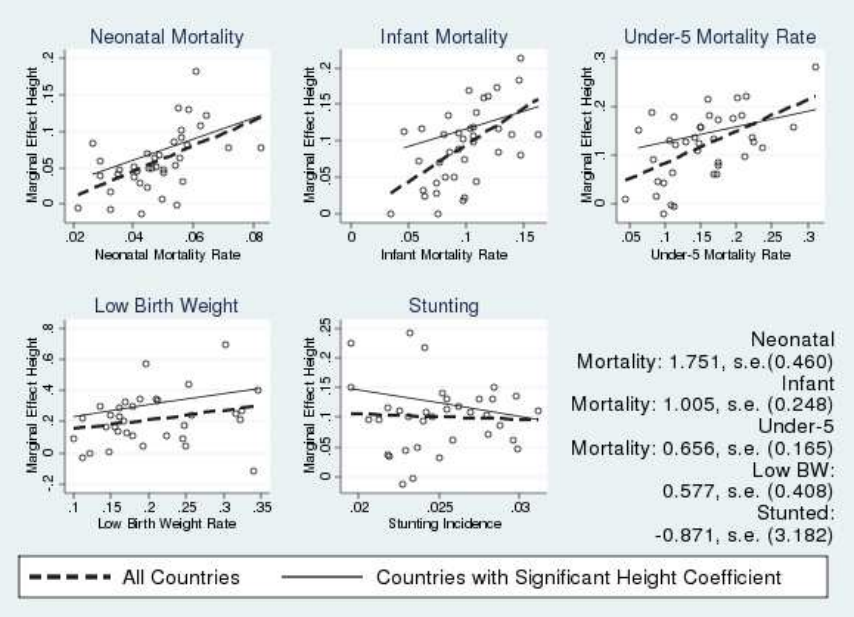

c) Average Education of Mothers

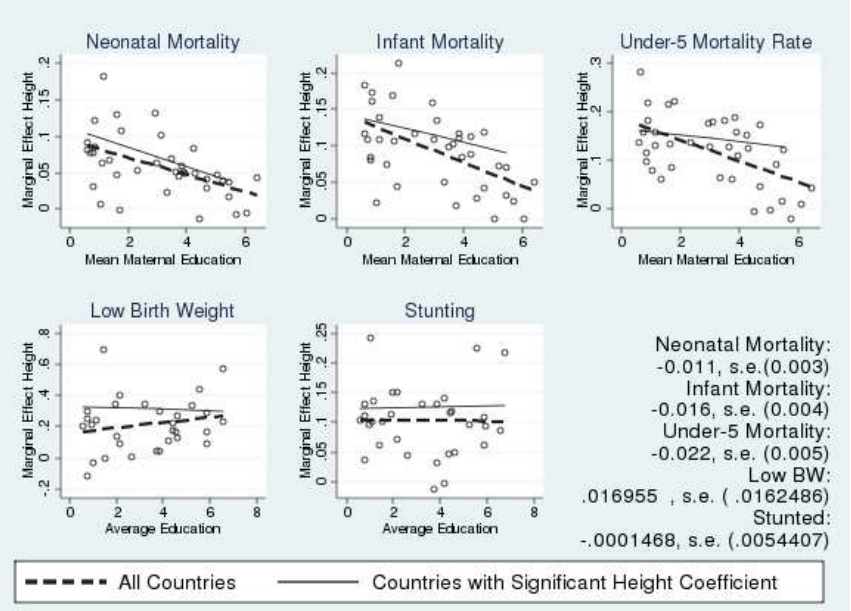




\section{d) Against GDP}
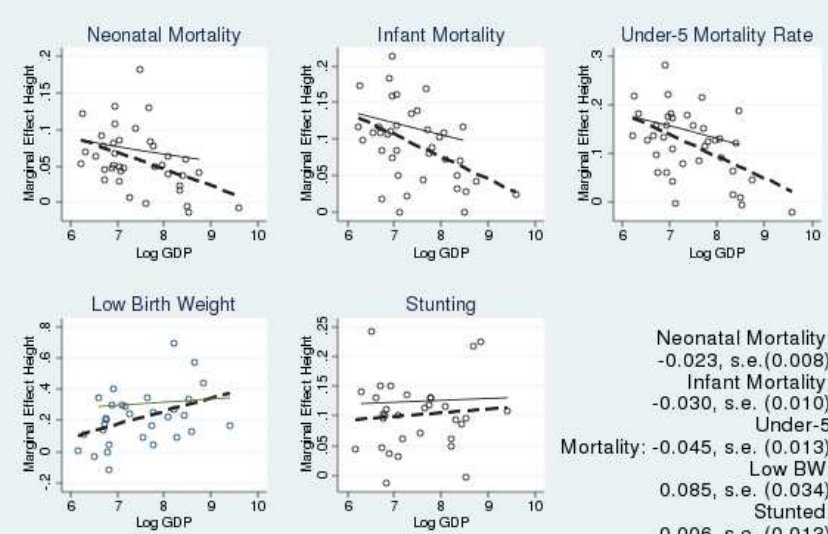

Neonatal Mortality . 023 , s.e. (0.008) 0.030 s.e. $(0.010)$ Mortality: -0.045 , se $(0.013$ Low BW: Stunted 0.006 , s.e. $(0.013)$

- - - - All Countries Countries with Significant Height Coefficient

\section{e) Against DPT Immunization Rates}
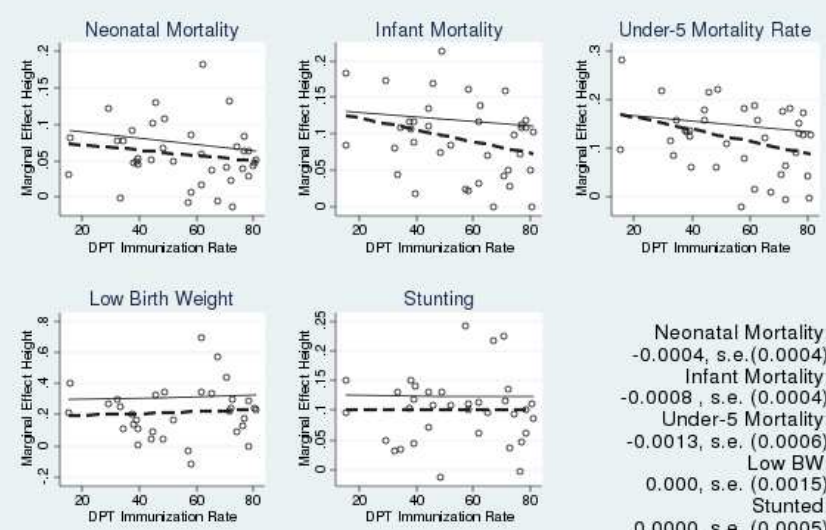

Neonatal Mortality: -0.0004 , s.e. $(0.0004)$ Infant Mortality: Under-5 Mortality: -0.0013 , s.e. $(0.0006$ Low BW: 0.000 , s.e. $(0.0015)$ 0.0000 , s.e. $(0.0005)$

--n-n. All Countries Countries with Significant Height Coefficient

\section{f) Against Measles Immunization Rates}

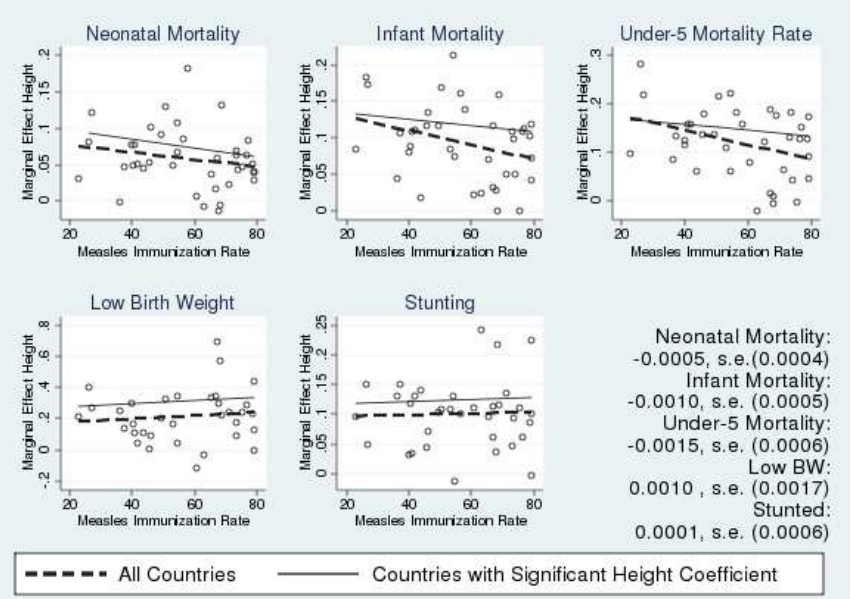


Figure A.8: Trends in Health and GDP: Pooled Sample a) Mean Mortality: 38 Countries

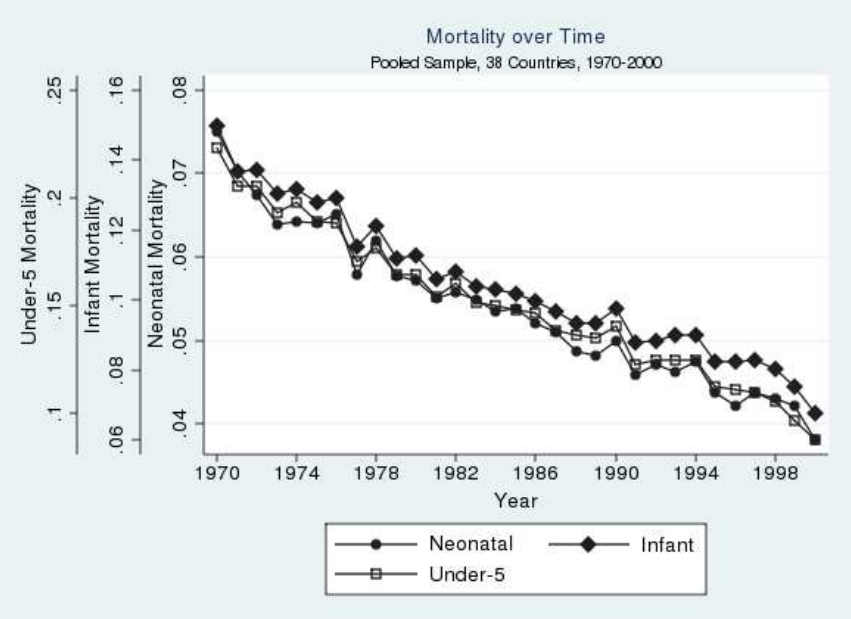

b) Standard Deviation of Mortality Rates: 38 Countries

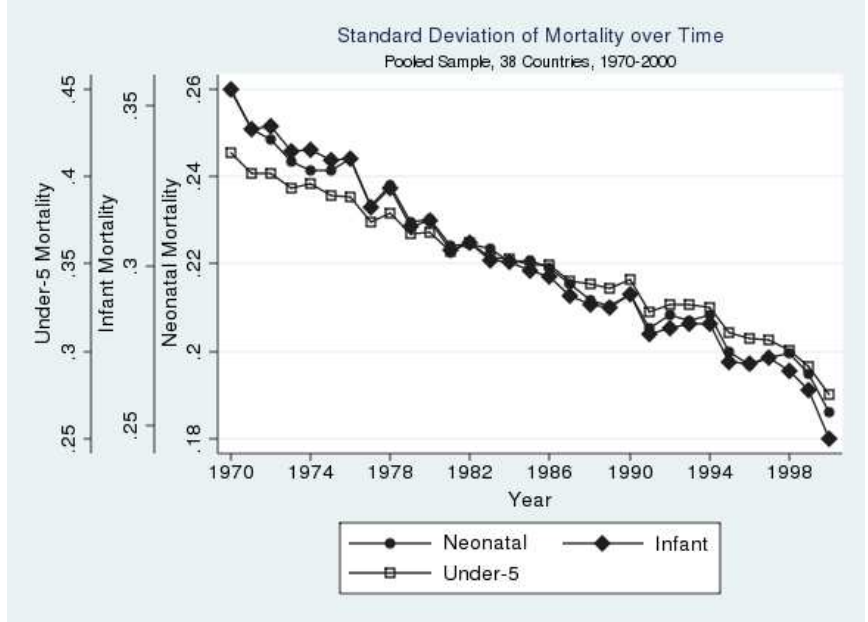

c) Mother's Height: Mean and s.d.

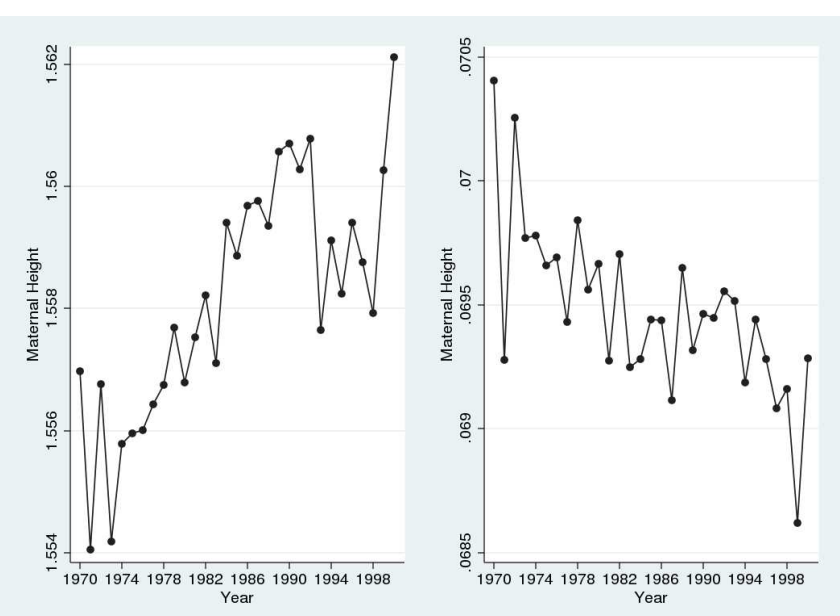


d) Log GDP: Mean and s.d., 38 Countries

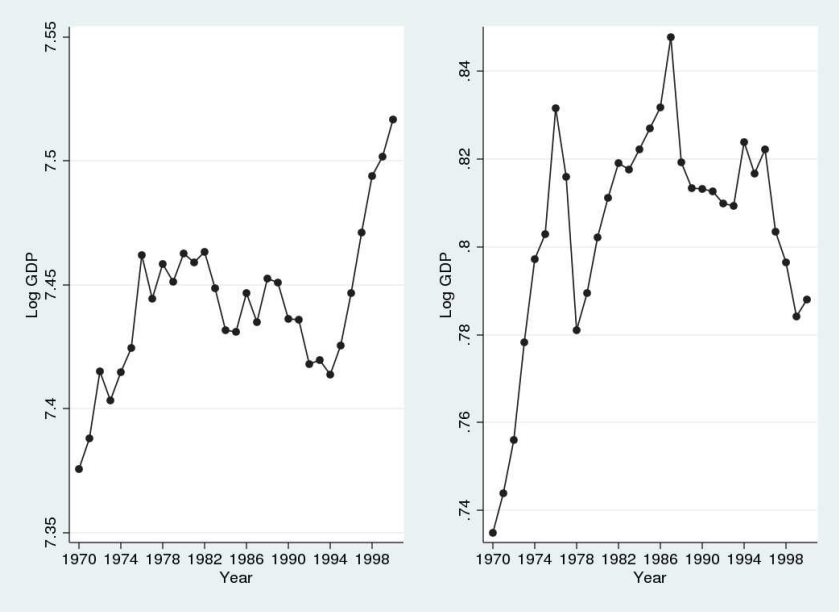

Figure A.9: Density plots of Country-Average Health a) Mortality

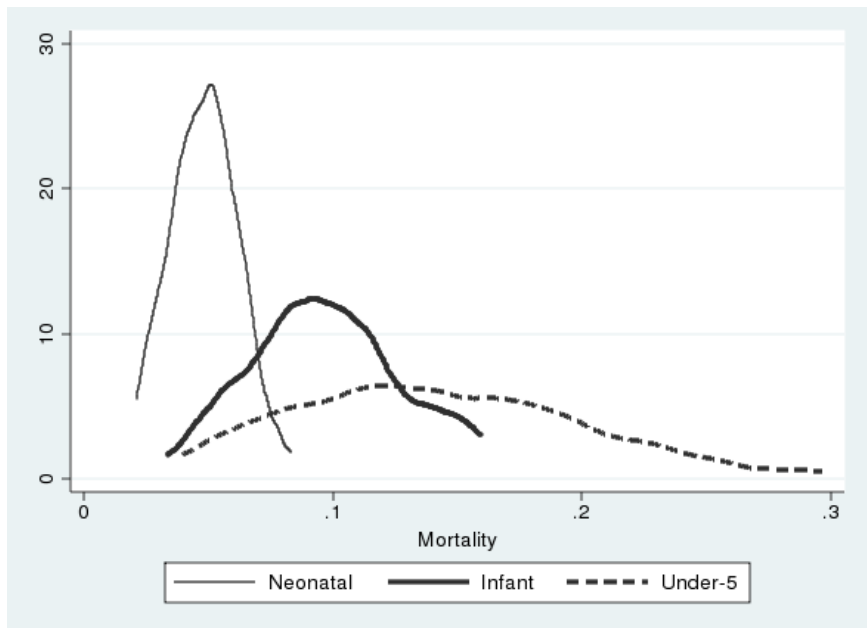

b) Stunting and Birth Weight

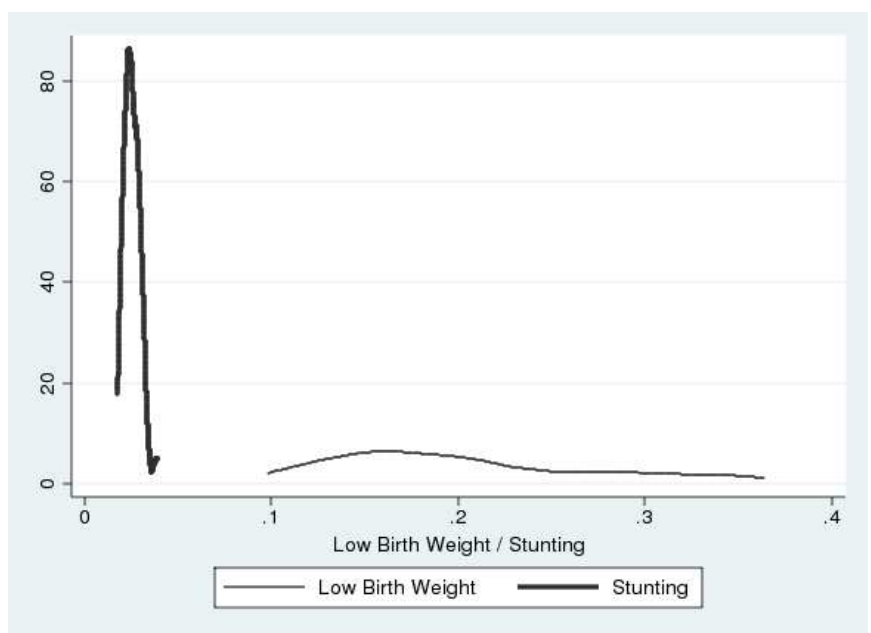


c) Mother Health

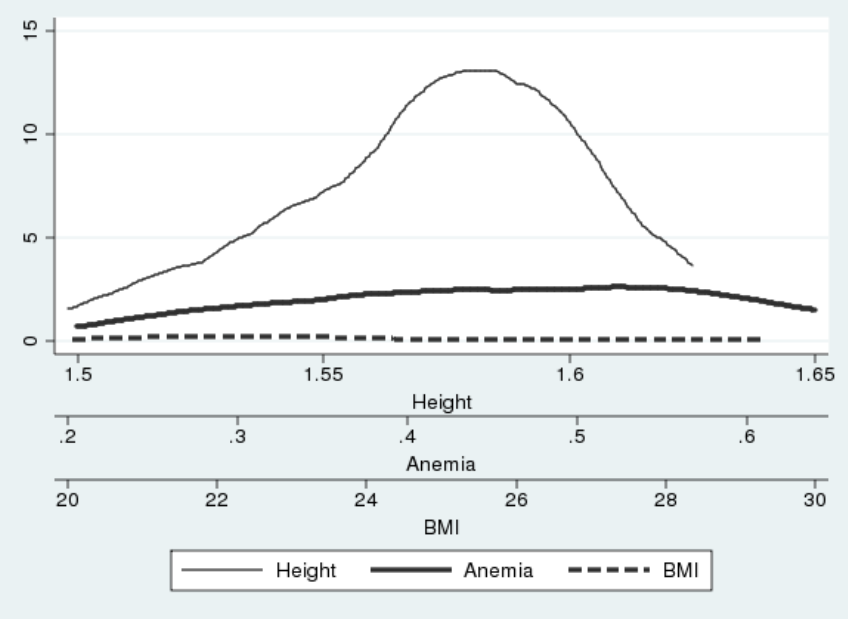

Figure A10 : Trends in Health and GDP: by Continent

a) Mortality Rates

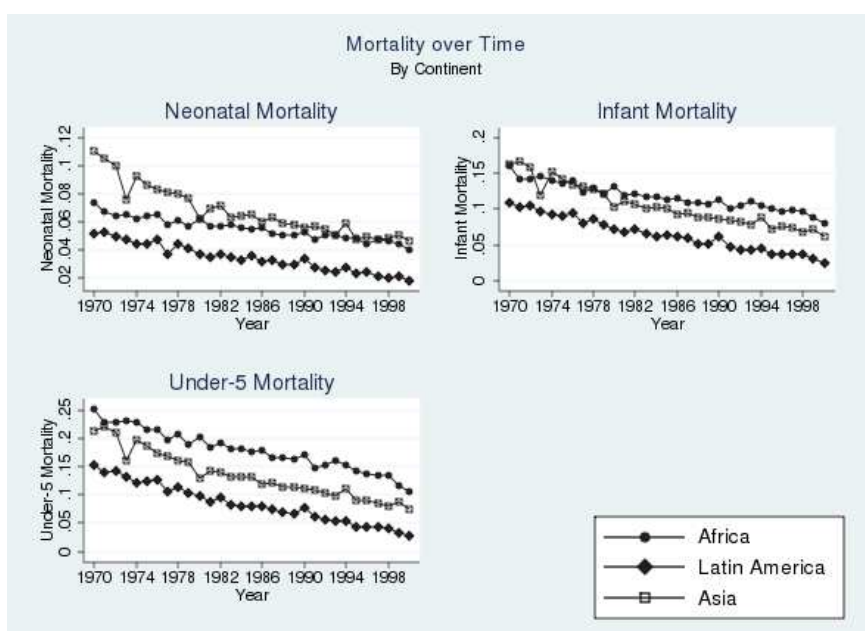

b) Mother Height and Log GDP

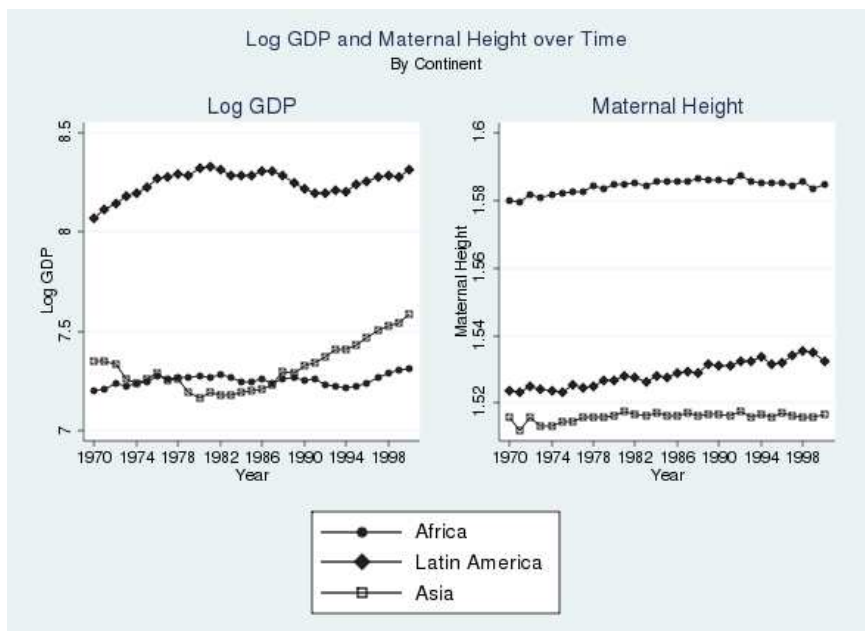


Figure A11: Trends in inequality in Health and GDP: by Continent

a) Mortality Rates

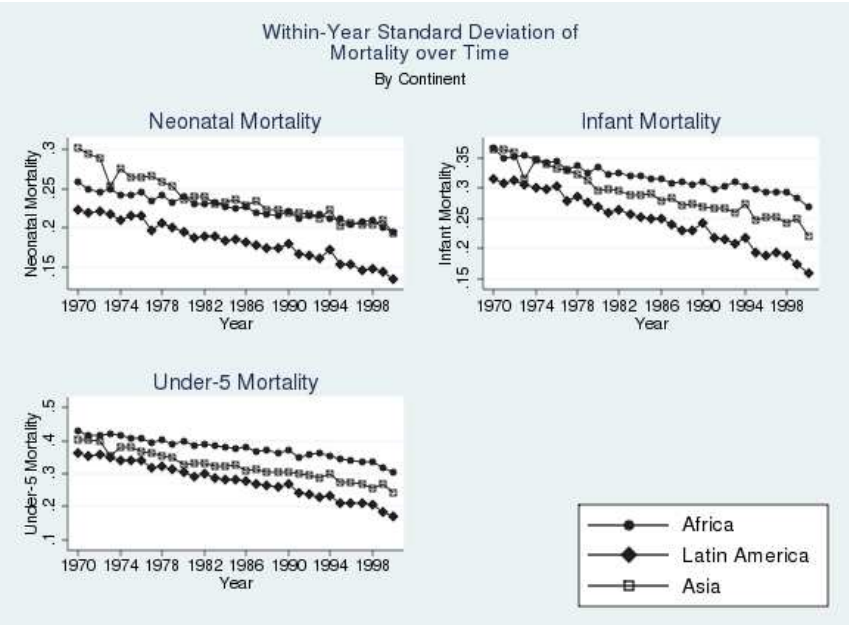

b) Within-Continent Standard Deviation of Height and GDP

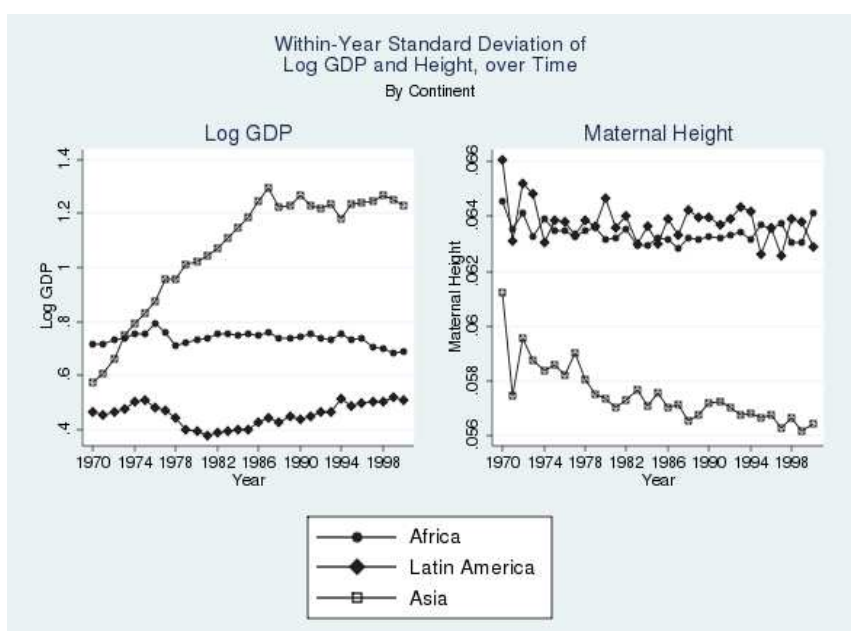

Figure A12: Changes over Time for the Case of India: Infant Mortality and Child Height

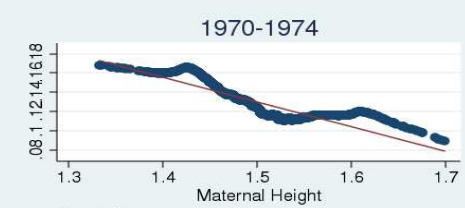

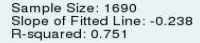

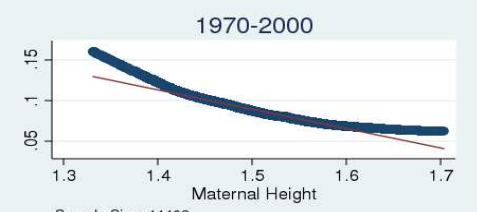

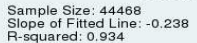

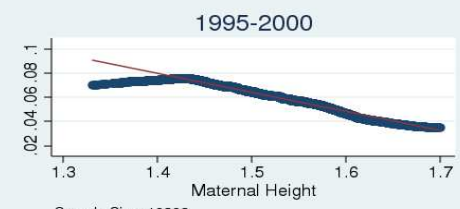

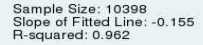

- Scatter of Lowess Predictions Linear Fit 
Map Displaying the 38 Countries in Sample

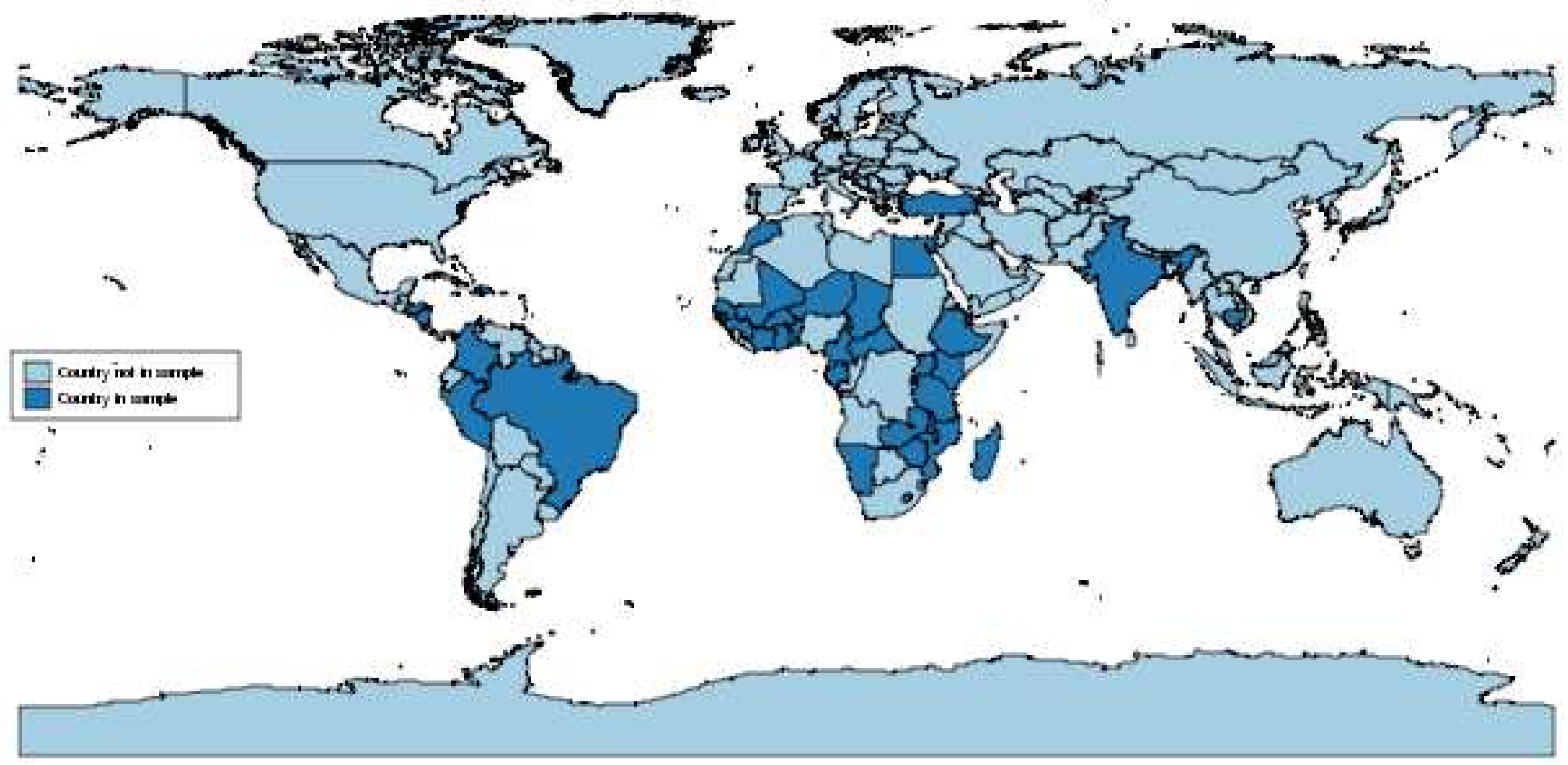

